\title{
Removal of Oxygen Demand and Acute Toxicity During Batch Biological Treatment of a Petroleum Refinery Effluent \\ by
}

\section{Brihas P. Sarathy}

B.Sc. (Chemical Engineering), Queen's University, 1998

\author{
A THESIS SUBMITTED IN PARTIAL FULFILMENT \\ OF THE REQUIREMENTS FOR THE DEGREE OF \\ MASTER OF APplied SCIENCE \\ in \\ The Faculty of GRaduate Studies \\ DEPARTMENT OF CHEMICAL AND BIOLOGICAL ENGINEERING \\ We accept this thesis as conforming \\ to the required standard
}

THE UNIVERSITY OF BRITISH COLUMBIA

August 2000

(c) Brihas P. Sarathy 2000 
In presenting this thesis in partial fulfilment of the requirements for an advanced degree at the University of British Columbia, I agree that the Library shall make it freely available for reference and study. I further agree that permission for extensive copying of this thesis for scholarly purposes may be granted by the head of my department or by his or her representatives. It is understood that copying or publication of this thesis for financial gain shall not be allowed without my written permission.

Department of Chemical Engineering

The University of British Columbia

Vancouver, Canada

Date Ang. 1,2000 


\section{Abstract}

This study was undertaken in order to investigate the removal of oxygen demand and acute toxicity from a petroleum refinery effluent. The results of this study provide a better understanding of the biodegradation process occurring at the Chevron refinery wastewater treatment plant (WWTP) in Burnaby, BC. The WWTP consists of a deep shaft bioreactor followed by a dissolved air flotation clarifier and effluent polishing biofilters. The treatment plant is able to degrade approximately $75 \%$ of the COD and $95 \%$ of the BOD present in the wastewater. During the study period, the toxicity of the wastewater before and after treatment was $1.9 \pm 0.12(\% \mathrm{v} / \mathrm{v})$ and $25.4 \pm 5.9(\% \mathrm{v} / \mathrm{v})$, respectively (as measured by the 5 minute Microtox ${ }^{\mathrm{TM}}$ assay in $\mathrm{EC}_{50}$ units).

The experimental program utilized two batch bioreactors operated at $35^{\circ} \mathrm{C}$ to characterize the removal of organic compounds (as measured by BOD and COD), and to determine the capacity of the biomass for acute toxicity removal. A six-litre batch bioreactor was operated for 52.5 hours (Run 1), and a $15 \mathrm{~L}$ batch bioreactor was operated for 120 hours (Run 2). In order to assess the abiotic rate of volatilization, a stripping test was also performed using the six-litre batch reactor.

In both runs, the BOD and COD reduction occurred over the first 24 hours of treatment. The BOD removal was $92-96 \%$, and the COD removal was $73-75 \%$. These values are similar to the removal levels reported at the Chevron refinery WWTP. Stripping accounted for 3\% of the COD removal over 52.5 hours. Since stripping was insignificant, the compounds contributing to $\mathrm{BOD}$ and $\mathrm{COD}$ were most likely removed via biodegradation.

Both runs showed similar patterns of toxicity removal. Rather than being continuously removed, as in the case of BOD and COD, toxicity appeared to be removed in discrete stages. The first stage of toxicity removal corresponded to the degradation of $\mathrm{BOD}$ and $\mathrm{COD}$, and the second stage occurred after BOD and COD had been removed. The raw wastewater in Runs 1 and 2 had a 5-minute $\mathrm{EC}_{50}$ of $4.6 \pm 0.5 \%$ and $4.9 \pm 0.4 \%$, respectively. In Run 1 , the toxicity was reduced to a 5-minute $\mathrm{EC}_{50}$ of $7.9 \pm 0.7 \%$ in 10 hours, and further removal did not occur until after 28 hours. In Run 2 , a 5 -minute $\mathrm{EC}_{50}$ of $16 \pm 3.2 \%$ was achieved over the first 10 hours, and the toxicity remained at this level until 48 hours. A second significant toxicity removal step between 48 and 72 hours resulted in a final 5 -minute $\mathrm{EC}_{50}$ of $27.8 \pm 1.6 \%$. 


\section{TABLe OF Contents}

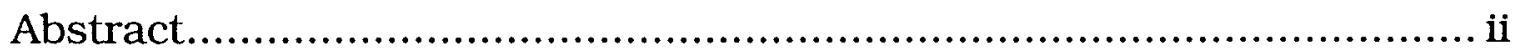

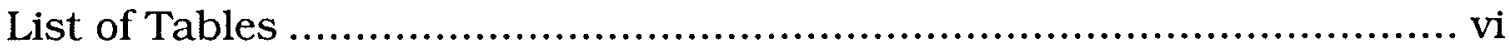

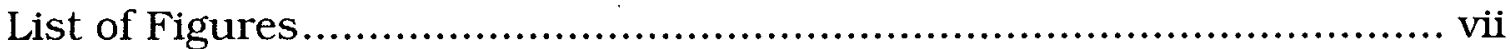

Acknowledgements .................................................................... viii

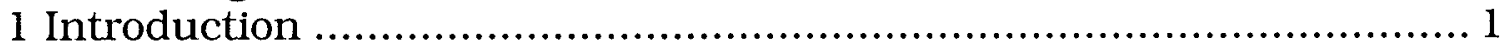

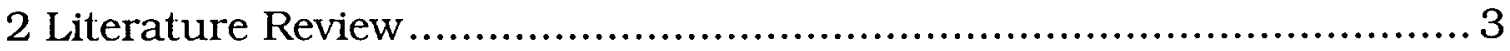

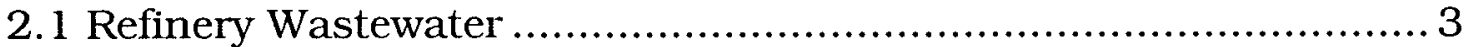

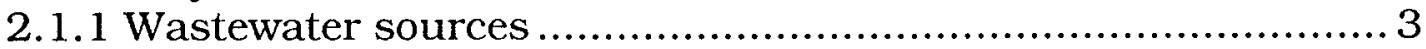

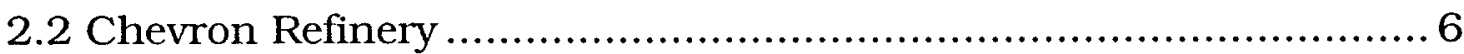

2.2.1 Chevron refinery wastewater ...................................... 7

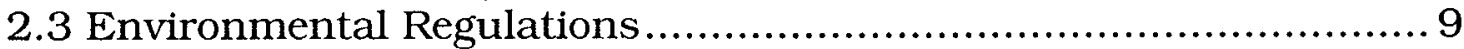

2.3.1 Toxicity of refinery wastewater ...................................... 11

2.3.2 Toxicity testing ...................................................... 12

2.3.2.1 Microtox ${ }^{\mathrm{TM}}$ acute toxicity test.................................. 12

2.3.2.2 Other acute toxicity tests ................................... 14

2.3.2.3 Effectiveness of toxicity tests............................. 15

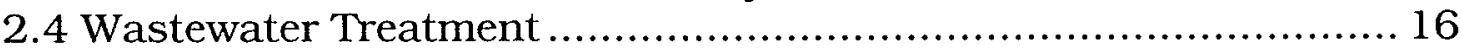

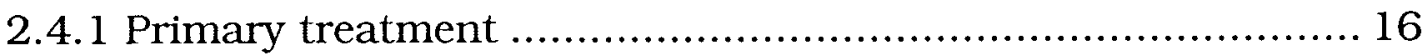

2.4.2 Secondary treatment.................................................... 16

2.4.2.1 Substrate removal mechanisms ............................. 18

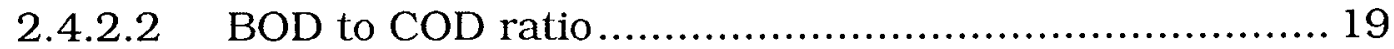

2.4.2.3 First order BOD removal rate ............................... 19

2.4.2.4 Sludge Age.................................................... 20

2.4.2.5 Aeration........................................................ 21

2.4.2.6 Temperature ..................................................... 21

2.4.2.7 pH …....................................................... 21

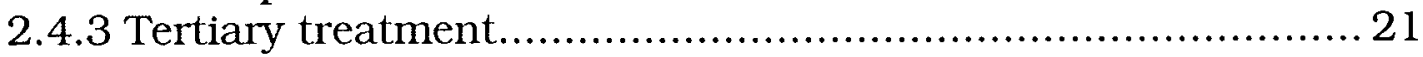

2.4.3.1 Activated carbon adsorption .............................. 22

2.4.3.2 Chemical oxidation ........................................ 22

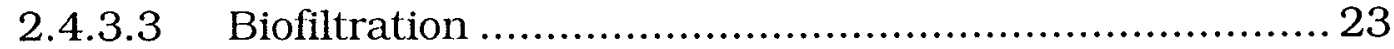

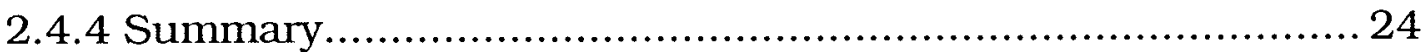

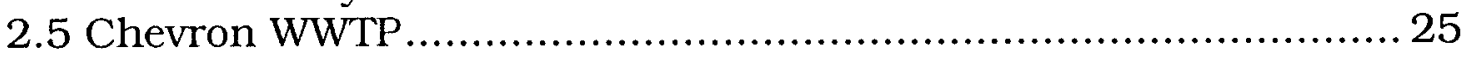

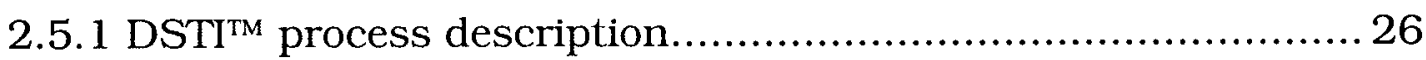

2.5.2 WWTP performance …............................................. 28

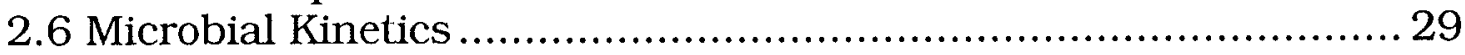

2.6.1 Growth and substrate uptake rates................................ 29

2.6.2 Limitations of Monod model and alternative models ............. 30

2.6.3 Inhibition ................................................................. 31

2.6.3.1 Competitive, non-competitive, and uncompetitive

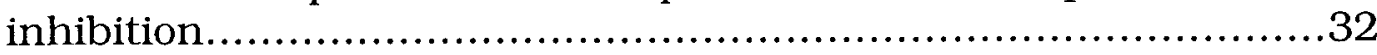

2.6.3.2 Substrate, product, and toxic compound inhibition..... 32

2.7 Measurement of Microbial Kinetic Constants ............................ 34

2.7.1 Respirometry .......................................................... 34

2.7.1.1 Respirometric methods ..................................... 34 


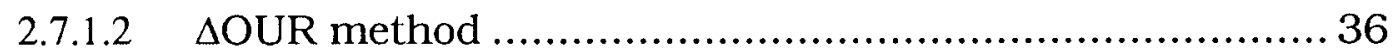

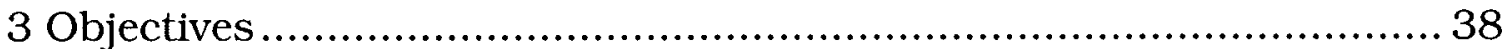

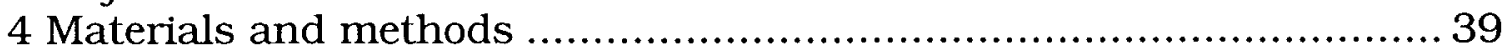

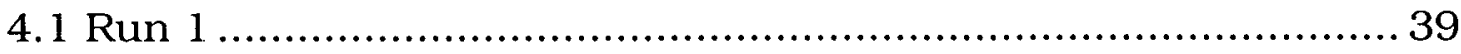

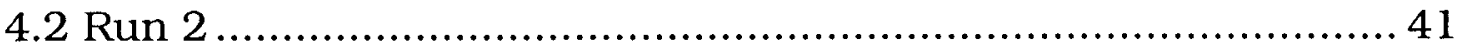

4.3 Stripping Test ............................................................. 43

4.4 Sample Collection and Preservation .................................... 43

4.4.1 Test of preservation method on sample COD ....................... 43

4.5 Sample Analysis ........................................................... 44

4.5.1 Biochemical oxygen demand (BOD) .............................. 44

4.5.2 Chemical oxygen demand (COD) ................................... 44

4.5.3 Mixed liquor suspended solids (MLSS) .......................... 45

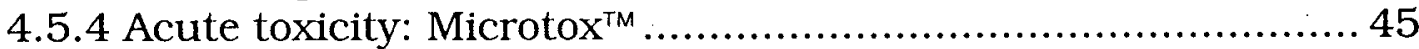

4.5.4.1 Toxicity units.................................................. 45

4.5.5 Oxygen uptake rate (OUR) ......................................... 46

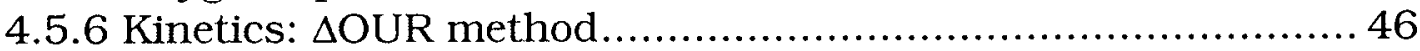

4.5.6.1 Determination of kinetic parameters ...................... 49

4.5.7 Analyses for specific chemical compounds ....................... 51

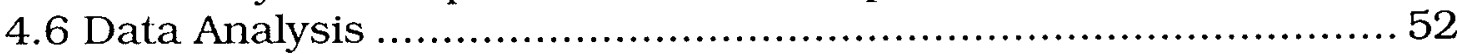

4.6.1 Measured values...................................................... 52

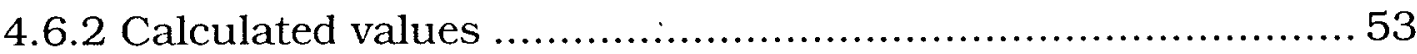

4.6.2.1 Slopes.............................................................. 53

4.6.2.2 Estimation of error on calculated values …............... 53

4.6.2.3 Non-linear regression method ............................... 53

4.6.3 Reported results ...................................................... 54

5 Results and Discussion........................................................ 55

5.1 Characteristics of Chevron Wastewater ................................. 55

5.2 Biochemical and Chemical Oxygen Demand............................. 56

$5.2 .1 \mathrm{BOD}$ and COD removal ............................................... 56

5.2 .2 Residual COD and BOD ............................................. 58

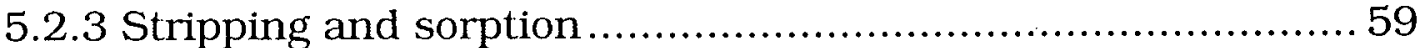

5.2 .4 Biodegradability of wastewater........................................6 60

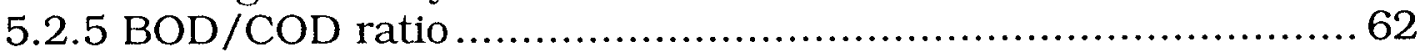

5.2.6 First order BOD removal rate ........................................6 63

5.2.7 Evaluation of Polyseed ${ }^{\circledR}$ as BOD inoculum .......................... 64

5.3 Specific Oxygen Uptake Rates ............................................. 65

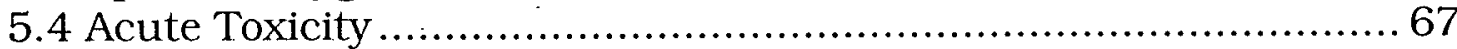

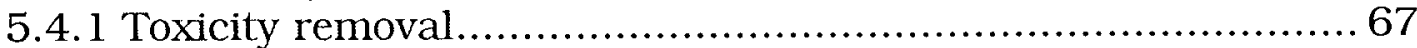

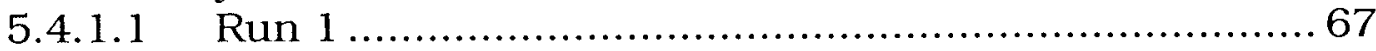

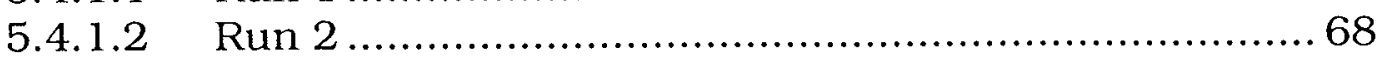

5.4.2 Chevron toxicity monitoring program …........................... 70

5.5 Possible BOD, COD, and Toxicity Sources............................. 73

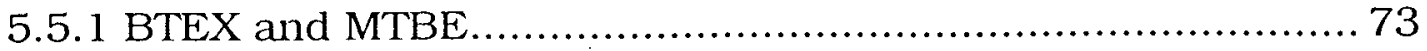

5.5.2 Phenols and EPH ........................................................ 74

5.5.3 Other toxicity sources ................................................. 75 


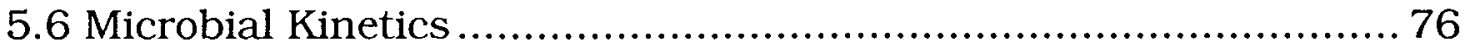

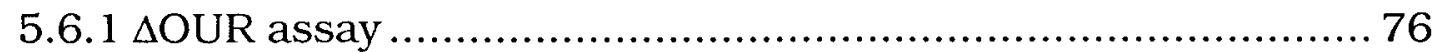

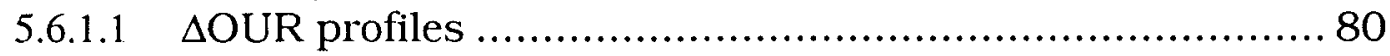

5.6 .2 Kinetics determined from batch test data ......................... 83

6 Conclusions........................................................................ 85

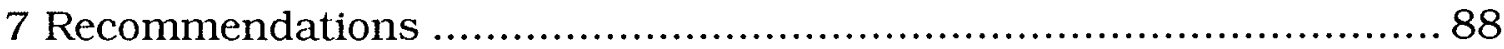

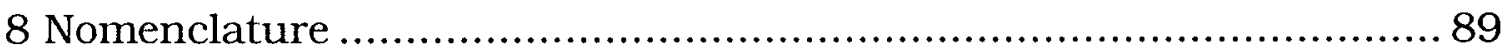

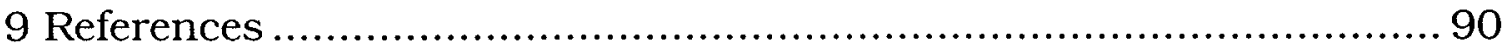

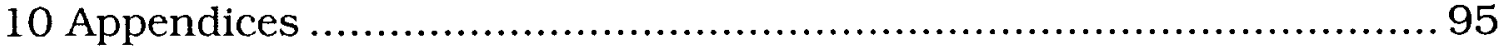

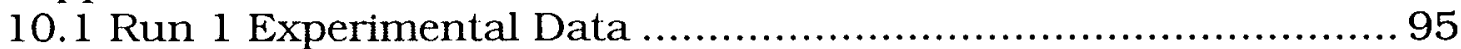

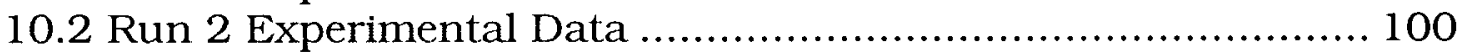

10.3 Stripping Experimental Data........................................ 105

10.4 Chevron Toxicity Monitoring Program (Hoy, 2000) ................. 106 


\section{LIST OF TABLES}

Table 2.1: Refinery Wastewater Sources and Constituents (Environment Canada, 1995) ........................................................................ 5

Table 2.2: Analysis of Select Water Streams at the Chevron Refinery ..... 8 Table 2.3: Total Flow and Contaminant Levels Captured by the Sampling Program ........................................................................ 8

Table 2.4: Summary of Federal Effluent Guidelines and Regulations

$\left(\mathrm{kg} / 10^{3} \mathrm{~m}^{3} / \mathrm{d}\right.$ of crude oil) (Environment Canada, 1974) 10

Table 2.5: Concentrations (mg/L) of Refinery Wastewater Pollutants

Before and After Biological Treatment (Rebhun et al., 1987) ........... 18

Table 2.6: Specifications of Chevron DSTI ${ }^{\mathrm{TM}}$ Reactor ..........................26

Table 2.7: Performance of Chevron WWTP ...................................... 28

Table 2.8: Effects of various types of inhibition on microbial kinetics ... 32

Table 4.1: Sampling Schedule for Run 1 ....................................... 40

Table 4.2: Sampling Schedule for Run 2 .................................... 42

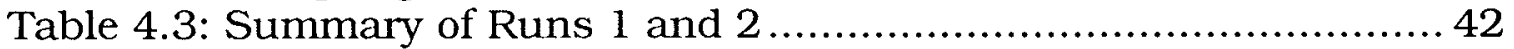

Table 5.1: Characteristics of Chevron Wastewater ............................ 55

Table 5.2: Wastewater Fractions ................................................6 60

Table 5.3: VH and MTBE Concentrations (mg/L) in Run 1 ..................73 73

Table 5.4: Phenols and EPH Concentrations in Run 2 ..................... 75

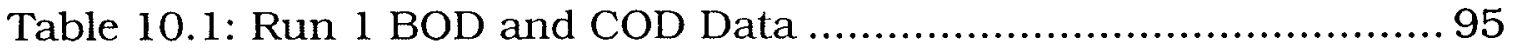

Table 10.2: Run 1 Solids Data ....................................................... 95

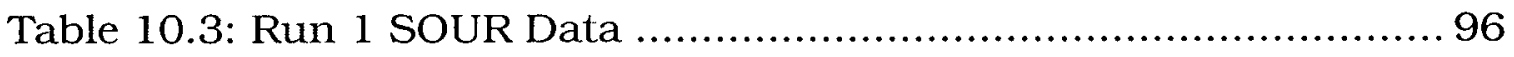

Table 10.4: Run 1 Acute Toxicity ................................................... 97

Table 10.5: Run $1 \Delta$ OUR Assay SOUR (mg O 2 /mg MLSS min) .............. 98

Table 10.6: Run $1 \Delta$ OUR Assay $\mathrm{O}_{2}$ Consumed (mg $\mathrm{O}_{2}$ ).................... 98

Table 10.7: Run $1 \Delta$ OUR Assay Solids ............................................ 98

Table 10.8: Run 1 Kinetic Constants............................................. 99

Table 10.9: Run 2 BOD and COD Data ........................................ 100

Table 10.10: Run 2 Solids Data................................................... 100

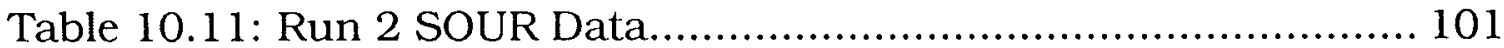

Table 10.12: Run 2 Acute Toxicity ............................................ 102

Table 10.13: Run $2 \Delta$ OUR Assay SOUR (mg O $\mathrm{O}_{2} / \mathrm{mg}$ MLSS min) .......... 103

Table 10.14: Run $2 \Delta$ OUR Assay $\mathrm{O}_{2}$ Consumed $\left(\mathrm{mg} \mathrm{O}_{2}\right) \ldots \ldots \ldots \ldots \ldots \ldots \ldots . \ldots 103$

Table 10.15: Run $2 \Delta$ OUR Assay Solids ......................................... 103

Table 10.16: Run 2 Kinetic Constants......................................... 104

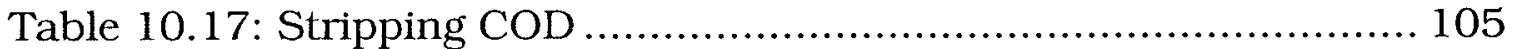

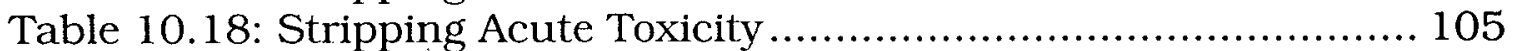

Table 10.19: Raw Wastewater Acute Toxicity ............................... 106

Table 10.20: Deep Shaft Effluent Acute Toxicity .............................. 106

Table 10.21: Biofilter Effluent Acute Toxicity ................................ 107 


\section{LIST OF FIGURES}

Figure 2.1: Simplified Flow Diagram for the Chevron Refinery (Chevron,

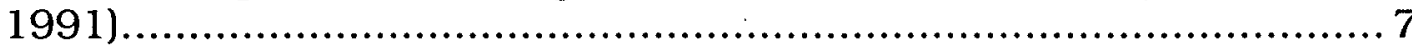

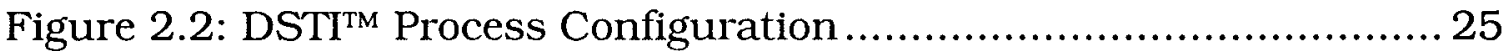

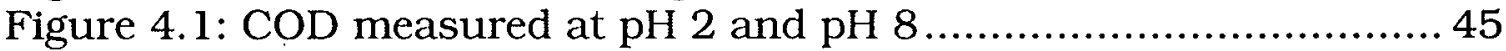

Figure 4.2: Respirometer......................................................... 47

Figure 4.3: Sample data from a respirometric kinetic assay .................48

Figure 4.4: Oxygen Consumed vs. Substrate Metabolized ...................50

Figure 4.5: Lineweaver-Burk plot to estimate kinetic parameters.......... 50

Figure 4.6: Non-linear regression to determine kinetic parameters ...... 51

Figure 5.1: BOD Degradation Profile .......................................... 57

Figure 5.2: COD Degradation Profile …….................................... 57

Figure 5.3: Effect of preservation method on COD measurement......... 59

Figure 5.4: Wastewater Degradability Characteristics..........................6 61

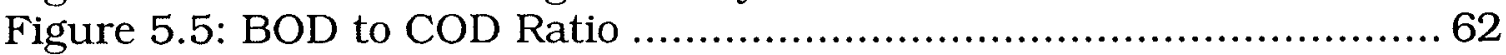

Figure 5.6: First order approximation of BOD degradation ..................6 63

Figure 5.7: BOD Comparison of Polyseed ${ }^{\circledR}$ to Chevron Seed ................. 64

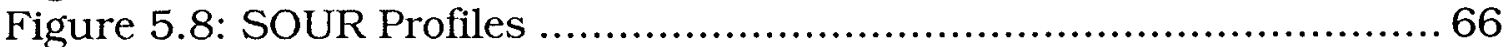

Figure 5.9: Run 1 Acute Toxicity Removal .......................................68 68

Figure 5.10: Acute Toxicity Removal Comparison .............................6 69

Figure 5.11: Chevron Toxicity Monitoring Program (5 min EC50) .......... 72

Figure 5.12: Chevron Toxicity Monitoring Program (15 min $\mathrm{EC}_{50}$ ) ......... 72

Figure 5.13: Maximum Specific Substrate Uptake Rates ................... 78

Figure 5.14: Half Saturation Constants for Runs 1 and 2................ 79

Figure 5.15: Run 1 Substrate Uptake Rate Profiles............................. 79

Figure 5.16: Run 2 Substrate Uptake Rate Profiles........................... 80

Figure 5.17: Run 1 OUR Injection Profiles (OUR vs. time in minutes) ... 82

Figure 5.18: Run 1 Batch Results Compared to $\triangle$ OUR Assay ................ 83

Figure 5.19: Run 2 Batch Results Compared to $\triangle$ OUR Assay............... 84 


\section{ACKNOWLEDGEMENTS}

This project would not have been possible without the help, guidance, and support of many others.

I would like to thank Sheldon Duff for providing me with financial assistance during the first half or this project, and the University of British Columbia for awarding me the UGF scholarship for the latter half.

I gratefully acknowledge Clive, Dave, and Jeff of Noram Engineering for their help during the initial stages of this project. Thanks to Ed and the staff at the Chevron Refinery for providing me with timely access to the WWTP.

Thanks to all the staff of the UBC Pulp and Paper Centre for providing me with excellent resources and lab space. Special thanks to Peter and Tim for their willingness to lend a hand and help out even at the shortest notice. I also gratefully acknowledge the help I received from the staff of the UBC Department of Chemical and Biological Engineering.

I am grateful to Steve Helle for the all the work he put into making the tedious respirometric assay user friendly.

Special thanks to Sheldon Duff for being a wonderful supervisor; I am most grateful for his excellent guidance that was provided in an honest, friendly, and straightforward manner throughout this project. A huge thanks also goes out to my wonderful research group: Chris, Maggie, Mike, Norman, and Steve $\mathrm{H}$. Thanks for all those productive and most entertaining group meetings! 
I am also thankful to all my colleagues who have made my time here most memorable: Heather, Steve S., Mike, Norm, Maggie, and Tazim.

Deepest thanks to all my family who have always given me their full support in all my endeavours.

Very special thanks to Maggie for helping me out every step of the way. 


\section{INTRODUCTION}

The separation and transformation of crude oil into gasoline, fuel oils, lubricating oils, asphalts and petrochemical feedstocks consumes large quantities of water (Dold, 1989). The end result is the production of a large amount of wastewater containing a range of contaminants from hydrocarbons and aromatic organic compounds to heavy metals. Wastewater generation rates of approximately one litre per litre of crude processed have been reported (Mahmud et al., 1979). Since the amount of wastewater discharged is dependent upon parameters such as the properties of the crude oil, types of processing units, final product mix, and method of treatment and disposal; the amount of wastewater discharged will be specific to each refinery, and reflect individual site conditions (UNEP, 1987).

The Chevron refinery in Burnaby, $\mathrm{BC}$ has a daily capacity of 7,150 cubic meters and it produces motor gasoline, asphalts, heating fuel oils, butanes, propane, diesel, and jet fuels. This results in the production of approximately 2,290 cubic meters of wastewater per day. Primary treatment of the effluent consists of the segregation of water containing $\mathrm{H}_{2} \mathrm{~S}$ and $\mathrm{NH}_{3}$ for sour water stripping, an API separator for gross oil/water separation, dispersed air flotation for removal of emulsified oil droplets, and aeration with equalization to remove trace sulphides. The primary treated effluent is stored in a holding pond prior to further treatment. Since late 1996, to provide secondary and tertiary treatment of their wastewater, the refinery has been operating a wastewater treatment plant (WWTP) that consists of a Deep Shaft Technology Inc. (DSTI ${ }^{\mathrm{TM}}$ ) activated sludge bioreactor followed by a dissolved air flotation clarifier and final effluent polishing biofilters. The treated effluent is routed to the Greater Vancouver Regional District (GVRD) sewer system, where it receives further treatment prior to being discharged. 
The treatment plant is able to degrade approximately $75 \%$ of the COD and $95 \%$ of the BOD present in the wastewater. During the study period, the toxicity of the wastewater before and after treatment was $1.9 \pm 0.12(\% \mathrm{v} / \mathrm{v})$ and $25.4 \pm 5.9(\% \mathrm{v} / \mathrm{v})$, respectively (as measured by the 5 minute Microtox ${ }^{\top \mathrm{M}}$ assay in $\mathrm{EC}_{50}$ units). Although there has been regular monitoring of pollutant levels at the inlet and outlet of the treatment process since the plant's start-up in late 1996, there has been no formal investigation into the effectiveness of the individual unit operations.

Chevron has submitted a proposal to the Ministry of the Environment (MOE) to directly discharge treated effluent into the Burrard Inlet. Direct discharge to the inlet would save Chevron the treatment costs it currently pays to the GVRD, and benefit the GVRD sewer system by reducing its treatment load. The Ministry as well as the public have concerns about this proposal (Tanner, 2000). In order for the MOE and the public to accept the proposal for direct discharge, the Chevron WWTP must consistently demonstrate effective treatment of the refinery's effluent.

To this effect, Chevron wanted to increase their understanding of the capabilities of their WWTP. In particular, they were interested in conducting studies to assess the ability of each unit operation to effectively remove BOD, COD, and acute toxicity. Based on the results of these studies, they will be able optimize the operation of their WWTP. 


\section{LITERATURE REVIEW}

\subsection{Refinery Wastewate $r$}

The separation and transformation of crude oil into gasoline, fuel oils, lubricating oils, asphalts and petrochemical feedstocks consumes large quantities of water (Dold, 1989). The end result is the production of a large amount of wastewater containing a range of contaminants from hydrocarbons and aromatic organic compounds to heavy metals. The wastewater generated from a refinery varies according to the processes used, the type of crude processed, and the final products manufactured. Typical wastes generated in the petroleum refining industry and their sources are listed in Table 2.1.

\subsubsection{Wastewater sources}

Refinery wastewaters are characterized as being high volume streams containing low concentrations of pollutants. These pollutants are typically dissolved and suspended solids, hydrocarbons, inorganics (ammonia, sulphides, and cyanides), metals, and phenols (UNEP, 1987). Hydrocarbons form the main component of the contaminants and are usually comprised of compounds containing hydrogen and four to twenty carbon atoms. The main fraction is straight chain hydrocarbons though aromatic and olefinic species are also present (Dold, 1989).

Wastewater sources can be divided into four different categories: oilyprocess water, non-oily water, storm water and sanitation wastewater. The oily-process water is generated from three main sources:

1. The main process units including the crude distillation unit (the desalters), the sweetening treatments (removal of sulphur containing chemicals), and the alkylation units.

2. The oil storage area (from roof drains and frequent tank draining to check for water in the storage tanks). 
3. The movement of the oil (from spills occurring during the loading of road tankers and rail wagons for oil transportation).

Non-oily water is accumulated from the boiler used for steam production, from the cooling towers supplying cooling process water and from the water treatment plants supplying soft water, drinking water and other process water. The storm water generated during heavy rainfall washes all of the oil spills from the refinery into the sewers and must be treated. Finally the water consumption of the refinery workers generates the sanitation wastewater stream. 
Table 2.1: Refinery Wastewater Sources and Constituents (Environment Canada, 1995)

\begin{tabular}{|c|c|}
\hline Source & Contaminants \\
\hline Crude Oil & $\begin{array}{c}\text { Chromates and heavy metals (iron, zinc, copper, lead, } \\
\text { nickel);organic compounds of sulphur, nitrogen, and } \\
\text { oxygen; desalting chemicals, dissolved salts, and } \\
\text { suspended solids }\end{array}$ \\
\hline $\begin{array}{c}\text { Intake } \\
\text { Water }\end{array}$ & $\begin{array}{c}\text { Depends on quality of water, treatment is usually needed } \\
\text { for boiler and cooling towers, the blowdown from these } \\
\text { processes is an effluent }\end{array}$ \\
\hline Storm Water & $\begin{array}{c}\text { Collects silt and spilled oil from processing plant and } \\
\text { tank farm, may contain phenols and toxic substances }\end{array}$ \\
\hline $\begin{array}{c}\text { Ballast } \\
\text { Water }\end{array}$ & $\begin{array}{c}\text { Generally contains oil, phenols, trace amounts of } \\
\text { suspended and dissolved solids }\end{array}$ \\
\hline $\begin{array}{c}\text { Sanitary } \\
\text { Wastes }\end{array}$ & $\begin{array}{c}\text { Generated by the personnel, may sometimes be } \\
\text { discharged directly to the municipal system }\end{array}$ \\
\hline $\begin{array}{c}\text { Process } \\
\text { Chemicals }\end{array}$ & $\begin{array}{c}\text { Caustic soda, sulphuric and phosphoric acid, amines, } \\
\text { glycol, ammonia, detergents for chemical cleaning, } \\
\text { antifoam agents, and corrosion inhibitors }\end{array}$ \\
\hline Catalysts & $\begin{array}{c}\text { Sulphonates, sulphates, organic esters, sulphuric acid, } \\
\text { hydrofluoric acid, fluorides, phosphates, phosphoric acid } \\
\text { Hydro treating - hydrogen sulphide and ammonia } \\
\text { Thermal cracking - ammonia, nitrogen compounds, } \\
\text { hydrogen sulphide, mercaptans, naphthenic acids, and } \\
\text { organic acids }\end{array}$ \\
\hline $\begin{array}{c}\text { Reaction } \\
\text { Products }\end{array}$ & $\begin{array}{c}\text { Catalytic Cracking - phenols, hydrogen sulphide, carbon } \\
\text { sulphides, triophenes, ammonia, cyanides, and cyanates } \\
\text { Reforming - Benzene, toluene, and xylene }\end{array}$ \\
\hline Additives & $\begin{array}{c}\text { Spills from chemical storage, corrosion inhibitors, anti- } \\
\text { knock compounds (MTBE), anti-oxidants }\end{array}$ \\
\hline
\end{tabular}




\subsection{Chevron Refinery}

The Chevron refinery in Burnaby, $\mathrm{BC}$ has a daily capacity of 7,150 cubic meters and it produces motor gasoline, asphalts, heating fuel oils, butanes, propane, diesel, and jet fuels. Its raw material feedstock includes conventional and synthetic crude oil as well as condensate and butanes. Synthetic crude is a light oil made from Alberta Tar Sands, and it is partially treated to remove sulphur before it arrives at the refinery. Condensate is a liquid extracted from natural gas; butanes are naturally occurring light gases found in conventional crude and natural gas (Chevron, 1991).

A simplified diagram of the Chevron refinery is presented in Figure 2.1. The refinery contains the following processing units: crude unit, splitter, catalytic cracking unit, catalytic reformer, polymerization and alkylation plants, a sulphur recovery plant, and a boiler plant. The polymerization and alkylation plants use catalysts to convert the lightweight molecules formed in the catalytic cracker to produce liquids called polymer gasoline and alkylate, important components of high-octane gasoline. The sulphur recovery plant removes about $97 \%$ of the sulphur from refinery fuel gas, resulting in clean burning, high quality fuels for the refinery's furnaces and boilers. The boiler plant provides steam to run the refinery's pumps and compressors (Chevron, 1991). 


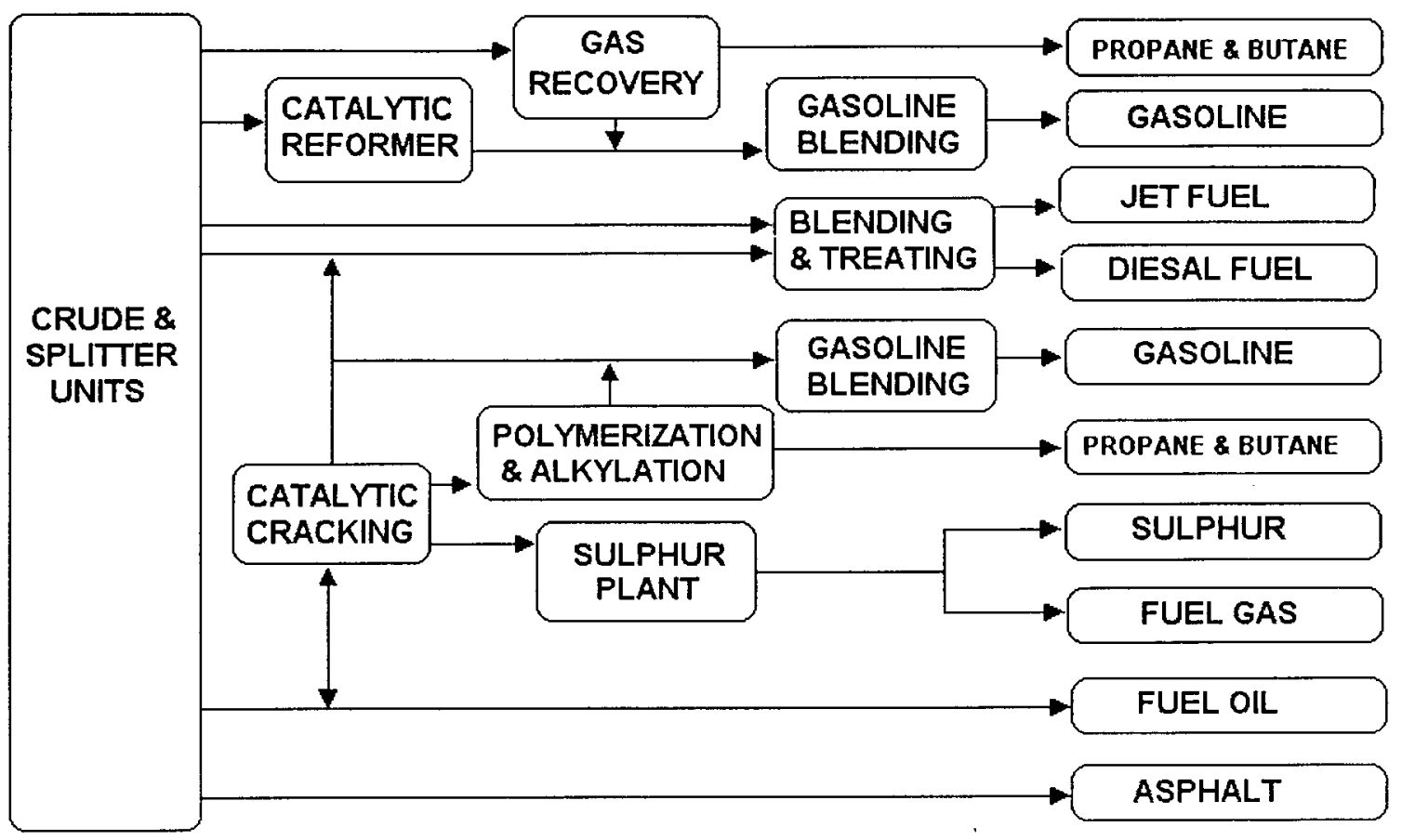

Figure 2.1: Simplified Flow Diagram for the Chevron Refinery (Chevron, 1991).

\subsubsection{Chevron refinery was tewater}

A survey of the wastewater streams at the Chevron refinery was conducted (Dobson et al., 1999). In this study, many of the streams were not easily accessible; hence only 7 of the 38 identified water sources were sampled (Table 2.2). This sampling program accounted for $40 \%$ of the total BOD, $38 \%$ of the total COD, and $48 \%$ of the total flow of the wastewater stream that required treatment (Table 2.3). 
Table 2.2: Analysis of Select Water Streams at the Chevron Refinery

\begin{tabular}{|c|c|c|c|c|c|c|c|c|}
\hline \multirow[b]{3}{*}{ Substance } & \multicolumn{8}{|c|}{ Water Streams Contaminant Concentrations $(\mathrm{mg} / \mathrm{L})$} \\
\hline & \multirow{2}{*}{\multicolumn{2}{|c|}{$\begin{array}{l}\text { Desalting Water } \\
\text { Crude }\end{array}$}} & \multicolumn{3}{|c|}{ Spent } & \multicolumn{2}{|c|}{$\begin{array}{l}\text { Boiler Plant } \\
\text { Blowdown }\end{array}$} & \multirow{2}{*}{$\begin{array}{c}\text { All } \\
\text { Wastewater } \\
\text { Streams }\end{array}$} \\
\hline & & & Alkylation & $\mathrm{FCC}$ & $\begin{array}{c}\text { Polymer- } \\
\text { ization }\end{array}$ & $\begin{array}{l}\text { Cooling } \\
\text { Tower }\end{array}$ & $\begin{array}{l}\text { Boiler } \\
\text { House }\end{array}$ & \\
\hline Fluoride & 0.54 & 0.445 & 0.155 & $<0.02$ & $<0.02$ & 0.145 & 0.06 & 0.26 \\
\hline Ammonia $\mathrm{N}$ & 34.925 & 5.66 & 2.79 & 0.010 & 0.009 & 0.0085 & $<0.005$ & 49 \\
\hline o-Phosphate & 0.2875 & 1.515 & 0.0015 & 0.0015 & 0.002 & 1.19 & 3.435 & 0.555 \\
\hline Sulphide & 51.5 & 50.8 & $<0.2$ & $<0.02$ & $<0.02$ & 0.02 & $<0.02$ & 37 \\
\hline Benzene & 24.85 & 24.65 & $<0.0005$ & $<0.0005$ & $<0.0005$ & $<0.0005$ & $<0.0005$ & 3.545 \\
\hline Ethylbenzene & 1.8325 & 1.785 & $<0.0005$ & $<0.0005$ & $<0.0005$ & $<0.0005$ & $<0.0005$ & 0.2945 \\
\hline Toluene & 21.225 & 27.7 & $<0.0005$ & $<0.0005$ & 0.0006 & $<0.0005$ & $<0.0005$ & 3.865 \\
\hline$m$-,p-Xylene & 6.135 & 8.375 & $<0.0005$ & $<0.0005$ & $<0.0005$ & $<0.0005$ & $<0.0005$ & 1.4605 \\
\hline$o$-Xylene & 3.175 & 3.835 & $<0.0005$ & $<0.0005$ & $<0.0005$ & $<0.0005$ & $<0.0005$ & 0.6625 \\
\hline $\begin{array}{l}\text { Oil and } \\
\text { Grease }\end{array}$ & 8.5 & 39.5 & $<5$ & $<5$ & $<5$ & $<5$ & $<5$ & 200 \\
\hline Total $\mathrm{BOD}_{5}$ & 285 & 388.5 & $<5$ & 8 & 10.5 & $<5$ & 6.5 & 200.5 \\
\hline Total COD & 920.5 & 1090 & 302 & 37.5 & 32 & 110.5 & 71 & 745 \\
\hline Phenols & 1.9 & 3.7 & 0.21 & 0.010 & 0.012 & $<0.2$ & 0.025 & 4.55 \\
\hline $\mathrm{pH}$ & 6 & 6 & 7 & 5.5 & 6 & N/A & 11 & 10 \\
\hline
\end{tabular}

Table 2.3: Total Flow and Contaminant Levels Captured by the

Sampling Program

\begin{tabular}{cccc}
\hline Substance & $\begin{array}{c}\text { Total Captured } \\
\text { from Sampling } \\
\text { (g/min) }\end{array}$ & $\begin{array}{c}\text { All Wastewater } \\
\text { Streams } \\
\text { (g/min) }\end{array}$ & $\begin{array}{c}\text { \% Captured } \\
\text { from } \\
\text { Sampling }\end{array}$ \\
\hline Fluoride & 0.19 & 0.33 & 57 \\
Ammonia $\mathrm{N}$ & 6.35 & 61.77 & 10 \\
o-Phosphate & 0.75 & 0.70 & 107 \\
Sulphide & 15.01 & 46.65 & 32 \\
Benzene & 7.25 & 4.47 & 162 \\
Ethylbenzene & 0.53 & 0.37 & 143 \\
Toluene & 7.15 & 4.87 & 147 \\
m-,p-Xylene & 2.12 & 1.84 & 115 \\
o-Xylene & 1.02 & 0.84 & 123 \\
Oil and Grease & 9.49 & 252.14 & 4 \\
BOD & 101.79 & 252.77 & 40 \\
COD & 354.89 & 939.21 & 38 \\
Phenols & 0.85 & 5.74 & 15 \\
Total Water Flow & $599.3 \mathrm{~L} / \mathrm{min}$ & $1260.7 \mathrm{~L} / \mathrm{min}$ & 47.5 \\
\hline
\end{tabular}




\subsection{Environmental Regulations}

In 1973, Environment Canada issued the Petroleum Refinery Effluent Regulations and Guidelines (Environment Canada, 1974), under the Federal Fisheries Act (1970) to protect fish and other marine organisms from the contaminants discharged by refineries. These Federal regulations limit the discharge of oil and grease, phenols, sulphides, ammonia nitrogen, total suspended solids (TSS), and $\mathrm{pH}$. Individual provinces have further guidelines on effluent quality. Table 2.4 summarizes the federal guidelines and regulations. The guidelines apply to refineries that were in operation prior to November 1, 1973, and the regulations apply to those built after this date. Each refinery is required to test for these five parameters thrice weekly, $\mathrm{pH}$ daily, and toxicity monthly.

The best practicable technology (BPT) described by these regulations and guidelines consists of (1) sour water stripping of ammonia and sulphide removal, (2) primary separation (e.g. API separator), (3) intermediate treatment (e.g. DAF unit), (4) secondary treatment (e.g. biological treatment), (5) final effluent clarification if required, and (6) storm water segregation as required. 


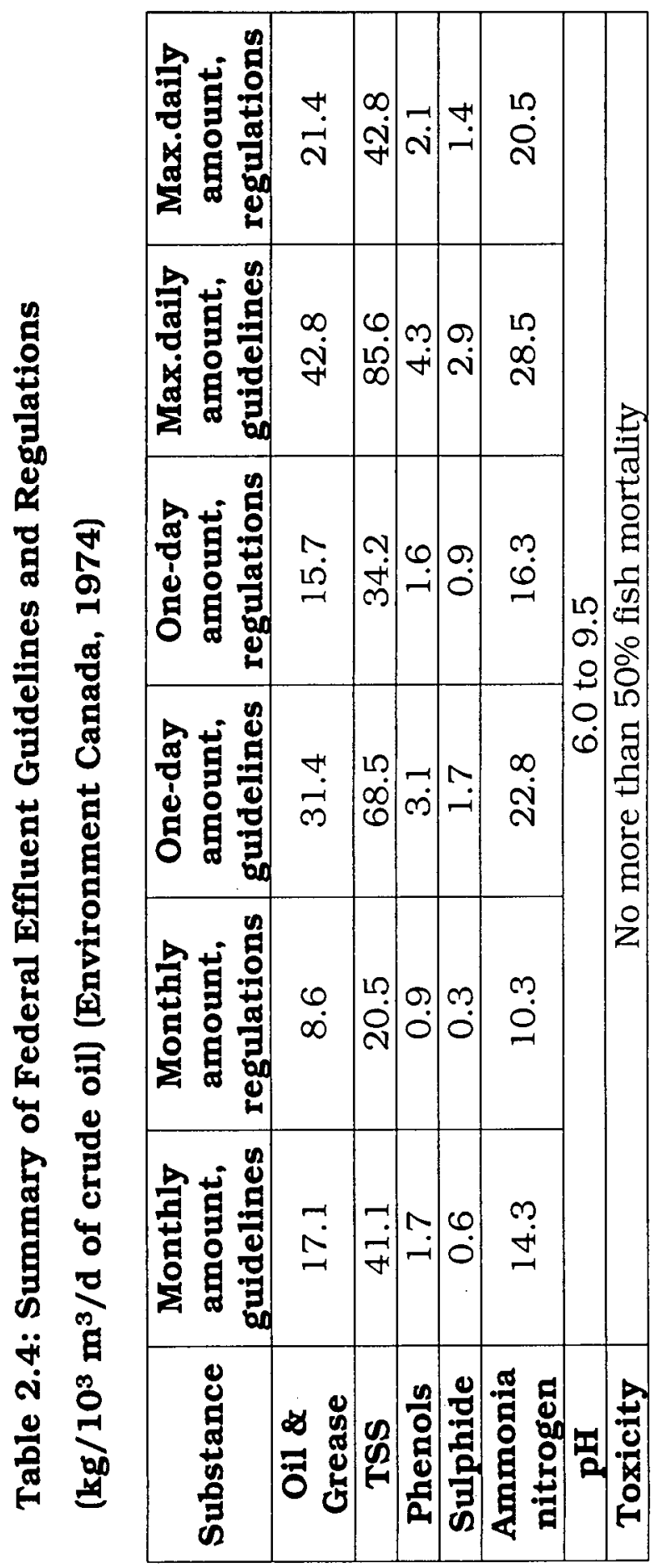




\subsubsection{Toxicity of refinery wa stewater}

During the past several decades, pollution control measurements have largely been based on conventional pollutants (oxygen-demanding materials, suspended solids, etc.) that were identified as causing water quality degradation (Metcalf and Eddy, 1991). There was an increasing concern in the 1980's regarding the carcinogenic or mutagenic potential of specific compounds and groups of compounds, even when present in low (trace) concentrations (Dold, 1989). This led to the compilation of priority pollutant lists, and the identification of specific chemical components in effluents from petroleum refineries (API, 1978; Burks, 1982; PACE, 1985; PACE, 1987; Gulyas, 1995). These chemical-specific monitoring programs were initially used to regulate toxicity, but they have several shortcomings. Primarily they are unable to identify synergistic effects or the bioavailabilty of the toxin (Metcalf and Eddy, 1991).

The more contemporary whole-effluent, or toxicity-based, approach to toxicity control involves the use of toxicity tests to measure the toxicity of treated wastewater discharges. Since it is not economically feasible to determine the specific toxicity of each of the thousands of potentially toxic compounds in complex effluents, whole-effluent toxicity testing using bioassays is a direct, cost effective means of determining effluent toxicity (Metcalf and Eddy, 1991).

Burks (1982) conducted a literature review of pollutants identified in petroleum refinery wastewaters. Citing Dorris et al. (1974) Burks stated that toxicity may be due to volatile substances, and citing the API (1978) he stated that organic chemicals might be responsible for acute toxicity. Chapman et al. (1994) investigated the toxicity of two separate Ontario refineries' intake and effluent streams. They concluded that was not possible to unequivocally attribute the toxicity of complex mixtures such 
as effluents to one or a few compounds. They found that the toxicity could not be attributed to contaminants likely to be specifically associated with oil refineries: volatiles, and oil and grease. Polyaromatic hydrocarbons (PAH), a group of compounds of concern in refinery effluents, were also not detected. They also stated that heavy metals, ammonia, and sodium were not likely causes of toxicity. Bleckmann et al. (1995) conducted a 2-year characterization and treatability study of a refinery wastewater. They conducted extensive chemical analysis, fractionations, and treatment alternatives to identify specific toxicants, but consistently identifiable or removable toxic agents were not identified. Based on these findings, it is unlikely that the toxicity in refinery wastewater can be attributed to a specific set of compounds.

\subsubsection{Toxicity testing}

Acute toxicity is toxicity that is severe enough to produce a response rapidly in the test organism (i.e. 48 to 96 hours for fish and 5 to 15 minutes for the Microtox ${ }^{\mathrm{TM}}$ assay). Acute means short, and does not necessarily imply mortality. The $\mathrm{LC}_{50}$ is the concentration of effluent in dilution water that causes mortality to $50 \%$ of the test population. The $\mathrm{EC}_{50}$ is the effluent concentration that causes a measurable negative effect on 50\% of the test population (Metcalf and Eddy, 1991).

\subsubsection{Microtox ${ }^{\mathrm{TM}}$ acute toxicity test}

The test utilized in this project was the Microtox ${ }^{\top M}$ acute toxicity test. It is a relatively quick and inexpensive procedure that utilizes Vibrio fischeri, a bioluminescent bacterium. The effect measured by the Microtox ${ }^{\mathrm{TM}}$ assay, light loss, is a measure of biological activity, rather than a count of organisms affected. The light measured is due to the respiration of the organisms, hence a change in its intensity implies a change in respiration. The use of metabolic rate data, instead of quantal 
data (i.e. mortality test data), and the large number ( 1 million) of organisms exposed in each test provides a level of confidence in the statistical values determined (Microbics, 1992).

By measuring initial light readings then exposing the bacteria to varying dilutions of the effluent sample, a set of data can be evolved. For lower sample dilutions (higher effluent concentrations) the toxic environment has a significant effect on the respiration of the organisms, which results in lower light emissions. The data obtained for 5 minute and 15 minute exposure times can then be converted into gamma $(\Gamma)$ values through the use of a correction factor, $R_{t}$ (Equations 2.1 and 2.2).

$$
R_{t}=\frac{I_{t}}{I_{o}}
$$

Where, $\quad I_{t}$ is the light output of the control (blank) remaining after time $t$.

$I_{0}$ is the initial light output.

$$
\Gamma_{t}=\frac{R_{t} \times I_{o}-I_{t}}{I_{t}}=\frac{R_{t} \times I_{o}}{I_{t}}-1
$$

Where, $\quad \Gamma$ is the ratio of light lost at time t to the light remaining at time $\mathrm{t}$ for a given sample concentration at a specified time. Rate theory for biological inhibition predicts a simple mathematical relationship between the concentration of a toxic material and the response of a susceptible organism when the response is measured in terms of gamma values (Equation 2.3).

$$
\Gamma=k C^{p}
$$

Where, $\quad k$ is a composite factor relating to free energy and volume changes of the reaction,

$\mathrm{C}$ is concentration of the effluent sample, and $p$ is the number of toxic molecules per target site. 
This relationship may be restated in the form of a linear equation for prediction of concentration from gamma values (Equation 2.4).

$$
\log C=b \times \log \Gamma+\log a
$$

This equation describes a line with a slope $b$ and intercept of $\log a$, in which $\mathrm{C}$ represents concentration and $\Gamma$ the corresponding gamma. Regression statistics of $\log C$ on $\log \Gamma$ are used to estimate the concentration that would give a nominal effect, for example an $\mathrm{EC}_{50}$. In this example $\mathrm{EC}_{50}$ represents a gamma of 1 . Since $\log 1$ is zero, cancelling the effect of the slope, the $\log \mathrm{C}$ estimate is identical to $\log \mathrm{a}$. Therefore, the $\mathrm{EC}_{50}$ is equal to the antilog of the intercept (log a). Concentrations, which cause other percent effects, can be estimated by substituting the log of the equivalent gamma value in the regression equation.

The $\mathrm{EC}_{50}$ indicates the concentration of the sample that will cause a $50 \%$ reduction in light emission (i.e. at an $\mathrm{EC}_{50}=100$, the wastewater is considered non-toxic while an $\mathrm{EC}_{50}=0.1$ is very toxic). One drawback of this test is that for effluents that display relatively low toxicity $\left(\sim 25<\mathrm{EC}_{50}<100\right)$, small statistical and random errors gain increasing significance, resulting in plots that contain significant scattering in data points.

\subsubsection{Other acute toxicity tests}

There are many other methods of determining acute toxicity, and these usually involve the use of marine and freshwater species. Common marine species include Champia parvula, the red alga; Mysidopsis bahia, the mysid shrimp; Menidia beryllina, the inland silverisides; and Cyrinidon variegates, the sheepshead minnow. Common freshwater species include Pimephales promelas, fathead minnow; Ceriodaphnia 
dubia, the daphnid shrimp; and Oncorhynchus mykiss, rainbow trout (Metcalf and Eddy, 1991).

\subsubsection{Effectiveness of toxicity tests}

Toxicity testing has been widely used in recent years. Even though organisms vary in sensitivity to effluent toxicity, the EPA has documented that toxicity of effluents correlates well with toxicity measurements in the receiving waters when effluent dilution was measured; and predictions of impacts from both effluent and receiving water toxicity tests compare favourably with ecological community responses in the receiving waters (Metcalf and Eddy, 1991).

Several studies have been carried out to determine the toxicity of various petroleum refinery effluents. Bleckmann et al. (1995) investigated the aquatic toxicity variability for fresh and saltwater species in refinery wastewater effluent. Of the five species tested (i.e. daphnid shrimp, fathead minnow, mysid shrimp, sheepshead minnow, and Vibrio fischeri) they found that mysid shrimp were the most sensitive, followed by Vibrio fischeri. Sherry et al. (1997) utilized various tests to evaluate the toxicity of effluents from three Ontario refineries. Acute toxicity was assessed by the following: Microtox ${ }^{\top \mathrm{M}}$ (i.e. Vibrio fischeri), an assay based on the electron transport in submitochondrial particles, water flea (Daphnia magna) bioassay, and rainbow trout (Oncorhynchus mykiss) bioassay. Only Microtox ${ }^{\mathrm{TM}}$ and the submitochondrial test detected acute toxicity in the effluent samples. Aruldoss et al. (1998) utilized Microtox ${ }^{\mathrm{TM}}$ to test the toxicity of refinery wastewater, and concluded that Microtox ${ }^{\mathrm{TM}}$ seemed to be an adequate screening tool for a quick evaluation of the nature of the refinery wastewater. 


\subsection{Wastewater Treatme nt}

A survey of the literature indicates that the majority of oil refineries employ end of pipe wastewater treatment. This type of treatment method is generally preferred for economic reasons over the treatment of individual wastewater streams, despite the fact that the streams are characterized by large variations in pollutant composition and differing susceptibilities to individual treatment.

Wastewater treatment is separated into three different stages: primary, secondary, and tertiary treatment. At present, primary and secondary treatment is generally required to meet the regulated effluent compositions, though tertiary treatments are being employed to a greater degree in order to comply with increasingly stringent toxicity discharge regulations.

\subsubsection{Primary treatment}

Primary refinery wastewater treatment entails the separation of the dispersed and free oil from the water stream. Typically an API separator is used to remove free oil droplets and other suspended solids of size 150 $\mu \mathrm{m}$ or larger (Dold, 1989). Smaller oil droplets and suspended solids down to $40 \mu \mathrm{m}$ are removed using dissolved air flotation (DAF) in conjunction with the use of coagulants that promote the formation of larger oil droplets and increase the adhesion of the oil droplets to the air bubbles.

\subsubsection{Secondary treatment}

Approximately 40 to 50 percent of the original suspended solids and virtually all of the original dissolved organics and inorganics are still present after primary treatment (Peavy et al., 1985). Combinations of chemical and physical operations can be employed to remove the solids 
and reduce the BOD to acceptable levels. However, such operations are very costly, in terms of both capital and operating expenses, and thus are not commonly used. Instead, biological processes are most often used for secondary treatment.

The major purpose of secondary treatment is to remove the soluble BOD that escapes primary treatment and to provide further removal of suspended solids. The basic elements needed for conventional aerobic secondary biological treatment are the availability of many microorganisms, good contact between these organisms and the organic material, the availability of oxygen, and the maintenance of other favourable environmental conditions (i.e. favourable temperature and sufficient time for the organisms to work).

In biological treatment, the organics in wastewater are used as a food source for the microorganisms, which degrade the compounds and convert them into biological cells (or biomass). Since refinery wastewater contains a multitude of organics, a mixed culture is required for complete treatment. The metabolic pathways, however, are not allowed to occur in their natural fashion. These processes are controlled in carefully engineered reactors to optimize both the rate and efficiency of the organic removal. To complete the treatment process, the newly created biomass must be removed from the wastewater.

A variety of approaches has been used in the past to meet the basic needs of wastewater treatment operations. The most common biological wastewater treatment systems in use at the present time are activated sludge units. The activated sludge process is very flexible and can be adapted to almost any type of biological waste treatment problem. Several variations of the activated sludge process exist, and include 
conventional plug-flow, sequencing batch reactor, and deep shaft reactor (Metcalf and Eddy, 1991).

Given enough treatment time most organic compounds will be removed from the wastewater stream. Table 2.5 lists the composition of a typical refinery waste stream before and after biological treatment as measured by Rebhun and Galil (1987), and compared by them with other values reported in literature.

Table 2.5: Concentrations (mg/L) of Refinery Wastewater Pollutants Before and After Biological Treatment (Rebhun et al., 1987)

\begin{tabular}{|c|c|c|c|c|}
\hline \multirow{2}{*}{ Component } & \multicolumn{2}{|c|}{ Influent } & \multicolumn{2}{c|}{ Effluent } \\
\cline { 2 - 5 } & R\&G & Literature & R\&G & Literature \\
\hline $\mathrm{pH}$ & 8.14 & $6.2-10.6$ & 7.85 & $6.7-7.9$ \\
\hline Total Suspended Solids & 98 & $15-85$ & 47 & $6-112$ \\
\hline Volatile Susp. Solids & 65 & -- & 26 & -- \\
\hline COD - total & 625 & $140-3340$ & 230 & $80-300$ \\
\hline COD - soluble & 443 & -- & 165 & -- \\
\hline BOD - total & 268 & $7-230$ & 19 & $4-100$ \\
\hline BOD - soluble & 143 & -- & 7 & - \\
\hline Hydrocarbons & 40 & $23-200$ & 4.8 & $0.5-9.0$ \\
\hline
\end{tabular}

\subsubsection{Substrate removal mechanisms}

Current treatment technology achieves a significant reduction in toxic contaminants and other pollutants generated in the petroleum refining process, with the principle reduction occurring in the activated sludge system. The removal mechanisms in activated sludge are biodegradation, stripping of volatile organic carbon (VOC) compounds, 
biosorption, nitrification, and bioaccumulation of heavy metals (Dold, 1989). Rebhun and Galil (1987) quantified the various substrate removal mechanisms in the biological treatment of an oil refinery effluent. The study revealed that $90 \%$ of the hydrocarbons were removed by biodegradation and stripping, and about $10 \%$ of the hydrocarbons were entrapped in the biofloc.

\subsubsection{2 $\mathrm{BOD}$ to $\mathrm{COD}$ ratio}

Although there are more complex procedures for determining biodegradability, the BOD/COD (Biochemical Oxygen Demand/Chemical Oxygen Demand) ratio is useful for design and for monitoring. The BOD/COD ratio provides a simple biodegradability criterion for industrial wastewater treatment. A ratio above 0.4 indicates that the wastewater is readily biodegraded in an activated sludge process, and vice versa (Capps et al., 1995). A longer residence time, which can be achieved by longer hydraulic retention times, or the addition of an adsorbent (such as activated carbon) is required to metabolize refractory substrates (i.e. a BOD/COD ratio less than 0.4).

\subsubsection{First order BOD removal rate}

Another measure of the biodegradability of a wastewater stream is the first order BOD removal rate constant (k). Metcalf and Eddy (1991) state that for polluted water and wastewater, a typical value of $\mathrm{k}$ is $0.23 \mathrm{day}^{-1}$. The value of reaction-rate constant varies significantly, however, with the type of waste. The range of $\mathrm{k}$ for wastewaters may be from 0.05 to 0.3 day $^{-1}$ or more at $20^{\circ} \mathrm{C}$ (Metcalf and Eddy 1991). In order to determine the removal rate at a temperature other than $20^{\circ} \mathrm{C}$, the van't Hoff-Arrhenius equation may be used: 


$$
k_{T}=k_{20} \theta^{(T-20)} \text {, where } \theta=1.056
$$

In order to determine the removal rate for a multi-component petroleum refinery effluent the work of Grau et al. (1975) is relevant. Equation 2.6 accounts for the decrease of removal rate caused by a reduced number of components and thus the decrease in total substrate concentration with time ( $n=1$ for first-order removal rate).

$$
-\frac{d S}{d t}=k X\left(\frac{S}{S_{o}}\right)^{n}
$$

A linear version of the equation above can be used to determine the value of $\mathrm{k}$ :

$$
-\log \frac{S}{S_{O}}=p t \quad \text { where, } \quad k=p \frac{S_{O}}{X_{O}}
$$

\subsubsection{Sludge Age}

The sludge age, or solids retention time (SRT), selected for design is a function of the degree of treatment required. A high sludge age results in a larger quantity of solids being carried in the system and a higher degree of treatment being obtained (Davis et al., 1998). A higher sludge age also results in the production of less waste sludge, and a larger oxygen demand.

Sludge age is usually calculated from the kinetic equation for growth of the biomass, and it is controlled by the fraction of sludge recycled to the reactor. Some toxic organics degrade very slowly in the activated sludge process; therefore long SRTs are required to achieve acceptable toxicity reduction (Eckenfelder, 1988). High sludge age is essential for effective operation of industrial wastewater treatment, since industrial wastewater typically contains a significant amount of refractory components. Moreover, high sludge age is also required for the proliferation of nitrifying bacteria, if ammonia is a critical contaminant. A minimum 
sludge age of 40 days is recommended for effective COD and ammonia nitrogen treatment for industrial wastewater (Capps et al., 1995).

\subsubsection{Aeration}

The system should be designed with enough aeration capacity to sustain optimum levels of dissolved oxygen at maximum pollutant loadings. The optimum DO concentration for activated sludge is $2.0-4.0 \mathrm{mg} / \mathrm{L}$ (Capps et al., 1995). Dissolved oxygen concentration is a function of partial pressure of oxygen, wastewater constituents, temperature, and mixing.

\subsubsection{Temperature}

The rate of most microbial reactions increases rapidly up to approximately $37^{\circ} \mathrm{C}$ and then falls off because of death of the microorganisms caused by denaturation of the cellular protein. The rate of microbial reaction doubles for every $10^{\circ} \mathrm{C}$ increase in temperature (McKinney, 1963). The optimum design temperature for mesophilic degradation is $32-35^{\circ} \mathrm{C}$ (Metcalf and Eddy, 1991).

\subsubsection{7 $\mathrm{pH}$}

The internal environment of a living cell is approximately neutral, and most organisms cannot tolerate extreme $\mathrm{pH}$ conditions (i.e. below 4 and above 9.5) (Kim and Armstrong, 1981). Most activated sludge systems treating organic wastewaters have an optimum $\mathrm{pH}$ range of 6.5-8.5 (Eckenfelder et al., 1985).

\subsubsection{Tertiary treatment}

Tertiary treatment methods are numerous and are usually used to further reduce the chemical oxygen demand, and the concentration of suspended solids in the effluent from the secondary stage. In addition, due to their toxic nature, increasing attention has been given in recent 
years to the removal of refractory organic compounds and priority pollutants from WWTP effluent streams. Tertiary treatment processes used for the treatment of toxic compounds include: activated carbon adsorption, chemical oxidation, and biofiltration.

\subsubsection{Activated carbon adsorption}

Powdered activated carbon (PAC) can be added to the wastewater stream to remove organic compounds and heavy metals through adsorption (Dold, 1989; Metcalf and Eddy, 1991). Carbon can be mixed in with the influent wastewater or fed directly into the aeration basin. This process has the advantage of being able to be integrated into existing treatment facilities at minimal capital cost. Activated carbon may also be used in the form of tertiary granular carbon columns (Eckenfelder, 1988).

\subsubsection{Chemical oxidation}

In some cases, toxicity and refractory organic reduction may be achieved be chemical oxidation. Common oxidants include permanganate, ozone and hydrogen peroxide. Eckenfelder (1988) states that chemical degradation of refractory organics may take several forms: (1) primary degradation which results in a change in the structure of the parent compound, and results in increased biodegradability; (2) acceptable degradation which results in a reduction in toxicity; and (3) ultimate degradation which results in the mineralization of the compounds. Ultimate degradation using chemical oxidation is often not economically feasible due to the large oxidant demand. Primary or acceptable degradation, using much less oxidant, integrated with biological treatment may provide a more cost effective method for tertiary treatment. 


\subsubsection{Biofiltration}

Biofiltration can be used in order to degrade the refractory compounds in the effluent from the secondary treatment stage (Grady et al., 1980; Pujol et al., 1994). The concept of submerged liquid biofiltration holds some similarities to an older, more established wastewater treatment process; trickling filtration. This latter practice involves trickling effluent through a packing medium on which a layer of bacteria and other microorganisms are grown. As liquid is passed over this layer, microbes degrade the soluble organics in the fluid for energy generation and the synthesis of new cells.

Aside from the use of a solid support medium for the growth of a biological film, submerged liquid biofiltration is a distinctly different operation than trickling filtration. One major difference is the size of the support media. Submerged biofilters utilize packing with typical diameters of $\sim 6 \mathrm{~mm}$, whereas trickling filter packing has dimensions 4 to 8 times larger. In addition, liquid biofilters are completely submerged, which is in contrast to the light distribution of liquid over trickling filters. A third difference is the accumulation of suspended solids, which does not occur to any great extent for trickling operations due to their relatively high void fraction $(-50 \%)$. In submerged biofilters, accumulation of suspended solids along with the growth of the biological layer, sometimes results in filter plugging, where the liquid flow is impeded by material trapped within the support media. Periodic backwashing of the biofilters ensures that the flow remains unimpeded. 


\section{$\underline{2.4 .4}$ Summary}

The treatment technology employed corresponds to the effluent quality required by specific regulations or guidelines. The treatment of refinery wastewaters generally contains some combination of the following: sour water stripping, sulphur removal, phenolic reduction, settling, $\mathrm{pH}$ adjustment, air flotation, biological oxidation, carbon adsorption, and filtration (Dold, 1989). 


\subsection{Chevron WWTP}

At the Chevron refinery in Burnaby, $\mathrm{BC}$, primary treatment of the effluent consists of the segregation of water containing $\mathrm{H}_{2} \mathrm{~S}$ and $\mathrm{NH}_{3}$ for sour water stripping, an API separator for gross oil/water separation, dispersed air flotation for removal of emulsified oil droplets, and aeration with equalization to remove trace sulphides. The primary treated effluent is stored in a holding pond prior to further treatment. Since late 1996, to provide secondary and tertiary treatment of their wastewater, the refinery has been operating a WWTP that consists of a DSTI ${ }^{\mathrm{TM}}$ bioreactor followed by a dissolved air flotation (DAF) clarifier and final polishing effluent biofilters (Figure 2.2). The decision to implement the upgrade was based on the need to reduce the plant's impact on off-site treatment facilities (i.e. the GVRD sewer system) (Freeman, 1997).

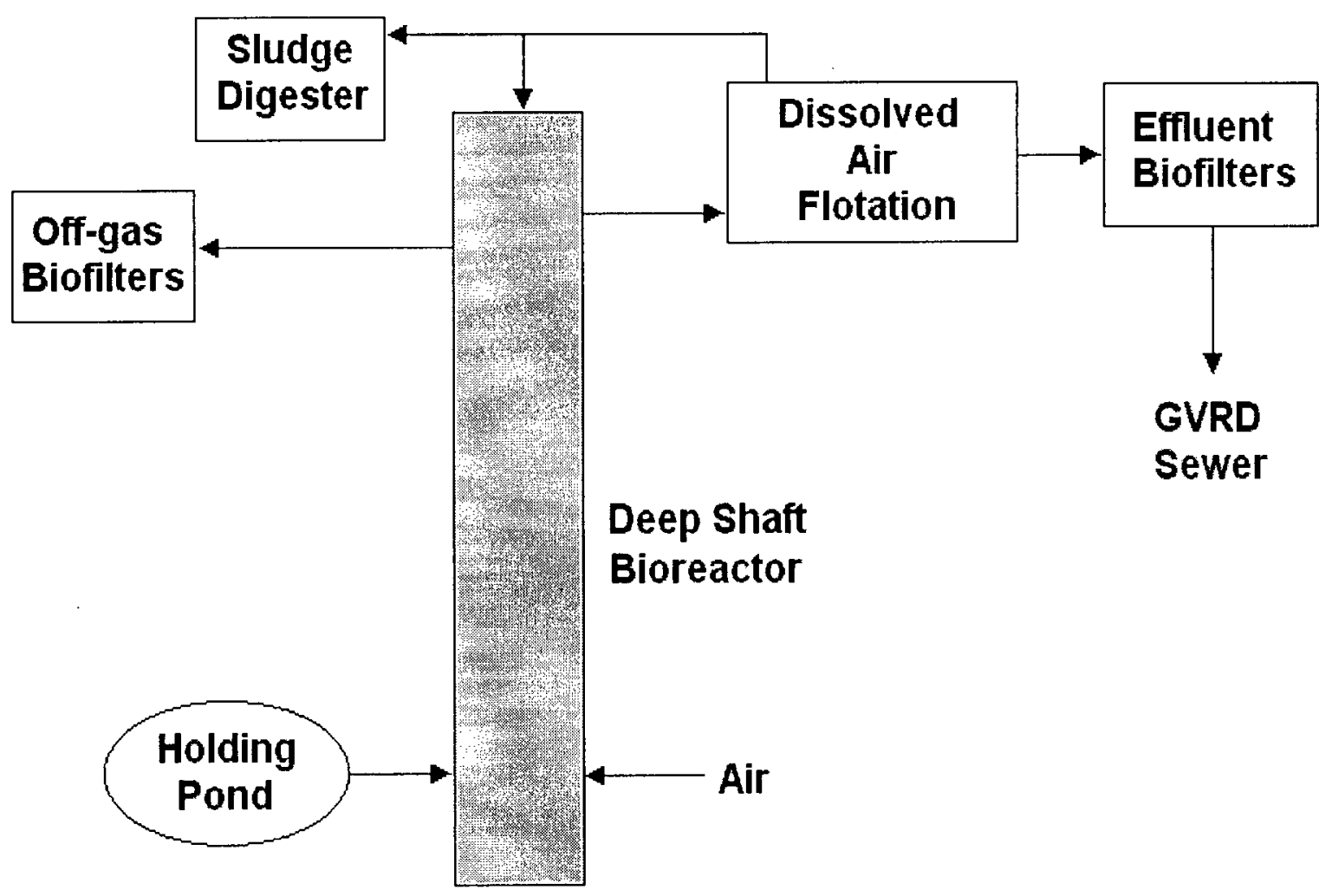

Figure 2.2: DSTI ${ }^{\mathrm{TM}}$ Process Configuration 
2.5.1 DSTI ${ }^{\mathrm{TM}}$ process description

Concentric column hyperbaric aeration reactors have been proven effective mass transfer devices and used in the treatment of wastewater streams for many years (Brenner, 1980). DSTI ${ }^{\mathrm{TM}}$ is a proprietary high rate biological process which operates within the general parameters of activated sludge processes and is applicable to the treatment of a wide variety of waste streams including petroleum refinery wastewater.

$\mathrm{DSTI}^{\mathrm{TM}}$ was so named because the process utilizes a deep shaft activated sludge reactor (Table 2.6). The principal behind this design is the presence of two distinct treatment stages within the column (i.e. oxidation and mixing) as well as enhanced oxygen transfer rates into the liquid phase due to increased hydrostatic pressures. The high concentration of dissolved $\mathrm{O}_{2}$ in turn promotes increased biodegradation efficiency from the resident microbial organisms (Freeman, 1997). High energy activated sludge processes, such as the deep shaft technology also yield a highly active biomass (Eckenfelder et al., 1993).

Table 2.6: Specifications of Chevron DSTI ${ }^{\mathrm{M}}$ Reactor

\begin{tabular}{|c|c|}
\hline Depth & $105 \mathrm{~m}$ \\
\hline Diameter & $1.8 \mathrm{~m}$ \\
\hline Flowrate & $2290-2750 \mathrm{~m}^{3} / \mathrm{d}$ \\
\hline HRT & $\sim 2.5 \mathrm{~h}$ \\
\hline F/M & $0.5-0.75$ \\
\hline Temperature & $35^{\circ} \mathrm{C}$ \\
\hline pH & $6-9$ \\
\hline Nutrients (C:N:P) & $100: 5: 1$ \\
\hline
\end{tabular}

High reaction rates within the oxidation zone ensure that the bulk of the organic compounds are biodegraded in this updraft portion of the vertical circulating loop. Recirculating liquor travels up to the riser and enters the head tank where entrained spent off gas bubbles are released, and 
the combined off gases flow through pipes to the off gas biofilters. Removal of the gaseous products of microbial respiration is necessary to prevent spent gas from re-entering the system and impairing the efficiency of the airlift mechanism by increasing the buoyancy of the mixed liquor within the downcomer.

Polished mixed liquor is withdrawn from the depths of the shaft and rapidly transferred $(2 \mathrm{~m} / \mathrm{s})$ to the flotation clarifier. This ensures that grit or solids do not settle out in the bottom of the shaft. Dissolved gas saturation in the polishing zone is also used to drive solids separation by flotation in the subsequent clarification step. The rapid depressurization of the mixed liquor as it travels to the surface results in a well aerated, low density floc. Efficient separation in the flotation clarifier produces a highly concentrated biomass (ca. 40,000 $\mathrm{mg}$ SS/L) and a high quality liquid effluent ( $<50 \mathrm{mg}$ TSS/L and $\sim 20 \mathrm{mg} \mathrm{BOD/L}$ ) ready for polishing in the effluent biofilters.

The final effluent treatment stage occurs immediately downstream from the DAF. Four refractory (liquid-submerged) biofilters, arranged in a parallel configuration, are designed to remove trace organics that were not biodegraded in the upstream processes. Air and water flow countercurrently though the biofilters. The wastewater flows down through the biofilters, and air is pumped up through aeration manifolds and spargers embedded in gravel beneath the media bed. When the effluent has passed this filtration step, it flows to the effluent diversion tank where it is either stored in the backwash storage tank or is discharged to the GVRD sewer system.

The biomass generated in the deep shaft reactor is either drawn off from the flotation solids to the aerobic sludge digester, where it is degraded to soluble organics and gases, or recycled back into the shaft to maintain 
the desired MLSS concentration. Gases evolved from sludge digestion or the two aforementioned processes are fed to four parallel off-gas biofilters, where remaining gaseous VOCs are stabilized.

\subsubsection{WWTP performance}

Table 2.7 presents the performance of the WWTP for BOD, COD, and acute toxicity (5-minute Microtox ${ }^{\mathrm{TM}}$ ) removal. These results are based on 15 months of plant operating data, and a 3-month toxicity monitoring program conducted by Hoy (2000). Despite the potential of the Chevron WWTP, recent reports have highlighted inconsistencies in its performance. Only three of the 12 quarterly reports submitted to the MOE since 1997 were trouble-free. Chevron has also been listed on the non-compliance list, B.C.'s polluter blacklist, seven times since 1990 (Tanner, 2000).

Table 2.7: Performance of Chevron WWTP

\begin{tabular}{|c|c|c|c|}
\hline & Influent & Effluent & $\%$ Removal \\
\hline BOD (mg/L) & $250-350$ & $5-15$ & $>95 \%$ \\
\hline COD (mg/L) & $400-600$ & $100-150$ & $\sim 75 \%$ \\
\hline Toxicity (EC $50 \% \mathrm{v} / \mathrm{v})$ & $\sim 2 \%$ & $\sim 25 \%$ & -- \\
\hline
\end{tabular}




\subsection{Microbial Kinetics}

2.6.1 Growth and substrate uptake rates

The specific growth rate of a microbial population is defined as follows:

$$
\mu=\left(\frac{d X}{d t}\right) \frac{1}{X}
$$

Where: $\quad \mathrm{X}$ : biomass concentration;

t: time.

The relationship between the specific biomass growth rate and the concentration of the growth limiting substrate is usually modelled using the Monod equation.

$$
\mu=\left(\frac{\mu_{\max } S}{K_{S}+S}\right)
$$

Where: $\quad \mu_{\max }$ : maximum growth rate;

S: substrate concentration;

$\mathrm{K}_{\mathrm{S}}$ : half-saturation coefficient.

Though originally developed for pure cultures and single component substrates, this kinetic model has often been used for mixed cultures, such as those found in an activated sludge treatment system, and multicomponent substrates, such as those found in wastewaters. In these cases, however, $\mu_{\max }$ and $\mathrm{K}_{\mathrm{s}}$ are not constant but variable, depending on the composition of the mixed culture. Shifts in culture population are reflected in changes of overall growth kinetic constants (Cech et al., 1984).

The primary purpose of wastewater treatment is not to cultivate mixed cultures and produce biomass, but to remove the substrates from solution. It is therefore desirable to express Equation 2.9 in substrate removal terms. 
Similar to the specific growth rate, the specific substrate uptake rate (q) is defined as follows:

$$
q=\left(\frac{d S}{d t}\right) \frac{1}{X}
$$

The observed growth yield coefficient is defined as the increase in biomass observed as the result of an uptake of substrate:

$$
Y_{o b s}=\frac{\left(\frac{d X}{d t}\right)}{\left(\frac{d S}{d t}\right)}=\frac{\mu}{q}
$$

Combining equations 2.9 and 2.11 yields:

$$
q=\left(\frac{\mu_{\max }}{Y_{o b s}}\right)\left(\frac{S}{K_{S}+S}\right)
$$

Further, the maximum specific substrate uptake rate, $\mathrm{q}_{\max }$, is defined as:

$$
q_{\max }=\left(\frac{\mu_{\max }}{Y_{o b s}}\right)
$$

Hence, the specific substrate uptake rate is given by:

$$
q=\left(\frac{q_{\max } S}{K_{S}+S}\right)
$$

The two parameters of this equation are $q_{\max }$ and $\mathrm{K}_{\mathrm{s}}$. The half saturation constant is the substrate concentration at which the specific substrate uptake rate is equal to one half the maximum rate. When the substrate concentration is low ( $\mathrm{S}<<\mathrm{K}_{\mathrm{S}}$ ), the uptake rate can be modeled based upon first order kinetics, with the first order rate constant equal to $\mathrm{q}_{\max } / \mathrm{K}_{\mathrm{s}}$. When the substrate concentration is high $\left(\mathrm{S}>>\mathrm{KS}_{\mathrm{S}}\right)$, the kinetics become zero order, with the uptake rate equal to $q_{\max }$.

2.6.2 Limitations of Monod model and alternative models Although the Monod expression is widely used to model microbial kinetics, it does have its limitations. The Monod model, without modifications, rarely fits experimental data from biological wastewater 
treatment studies (Helle, 1999). Although there is a similarity to Michaelis-Menten enzyme kinetics, the Monod model is purely empirical. It has been widely observed in the literature that the Monod expression does not saturate quickly enough to sufficiently fit experimental data (Powell, 1972; Bader, 1978; Helle, 1999).

A number of other equations have been proposed to describe experimental microbial growth (or substrate uptake) data. These equations are more complicated mathematically, and completely empirical. They all saturate faster, at increasing substrate concentrations, than Monod's equation. A few of these expressions are presented below in terms of substrate uptake kinetics.

$$
\begin{aligned}
& \text { Tessier: } & q & =q_{\max }\left(1-e^{k S}\right) \\
& \text { Moser: } & q & =\frac{q_{\max } S^{n}}{K+S^{n}} \\
& \text { Contois: } & q & =\frac{q_{\max } S}{K_{S X} X+S}
\end{aligned}
$$

Depending on the experimental data, one of these equations may be provide a better fit than the others (Shuler and Kargi, 1992).

\subsubsection{Inhibition}

Inhibition has a detrimental effect on the ability of the biomass to effectively treat wastewater. At high concentrations of substrate or product and in the presence of inhibitory substances in the medium, growth becomes inhibited, and growth rate depends on inhibitor concentration (Shuler and Kargi, 1992). Shuler and Kargi list three categories of inhibition, namely substrate inhibition, product inhibition, and inhibition by toxic compounds. Within each of these categories the 
inhibition mechanisms may include one or more of the following: competitive, non-competitive, or uncompetitive inhibition (Table 2.8).

2.6.3.1 Competitive, non-competitive, and uncompetitive inhibition Competitive inhibitors are usually substrate analogs and compete with substrate for the active site of an enzyme. The net effect of competitive inhibition is an increased value of the half saturation constant $\left(\mathrm{K}_{\mathrm{s}}\right)$, and a corresponding reduced reaction rate (in wastewater treatment the rate of concern is $\left.\mathrm{q}_{\max }\right)$. Non-competitive inhibitors are not substrate analogs, but rather bind on sites other than the active site and reduce enzyme affinity for the substrate. The net effect of non-competitive inhibition is a reduction in reaction rate. In some cases both the reaction rate is reduced and the $\mathrm{K}_{\mathrm{s}}$ is increased. Uncompetitive inhibitors bind to a complex of the enzyme and substrate, and have no affinity for the enzyme itself. The net effect of uncompetitive inhibition is a reduction in both the reaction rate and $\mathrm{K}_{\mathrm{s}}$.

Table 2.8: Effects of various types of inhibition on microbial kinetics

\begin{tabular}{|c|c|c|}
\hline & $\mathrm{q}_{\max }$ & $\mathrm{K}_{\mathrm{s}}$ \\
\hline Competitive & decrease & increase \\
\hline Non-competitive & decrease & $\begin{array}{c}\text { possible } \\
\text { increase }\end{array}$ \\
\hline Uncompetitive & decrease & decrease \\
\hline
\end{tabular}

2.6.3.2 Substrate, product, and toxic compound inhibition In some cases, microbial growth rate can be inhibited by elevated concentrations of substrate. Similar to enzyme kinetics, substrate inhibition of growth may be competitive or non-competitive.

High concentrations of product can also inhibit microbial growth. Product inhibition may be competitive or non-competitive, and in some 
cases when the mechanism is not known, the inhibited growth rate is approximated to exponential or linear decay expressions.

The presence of toxic compounds, possibly generated as intermediate metabolites, can also be inhibitory to microbial growth. Inhibition by toxic compounds may be competitive, non-competitive, or uncompetitive. 


\subsection{Measurement of Mic robial Kinetic Constants}

A multitude of different tests have been developed for determining microbial kinetic constants, both for biomass growth and substrate uptake, in biological wastewater treatment systems (Helle, 1999). A simple method consists of a series of batch tests. During each test, a sample of wastewater is seeded with biomass. The substrate and biomass concentrations are measured to determine the biomass growth rate and the substrate uptake rate. If many different starting substrate concentrations are used, the initial rate (growth or substrate uptake) at each concentration may be measured to obtain the relationship between rate and substrate concentration (Helle, 1999). This method requires that an accurate assay be available to measure the substrate concentrations. Analytical methods for substrate concentrations tend to be time consuming, inaccurate or non-existent; they are especially problematic when low substrate concentrations are used (Helle, 1999).

\subsubsection{Respirometry}

Respirometric methods are often used as a surrogate for substrate analysis in determining microbial kinetic constants. The dissolved oxygen concentration can be measured throughout the tests accurately, immediately and continuously, not to mention easily and cheaply. Respirometric methods are so sensitive that even very low substrate concentrations bring about recordable changes in oxygen uptake rate (OUR).

\subsubsection{Respirometric methods}

Over the years, many respirometric methods have been developed, including batch tests and continuous methods. Most are very similar and make similar assumptions. Product formation and energy spilling are assumed to be negligible (Mahendraker et al., 1995). Energy spilling occurs when anabolism and catabolism are not perfectly coupled, thus 
the cell does not use all the energy obtained from the oxidation of substrate. This uncoupling between anabolism and catabolism occurs under nutrient limitation, and results in a decreased yield. Mechanisms for energy spilling include: production of storage compounds, excretion of catabolic products, deletion of sites for oxidative phosphorylation, and wastage of ATP (Helle, 1999). Respiration of protozoa and nitrifiers is also assumed to be negligible as is their influence on the and growth rate (Mahendraker et al., 1995). The OUR due to endogenous metabolism may be accounted for and subtracted from the overall OUR. These assumptions along with the assumption of a constant yield, results in the following: $\mu$ and $q_{\max }$ are proportional to the amount of oxygen consumed.

Respirometric methods may be broadly categorized based on the initial F/M ratio (Helle, 1999). The first category utilizes a small microbial inoculum and a large $\mathrm{F} / \mathrm{M}$ ratio. The OUR is monitored over a long time period, usually at least one day. These tests can be used for the following purposes:

- determine microbial growth rates

- measure the biodegradation potential of various substrates

- measure the inhibition of the growth rate by toxic substances

- determine the ability of the biomass to adapt to different substrates

- measure BOD

- determine the treatment time required for a given waste

Since significant growth usually occurs during the high F/M tests, the microbial composition at the end of the test may not be the same as the composition at the start of the test (Helle, 1999). If mixed cultures are used, as with activated sludge, these tests will select for the fast growing 
microbes, which have different growth rates and substrate uptake stoichiometry than slow growing microbes.

The second category of respirometric methods uses large biomass concentrations and smaller $\mathrm{F} / \mathrm{M}$ ratios, and generally takes several hours to complete. In these tests, the biomass is not given time to adapt to new conditions, hence results will be strongly dependent on the culture history. Chudoba et al. (1992) state that the results from these tests will yield kinetic parameters closer to those found in actual WWTPs than results from tests in the first category. These tests can be used for the following purposes:

- measure the biodegradation kinetics

- determine the readily biodegradable fractions of wastewater

- determine required treatment time

- determine the short term BOD

In these tests, endogenous respiration may be a significant fraction of the total OUR and must taken into account.

\subsubsection{2 $\triangle$ OUR method}

The most thoroughly developed method that has been used by a number of experimenters is the method of Cech and Chudoba (Helle, 1999; Cech et al., 1984). This is the method used in this project and it is described in detail in Section 4.5.6. The substrate biodegradation rate is assumed to be proportional to the exogenous OUR (or the $\Delta O U R$ ), which is calculated by subtracting the endogenous OUR from the total OUR after substrate addition (Equation 2.18). The proportionality constant is (1-Y).

$$
q=\frac{\Delta O U R}{(1-Y)}=\frac{\Delta O U R}{(O C / S)}, \text { where } Y=\frac{S-O C}{S}=1-(O C / S) 2.18
$$

The yield is based on the assumption that the substrate that is not oxidized is used for growth, and all the substrate added is utilized. OC 
represents the oxygen consumed due to substrate addition, and does not include the oxygen used in endogenous respiration. For data analysis, pseudo steady state is assumed, that is the microbes immediately achieve the metabolic state corresponding to the added substrate concentration. The maximum $\triangle O U R$ achieved during the test is assumed to be the $\triangle$ OUR that corresponds to the initial substrate concentration of that test. If these assumptions are valid, the $\triangle O U R$ may be converted to a substrate uptake rate and graphed versus the added substrate concentration to obtain the relationship between the substrate uptake rate and the concentration. The data may fit the Monod model, but the other equations presented in Section 2.6.2 may provide a better fit as they allow for faster saturation. 


\section{OBJectrves}

This study was undertaken in order to provide a better understanding of the biodegradation process occurring at the Chevron refinery wastewater treatment plant in Burnaby, BC. The following objectives were determined:

Using batch biological tests,

1. characterize the removal of organic compounds (as measured by $\mathrm{BOD}$ and $\mathrm{COD}$ );

2. determine the capacity of the biomass for acute toxicity removal;

3. determine the abiotic rate of volatilization of COD and acute toxicity; and

4. investigate possible sources of $B O D, C O D$ and acute toxicity in the refinery effluent.

Using respirometry,

5. determine the specific oxygen uptake rate throughout the batch tests;

6. determine the microbial kinetics throughout the batch tests. 


\section{MATERIALS AND MET HODS}

The purpose of the experimental program was to determine the kinetics of removal of organic material (as measured by BOD and COD) and acute toxicity during batch biological treatment. The experimental program was carried out using two batch reactors operated at $35^{\circ} \mathrm{C}$. A six-litre batch reactor was operated for 52.5 hours, and a $15 \mathrm{~L}$ batch reactor was operated for 120 hours. These runs will hereafter be referred to as Run 1 and Run 2, respectively. In order to examine the abiotic rate of volatilization, a stripping test was also performed in the six-litre batch reactor. The wastewater feed for all runs was collected from Holding Pond \# 3 at the Chevron refinery on October 27, 1999. Forty litres of the petroleum refinery effluent was collected in two 20 L HDPE Nalgene jerry cans and stored with minimal headspace at $4^{\circ} \mathrm{C}$. The biomass used to seed Runs 1 and 2 was collected from the Chevron WWTP Deep Extraction sampling port on October 27, 1999 and December 17, 1999, respectively.

\subsection{Run 1}

Run 1 was carried out in a six-litre cylindrical jacketed Plexiglas reactor. Reactor temperature was maintained at $35^{\circ} \mathrm{C}$ by circulating water from a constant temperature bath (VWR Scientific, Model 1131) through the annular Plexiglas jacket encasing the reactor. Samples were collected from the sampling port at the bottom of the reactor. Two aquarium pumps (Rolf C. Hagen Inc., Optima Model) supplied a total of five standard litres per minute (SLPM) of air to the reactor. The air flowrate was measured using a digital flow meter (Matheson Gas Products, Model 8111-1424). Aside from agitation provided by aeration, mixing was provided by a stir bar and a magnetic stirrer (Fisher Scientific). 
The six-litre reactor was operated for 52.5 hours from October 30 to November 1, 1999. Before the run commenced, 4.4 litres of wastewater was warmed overnight to $35^{\circ} \mathrm{C}$ in the reactor. The wastewater $\mathrm{pH}$ was 8 , and it was not adjusted. To prepare an active seed culture for Run 1, two litres of biomass ( $4756 \pm 240 \mathrm{mg} \mathrm{SS} / \mathrm{L}$ ) were combined with $200 \mathrm{ml}$ of refinery wastewater $(316 \pm 10 \mathrm{mg} \mathrm{BOD} / \mathrm{L})$, and aerated at $35^{\circ} \mathrm{C}$ overnight. On the following day, $5 \mathrm{ml}$ of each of the following $\mathrm{BOD}$ nutrient solutions (Standard Method 5210) were added to the six-litre reactor: phosphate buffer, $\mathrm{MgSO}_{4}, \mathrm{CaCl}_{2}$, and $\mathrm{FeCl}_{3}$ (APHA, 1992). Aeration was then initiated, and the reactor was seeded with $650 \mathrm{ml}$ of biomass ( $4000 \mathrm{mg} \mathrm{SS} / \mathrm{L}$ ) in order to obtain a MLSS concentration in the reactor of approximately $500 \mathrm{mg} / \mathrm{L}$. The DO in the reactor was monitored for the first 2 hours to ensure that the five SLPM aeration rate was sufficient to maintain the DO level above $5 \mathrm{mg} / \mathrm{L}$. The samples collected and the analyses performed are itemized in Table 4.1. All samples were collected and preserved as described in section 4.4.

Table 4.1: Sampling Schedule for Run 1

\begin{tabular}{|c|c|c|}
\hline Sample Time (h) & Volume Collected (mL) & Analyses \\
\hline 0 & 460 & $1,2,3,4,5,6$ \\
\hline 2.25 & 510 & $1,2,3,4,5,6,7$ \\
\hline 4 & 460 & $1,2,3,4,5$ \\
\hline 6 & 460 & $1,2,3,4,5$ \\
\hline 8 & 510 & $1,2,3,4,5,6,7$ \\
\hline 10 & 460 & $1,2,3,4,5$ \\
\hline 24 & 460 & $1,2,3,5,6$ \\
\hline 24.5 & 50 & 7 \\
\hline 27.75 & 460 & $1,2,3,5$ \\
\hline 52.5 & 460 & $1,2,3,5,6$ \\
\hline
\end{tabular}

1:BOD, 2:COD, 3:OUR, 4:Kinetics, 5: Microtox ${ }^{\mathrm{TM}}, 6: \mathrm{VH} / \mathrm{VPH} / \mathrm{BTEX}, 7: \mathrm{MLSS}$ 


\subsection{Run 2}

Run 2 was carried out in a $15 \mathrm{~L}$ (working volume) cylindrical jacketed Plexiglas reactor. Reactor temperature was maintained at $35^{\circ} \mathrm{C}$ by circulating water from a constant temperature bath (VWR Scientific, Model 1131) through the annular Plexiglas jacket encasing the reactor. Samples were collected from the sampling port at the bottom of the reactor. Building air supplied the reactor with 13-15 SLPM of air. The air flowrate was measured using a digital flow meter (Matheson Gas Products, Model 8111-1424).

The $15 \mathrm{~L}$ reactor was operated for 120 hours from December 19 to. December 24, 1999. Before the run commenced, 14 litres of wastewater were warmed overnight to $35^{\circ} \mathrm{C}$ in the reactor. The wastewater $\mathrm{pH}$ was 8 , and it was not adjusted. To prepare an active seed culture for the 15litre reactor, two litres of biomass $(6053 \pm 26 \mathrm{mg} \mathrm{SS} / \mathrm{L})$ were aerated at $35^{\circ} \mathrm{C}$ overnight. On December $19^{\text {th }}, 15 \mathrm{ml}$ each of the following BOD nutrient solutions (Standard Method 5210) were added to the $15 \mathrm{~L}$ reactor: phosphate buffer, $\mathrm{MgSO}_{4}, \mathrm{CaCl}_{2}$, and $\mathrm{FeCl}_{3}$ (APHA, 1992). After the raw samples were collected, aeration was initiated, and the remaining $12.3 \mathrm{~L}$ in the reactor were seeded with $1.12 \mathrm{~L}$ of biomass $6053 \pm 26 \mathrm{mg}$ $\mathrm{SS} / \mathrm{L}$ ) in order to obtain a MLSS concentration of approximately 500 $\mathrm{mg} / \mathrm{L}$. The DO in the reactor was monitored for the first 2 hours to ensure that the 13-15 SLPM aeration rate was sufficient to maintain the DO level above $5 \mathrm{mg} / \mathrm{L}$. The samples collected and the analyses performed are itemized in Table 4.2. All samples were collected and

preserved as described in section 4.4. A summary of the operating conditions for Runs 1 and 2 is presented in Table 4.3. 
Table 4.2: Sampling Schedule for Run 2

\begin{tabular}{|c|c|c|}
\hline Sample Time (h) & Volume Collected (L) & Analyses \\
\hline Raw & 1.7 & $1,2,5,6$ \\
\hline 0.5 & 1.6 & $1,2,3,4,5,6,7$ \\
\hline 3 & 1.1 & $1,2,3,4,5,6$ \\
\hline 10 & 1.6 & $1,2,3,4,5,6,7$ \\
\hline 24 & 1.6 & $1,2,3,5,6,7$ \\
\hline 48 & 1.6 & $1,2,3,5,7$ \\
\hline 72 & 1.6 & $1,2,3,5,7$ \\
\hline 96 & 1.6 & $1,2,3,5,7$ \\
\hline 120 & 1.6 & $1,2,3,5,7$ \\
\hline
\end{tabular}

1:BOD, 2:COD, 3:OUR, 4:Kinetics, 5: Microtox ${ }^{\mathrm{TM}}$, 6:Phenol/EPH, 7:MLSS

Table 4.3: Summary of Runs 1 and 2

\begin{tabular}{|c|c|c|}
\hline & Run 1 & Run 2 \\
\hline Reactor Working Volume (L) & 5.05 & 13.42 \\
\hline Raw Wastewater Volume (L) & 4.4 & 12.3 \\
\hline Seed Volume (L) & 0.65 & 1.12 \\
\hline Seed Concentration (mg SS/L) & $4756 \pm 240$ & $6053 \pm 26$ \\
\hline Initial MLSS (mg/L) & $501 \pm 14$ & $636 \pm 19$ \\
\hline Run time (h) & 52.5 & 120 \\
\hline Aeration Rate (SLPM) & 5 & $13-15$ \\
\hline Temperature $\left({ }^{\circ} \mathrm{C}\right)$ & 35 & 35 \\
\hline pH & 8 & 8 \\
\hline \multicolumn{3}{|l|}{$\begin{array}{l}\text { BOD Nutrient Solutions Added } \\
\text { (mL Nutrient/L Wastewater) }\end{array}$} \\
\hline Phosphate Buffer & 1.1 & 1.1 \\
\hline $\mathrm{MgSO}_{4}$ & 1.1 & 1.1 \\
\hline $\mathrm{CaCl}_{2}$ & 1.1 & 1.1 \\
\hline$\overline{\mathrm{FeCl}_{3}}$ & 1.1 & 1.1 \\
\hline
\end{tabular}




\subsection{Stripping Test}

A stripping test was carried out from November 22 to 23, 1999 in order to determine the relative contribution of stripping to COD and toxicity removal. The test was conducted in the six-litre reactor in the same manner as Run 1, except that no biomass was added to the reactor. In order to ensure abiotic conditions during this run, the $\mathrm{pH}$ of the wastewater was reduced to 2 . The aeration, temperature, and sampling scheme for this run were the same as those in Run 1. All samples were collected and preserved as described in section 4.4.

\subsection{Sample Collection and Preservation}

After the reactor sampling port was purged, samples were collected and preserved. In order to arrest any further biological activity, the samples were immediately acidified to $\mathrm{pH} 2$ or less with concentrated $\mathrm{H}_{2} \mathrm{SO}_{4}$. The samples were then filtered by vacuum filtration through Whatman 41 Ashless (11 cm diameter) filter papers. The resulting soluble sample fractions were stored at $4^{\circ} \mathrm{C}$ with minimal headspace.

\subsubsection{Test of preservation method on sample COD}

The possibility that the sample preservation technique may have affected the resulting COD was investigated. It was hypothesized that sample acidification might have resulted in the dissolution of capsular cellular material. This would have resulted in a higher COD than if the samples had been filtered prior to acidification. A test was conducted in the same manner as Run 1 (Section 4.1), and the samples collected were preserved in two ways: acidification followed by filtration and filtration follow by acidification. The wastewater and biomass used in this test was collected at the Chevron WWTP on April 24, 2000. 


\subsection{Sample Analysis}

\subsubsection{Biochemical oxygen demand (BOD)}

Soluble BOD was measured according to Standard Method 5210 B, 5day BOD test (APHA, 1992). The $\mathrm{pH}$ of the preserved samples was adjusted to seven using concentrated $\mathrm{NaOH}$ prior to analysis. Biomass obtained from the Chevron WWTP was used to seed the BOD tests.

In order to determine the efficacy of Polyseed ${ }^{\circledR}$ (InterBio, Houston, Texas), an "all-purpose" BOD seed inoculum, a duplicate set of BOD tests was performed using Polyseed ${ }^{\circledR}$ as inoculum on samples from Run 1. In order to prepare the seed solution, one capsule of Polyseed ${ }^{\circledR}$ was added to 500 $\mathrm{mL}$ of BOD dilution water and stirred for one hour, as per instructions provided by the manufacturer.

\subsubsection{Chemical oxygen demand (COD)}

Soluble COD was measured according to Standard Method $5220 \mathrm{~B}$, closed reflux, colorimetric method (APHA, 1992). The $\mathrm{pH}$ of the preserved samples was not adjusted before testing. As shown in Figure 4.1 , the COD test results are not dependent on the initial $\mathrm{pH}$ of the samples.

In accordance with Standard Method 5220 B (APHA, 1992), all samples were analysed in triplicate, and their absorbance measured at $600 \mathrm{~nm}$. A new calibration curve was prepared whenever new COD chemicals were prepared, using seven standards of known COD concentration, ranging from 20 to $900 \mathrm{mg} / \mathrm{L}$. 


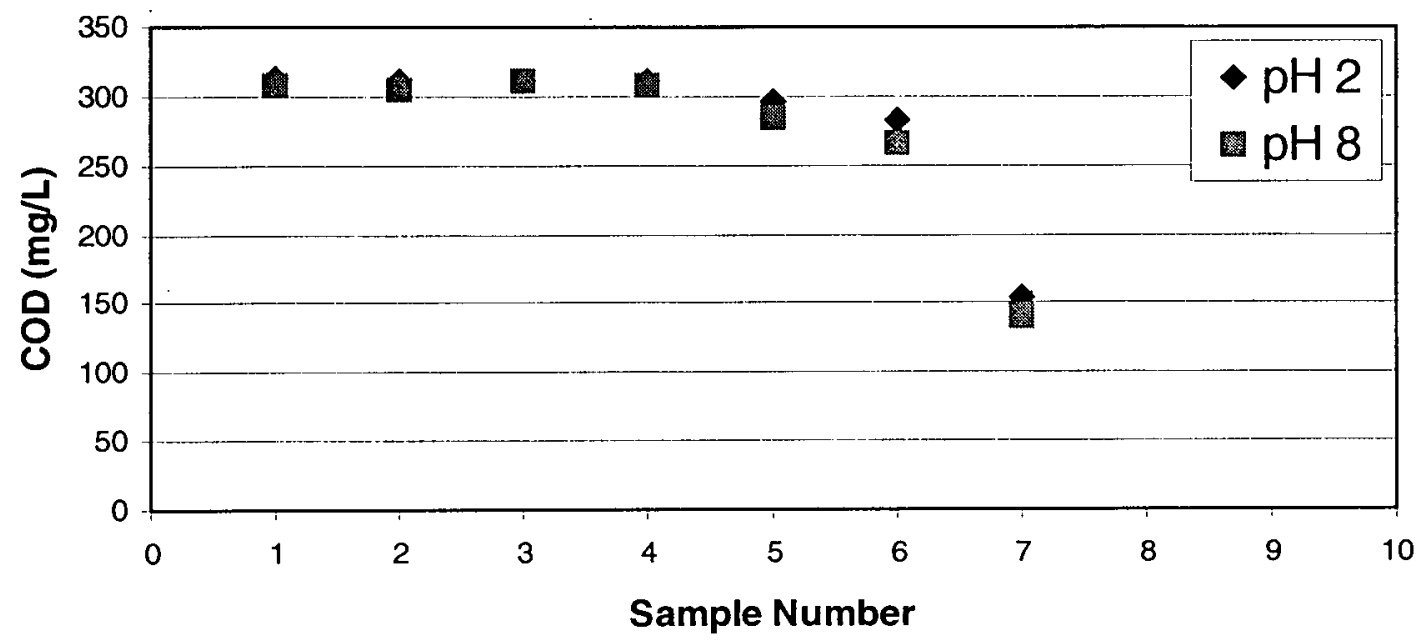

Figure 4.1: COD measured at $\mathrm{pH} 2$ and $\mathrm{pH} 8$

4.5.3 Mixed liquor suspend ed solids (MLSS)

Suspended solids were measured according to standard method $2540 \mathrm{D}$ (APHA, 1992) with the exception that samples were analysed in triplicate instead of duplicate. Solids analysis was always performed immediately after sampling.

\subsubsection{Acute toxicity: Microt ox}

Acute toxicity of effluent samples was determined using a Microtox ${ }^{\text {TM }} 500$ analyser. Analyses were run using the full range test, according to standard procedures (Microbics, 1992). The $\mathrm{pH}$ of the preserved samples was adjusted to seven using concentrated $\mathrm{NaOH}$ prior to analysis. The toxicity data were analysed using Microtox ${ }^{\mathrm{TM}}$ computer software created by the Microbics Corporation.

\subsubsection{Toxicity units}

In order to present toxicity as a mass-based parameter, analogous to $\mathrm{BOD}$ and $\mathrm{COD}, \mathrm{EC}_{50}$ values can be converted to toxicity units (TU). 


$$
T U=\frac{100}{E C_{50}}
$$

The conversion of $\mathrm{EC}_{50}$ values to TU results in a higher weighting of the lower $\mathrm{EC}_{50}$ values. This conversion implies that a change in $\mathrm{EC}_{50}$ from $1 \%$ to $2 \%$ has a much larger impact on toxicity removal than a change in $\mathrm{EC}_{50}$ from $2 \%$ to $4 \%$. The first case results in a 50-point TU decrease (100 to $50,50 \%$ removal), whereas the second case results in a 25-point TU decrease (50 to $25,50 \%$ removal of residual but only $25 \%$ removal overall). Due to the distortion caused by converting to TU units, toxicity has been reported as $\mathrm{EC}_{50}(\% \mathrm{v} / \mathrm{v})$.

\subsubsection{Oxygen uptake rate (OUR)}

The biomass OUR was monitored at various times throughout each reactor run by collecting a $300 \mathrm{ml}$ sample from the reactor in a standard BOD bottle, and monitoring the decrease in DO (YSI Inc., Model 5905) over 10 minutes. Mixing was provided by the DO probe as well as a magnetic stir plate and stir bar. The data from the DO meter (YSI Inc., Model 59) were recorded on a computer via a RS-232 data acquisition port. The OUR ( $\mathrm{mg} \mathrm{O}_{2} / \mathrm{L} \mathrm{min}$ ) was determined by calculating the slope of the recorded DO profile. The OUR was converted to a specific oxygen uptake rate (SOUR) by dividing the OUR by the MLSS concentration at the time of the test.

\subsubsection{Kinetics: $\underline{\text { OUR }} \underline{\text { method }}$}

Microbial substrate uptake kinetics were determined using a respirometric method developed by Cech et al. (1984). Each sample was tested in duplicate. As discussed in section 4.5.6.1, the OUR values were converted to substrate uptake rates (SUR) using a yield constant, which is determined from the dissolved oxygen and substrate concentration data. This method was chosen due to the accuracy with 
which DO may be measured, and because it was relatively easy to carry out.

The respirometer (Figure 4.2), made by Canadian Scientific Glassblowing Company Ltd., consisted of a jacketed $180 \mathrm{~mL}$ glass vessel equipped with ports for DO measurement, aeration and sample injection. The temperature was maintained at $35^{\circ} \mathrm{C}$ by circulating water from a constant temperature bath (VWR Scientific, Model 1131) through the annular jacket encasing the respirometer. Mixing was provided by the DO probe (YSI Inc., Model 5905) as well as a magnetic stir plate and stir bar. An aquarium pump (Rolf C. Hagen Inc., Optima Model) provided the necessary aeration.

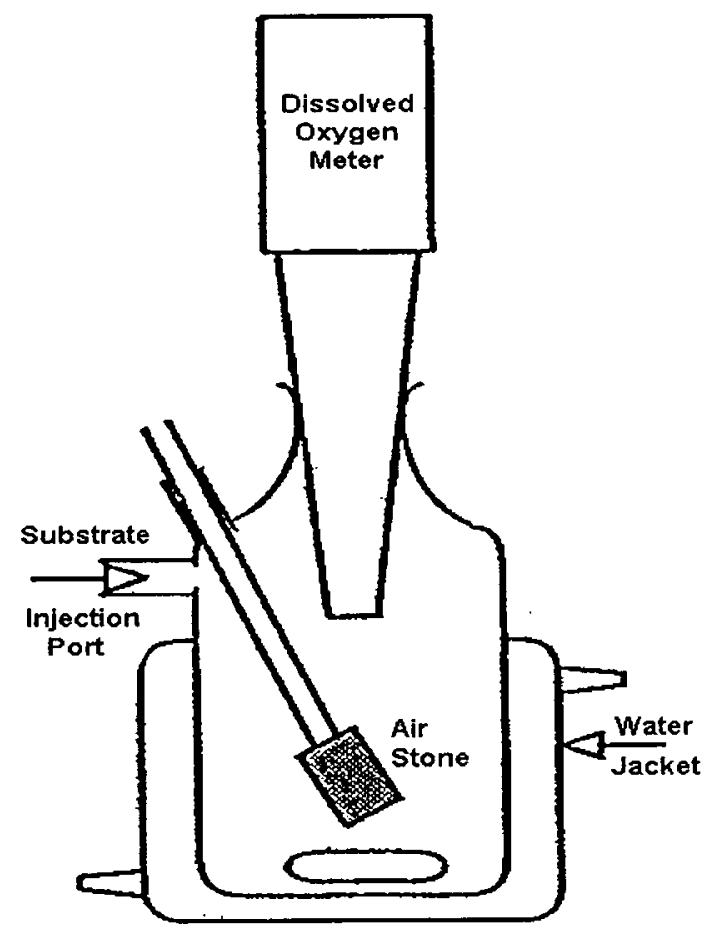

\section{Figure 4.2: Respirometer}

The biomass used to perform kinetic tests on the samples collected from Runs 1 and 2 was collected on November 12, 1999 and January 13, 2000 , respectively. The biomass obtained from the Chevron WWTP was diluted to a concentration of 700-800 mg/L MLSS; the exact 
concentration was measured at the end of the test and used in subsequent calculations. This diluted mixed liquor was added to the respirometer and aerated for 30 minutes in order to degrade any substrate present. After this aeration period, aeration was stopped and the DO probe was inserted into the respirometer. Prior to sample addition, the probe was given time to stabilize, and the endogenous respiration rate was measured for at least two minutes. A known amount of substrate, adjusted to $\mathrm{pH} 7$ with concentrated $\mathrm{NaOH}$, was added through an injection port using Becton-Dickinson syringes and the change in respiration rate, as reflected by DO concentration changes, was monitored. Upon injection, the OUR immediately increased and then slowly returned to the initial endogenous rate. In order to ensure that the complete OUR profile, as shown in Figure 4.3, was captured, data were collected for 2-3 minutes after sample injection. At the end of the test, data collection was terminated, and the DO probe was removed from the respirometer. Before another sample was injected, the mixed liquor was aerated until the DO value was $6-8 \mathrm{mg} / \mathrm{L}$.

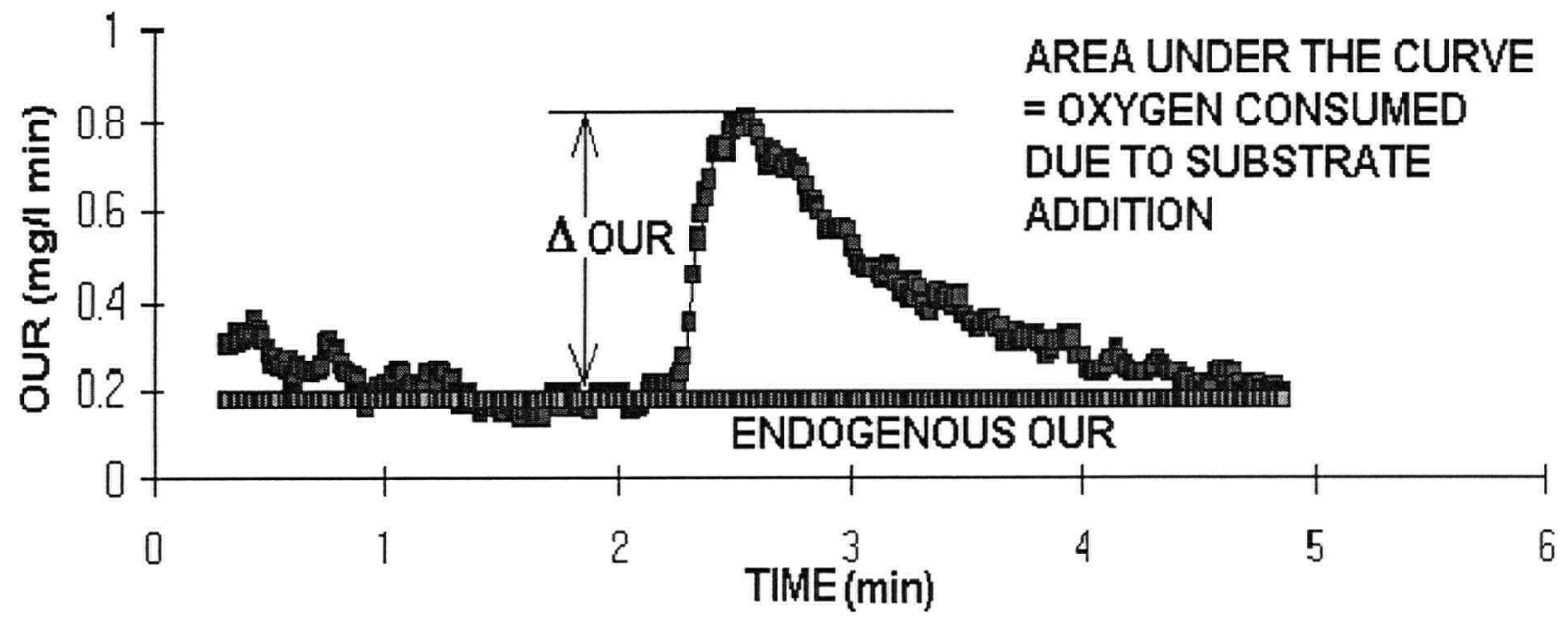

Figure 4.3: Sample data from a respirometric kinetic assay 
The data from the DO meter (YSI Inc., Model 59) were imported into a spreadsheet-using Collect (Labtronics Inc., Guelph, Canada). Collect is a software program which gathers data from the DO meter's RS-232 port. The DO, percent saturation, and temperature were recorded every second. Using a built in macro, the $\triangle$ OUR and oxygen consumed were determined for each substrate injection. The values were divided by the MLSS concentration in the respirometer in order to obtain specific $\triangle$ OUR (SOUR) and oxygen consumed per mg of MLSS.

\subsubsection{Determination of kinetic parameters}

From a graph of oxygen consumed versus substrate added (Figure 4.4) the ratio of oxygen consumed to BOD was determined. It was assumed that all the substrate added (measured as BOD) was metabolized by the biomass. This ratio (OC/S) was used to convert the $\Delta$ OUR to specific substrate uptake rate (q) (Equation 2.18, p.36). As discussed in Section 2.7.1, the change in OUR is related to the amount of substrate added, and this relationship can be modelled using Monod (or other) kinetics. Kinetic parameters, $\mathrm{q}_{\max }$ and $\mathrm{K}_{\mathrm{s}}$, were estimated by plotting a Lineweaver-Burk plot (Figure 4.5). Using the values derived from the Lineweaver-Burk plot as initial estimates of $\mathrm{q}_{\max }$ and $\mathrm{K}_{\mathrm{s}}$, non-linear regression with the Monod and Tessier models were used to determine the best-fit lines for the data points (Figure 4.6), and obtain more accurate values for $\mathrm{q}_{\max }$ and $\mathrm{K}_{\mathrm{s}}$. 


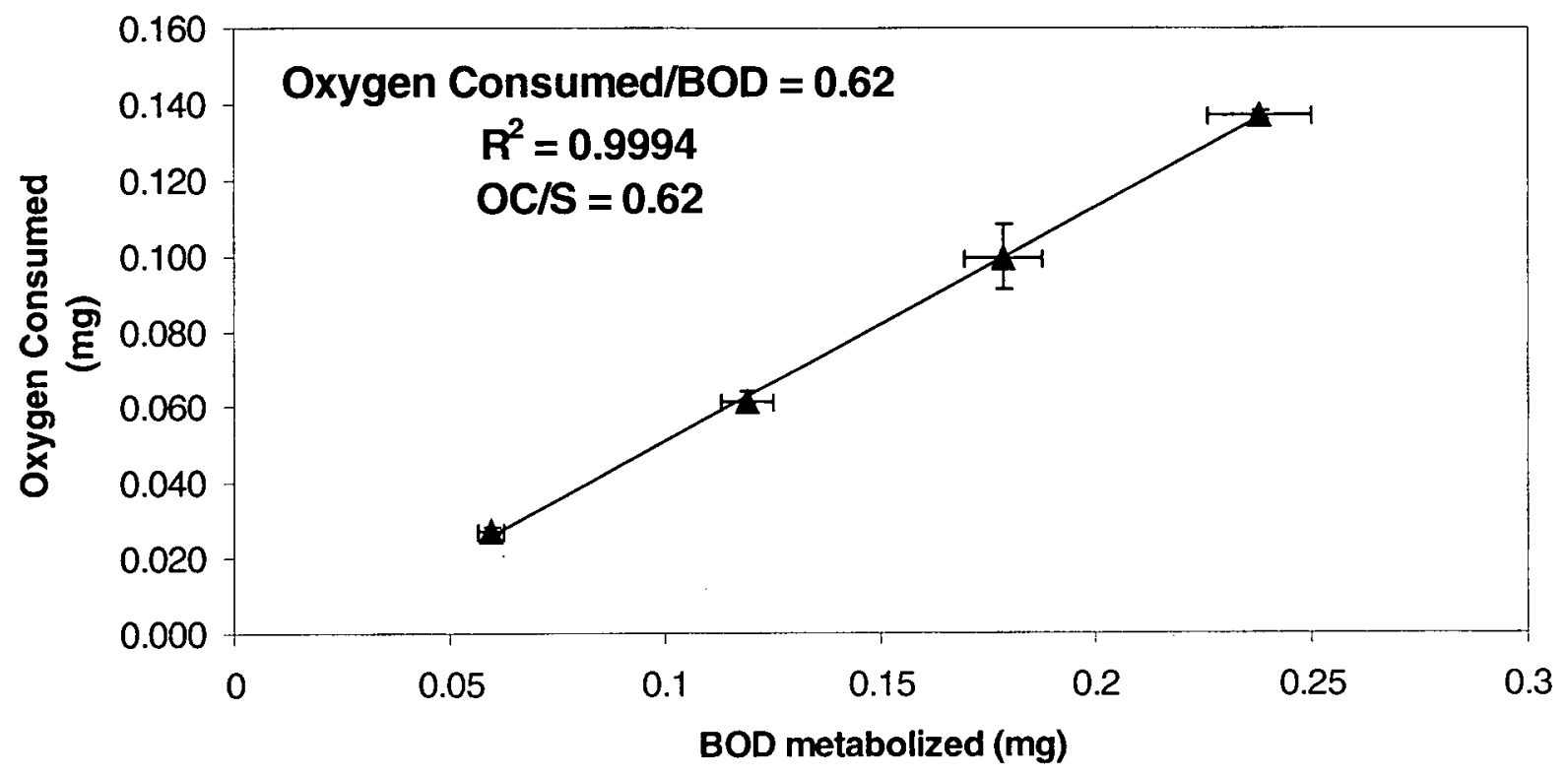

Figure 4.4: Oxygen Consumed vs. Substrate Metabolized

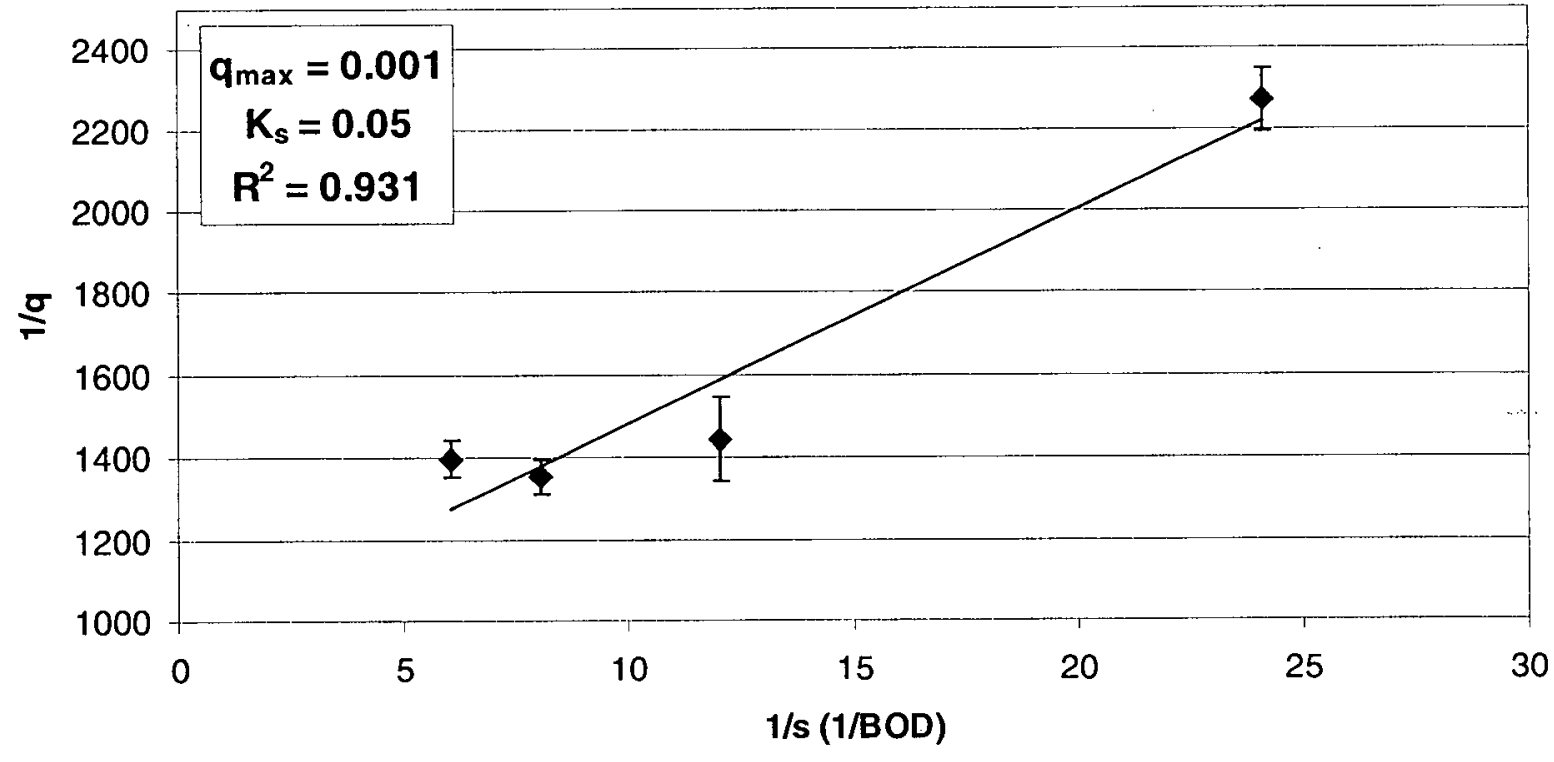

Figure 4.5: Lineweaver-Burk plot to estimate kinetic parameters 


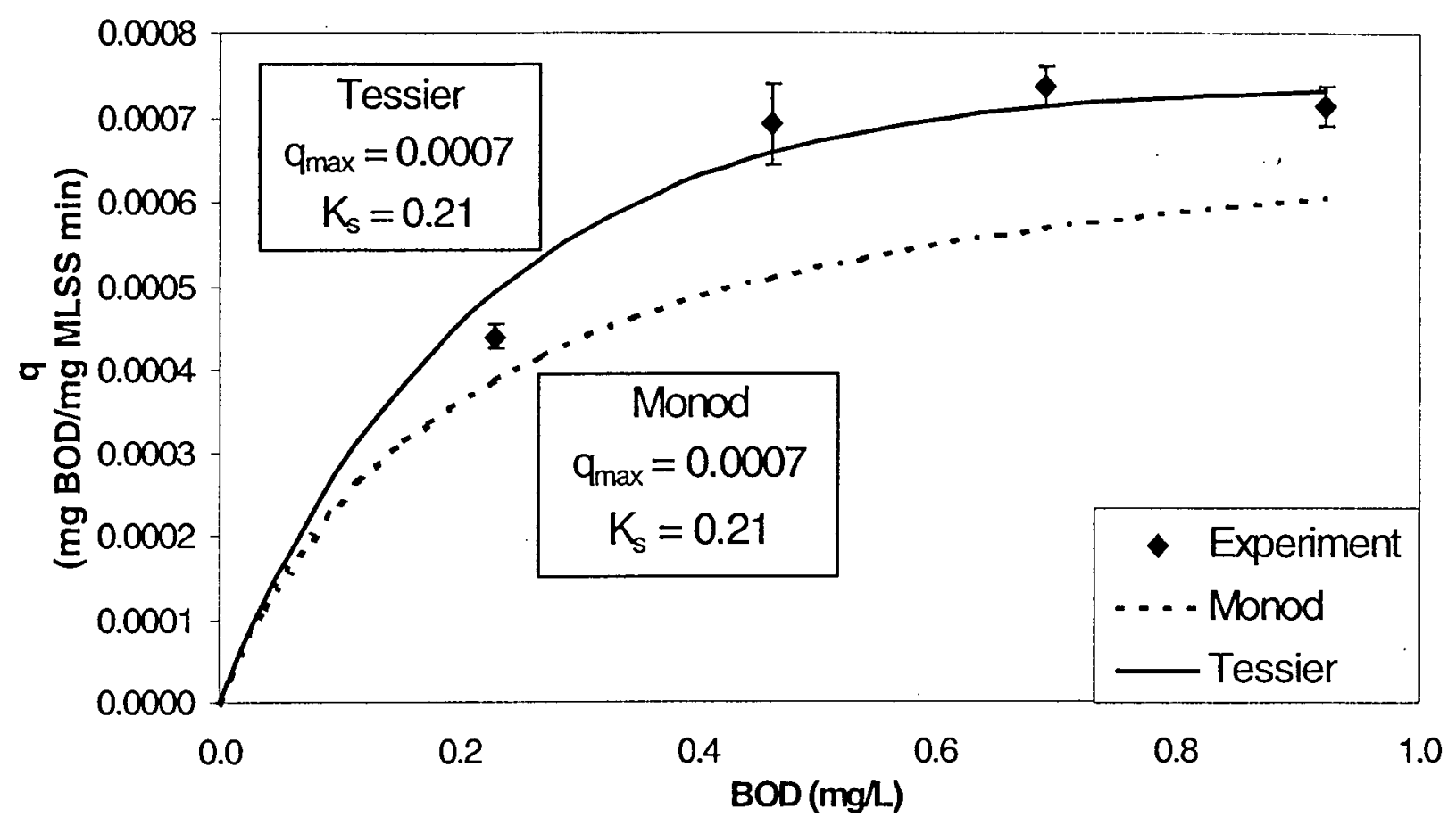

Figure 4.6: Non-linear regression to determine kinetic parameters

The Monod model did not saturate quickly enough to reach the experimental $\mathrm{q}_{\max }$ value. The Tessier model, on the other hand, was able to saturate more quickly and produce a good fit to the experimental data. Since the Tessier kinetic model fit the experimental data better than the Monod model, the microbial kinetic parameters were determined by a non-linear regression based on the Tessier model.

\subsubsection{Analyses for specific chemical compounds}

Analytical Services Laboratories Ltd. of Vancouver, BC performed the tests for the following compounds: Volatile Hydrocarbons (VH), Benzene, Toluene, Ethyl benzene, Xylene (BTEX), Extractable Petroleum Hydrocarbons (EPH), and Phenols.

VH analysis was carried out according to the BC MELP Method "Volatile Hydrocarbons in Water" (ASL, 1999). The VH assay determines the concentration of volatile hydrocarbons C6-C10. BTEX analysis was 
based on US EPA Methods 624/524 and 5030/8260. These procedures involved purge and trap extraction of the sample and subsequent analysis of the volatile components by capillary column gas chromatography with mass spectrometric detection (ASL, 1999).

The EPH assay was carried out according to BC MELP Method for "Extractable Petroleum Hydrocarbons in Water by GC/FID”, July 1999. The procedure involved sample extraction with dichloromethane, which was thereafter transferred to toluene and analysed by capillary column gas chromatography with flame ionization detection (ASL, 1999).

ASL carried out analysis of phenols in accordance to Standard Method 5330 D, direct photometric method (APHA, 1992).

\subsection{Data Analysis}

\subsubsection{Measured values}

Replicate values for each sample were used to calculate an average and estimate an error on this latter value. Error was approximated as the $95 \%$ confidence interval. This interval was calculated with the confidence function built into the MS-Excel software package (Microsoft, 2000). This function uses a Student-t test and assumes a symmetric gaussian distribution.

In the case of all the analyses performed, replicates actually originated from the same sample. Thus the error associated with these results is only representative of error imparted by the method of analysis itself and does not take into account errors in sampling, manipulation of the sample, and sample dilution. 


\subsubsection{Calculated values}

\subsubsection{Slopes}

Slopes were determined from experimental results with the slope function built into the MS-Excel software package (Microsoft, 2000). This function returns the slope of the linear regression line through the data points. The accuracy of this slope was assessed with the square of the Pearson product $\left(\mathrm{R}^{2}\right)$. The Pearson product reflects the extent of a linear relationship between two data sets. The $\mathrm{R}^{2}$ value can be interpreted as the proportion of variance in the dependent variable attributable to the variance in the independent variable. No error was estimated on slopes.

\subsubsection{Estimation of error on calculated values}

Error analysis was performed on BOD, COD, OUR, Microtox ${ }^{\mathrm{TM}}$, kinetic parameters and all other calculated values, save slopes. Error on values that are the average of a series of results was estimated as the $95 \%$ confidence interval for the series.

\subsubsection{Non-linear regression method}

Non-linear regression was carried out using the solver function built into the MS-Excel software package (Microsoft, 2000). In order to obtain accurate values of $\mathrm{q}_{\max }$ and $\mathrm{Ks}$ (see Section 4.5.6.1), the solver function was set to minimize the error between the experimental data points and the theoretical kinetic model by changing the values of $q_{\max }$ and $\mathrm{K}_{\mathrm{s}}$ obtained from the Lineweaver-Burk plot. 


\section{$\underline{4.6 .3}$ Reported results}

Values quoted in this thesis are reported as the average \pm the $95 \%$ confidence interval. Likewise, values plotted in graphs represent the average and the error bars represent the 95\% confidence interval. All values plotted do include error bars, although the data point often hides these bars. 


\section{Results and Discu ssion}

\subsection{Characteristics of Chevron Wastewater}

The characteristics of the wastewater sample collected on October 27, 1999, and used in Runs 1 and 2 are presented in Table 5.1.

Table 5.1: Characteristics of Chevron Wastewater

\begin{tabular}{|c|c|c|c|c|}
\hline & \multicolumn{2}{|c|}{ Run 1} & \multicolumn{2}{|c|}{ Run 2} \\
\hline & Amount & 95\% C.I. & Amount & 95\% C.I. \\
\hline BOD (mg/L) & 316 & 10 & 234 & 62 \\
\hline COD (mg/L) & 593 & 6 & 510 & 0 \\
\hline BOD/COD & 0.53 & 0.02 & 0.46 & 0.12 \\
\hline $\operatorname{Toxicity}^{1}\left(\right.$ EC $_{50} \%$ v/v) & 4.6 & 0.5 & 4.9 & 0.4 \\
\hline $\mathrm{EPH}^{2}(\mathrm{Cl0}-32)(\mathrm{mg} / \mathrm{L})$ & -- & -- & 17.3 & -- \\
\hline Phenols (mg/L) & -- & -- & 20 & -- \\
\hline $\mathrm{VH}^{3}(\mathrm{C} 6-10)$ & 8.8 & -- & -- & -- \\
\hline Benzene (mg/L) & 2.43 & -- & -- & -- \\
\hline Toluene (mg/L) & 2.57 & -- & -- & -- \\
\hline Ethyl-benzene (mg/L) & 0.218 & -- & -- & -- \\
\hline m- \& p-Xylene (mg/L) & 1.09 & -- & -- & -- \\
\hline o-Xylene (mg/L) & 0.564 & -- & -- & -- \\
\hline $\operatorname{MTBE}^{4}(\mathbf{m g} / \mathrm{L})$ & 0.327 & -- & -- & -- \\
\hline $\mathbf{p H}$ & 8 & -- & 8 & -- \\
\hline
\end{tabular}

1: Microtox $^{\mathrm{TM}}$ assay, 5-minute exposure

2: Extractable Petroleum Hydrocarbons

3: Volatile Hydrocarbons

4: Methyl tertiary-butyl ether

--: Not Determined

In order to eliminate batch-to-batch variability, the same sample of wastewater was used for Runs 1 and 2. Although the wastewater was stored with minimal headspace at $4^{\circ} \mathrm{C}$, there was still a loss of $82 \mathrm{mg}$ $\mathrm{BOD} / \mathrm{L}$ and $83 \mathrm{mg} \mathrm{COD} / \mathrm{L}$ between Runs 1 and 2 . The initial toxicity and BOD/COD ratio of the wastewater were not significantly affected. 


\subsection{Biochemical and Ch emical Oxygen Demand}

\subsubsection{BOD and COD removal}

Batch biological treatment runs were carried out to determine kinetics of removal of $B O D$ and $C O D$. In both runs, $B O D$ and $C O D$ reduction occurred over the first 24 hours of treatment (Figure 5.1, Figure 5.2). The BOD levelled off at a final value of 7-16 mg/L, and the COD at 104-116 $\mathrm{mg} / \mathrm{L}$, values that represented $92 \%-96 \%$, and $73 \%-75 \%$ removal, respectively. These values are similar to the removal levels reported at the Chevron refinery WWTP as discussed in Section 2.5.2.

The shape of the degradation profiles is consistent with a multicomponent wastewater. As predicted by the Monod equation, at high substrate concentrations ( $\mathrm{S}>>\mathrm{K}_{\mathrm{s}}$ ), the rate of substrate utilisation for a given compound (or set of compounds) will be constant over time (i.e. $q_{\max }=$ constant). Thus, the overall curved nature of the substrate vs. time graphs indicates that different components were metabolised throughout the runs. Since the BOD and COD vs. time graphs for Run 1 are linear from 0 to 6 hours, and from 6 to 24 hours it is likely that the microbes were consuming substrates with similar biodegradability during these time intervals (see Table 5.2, Section 5.2.4). 


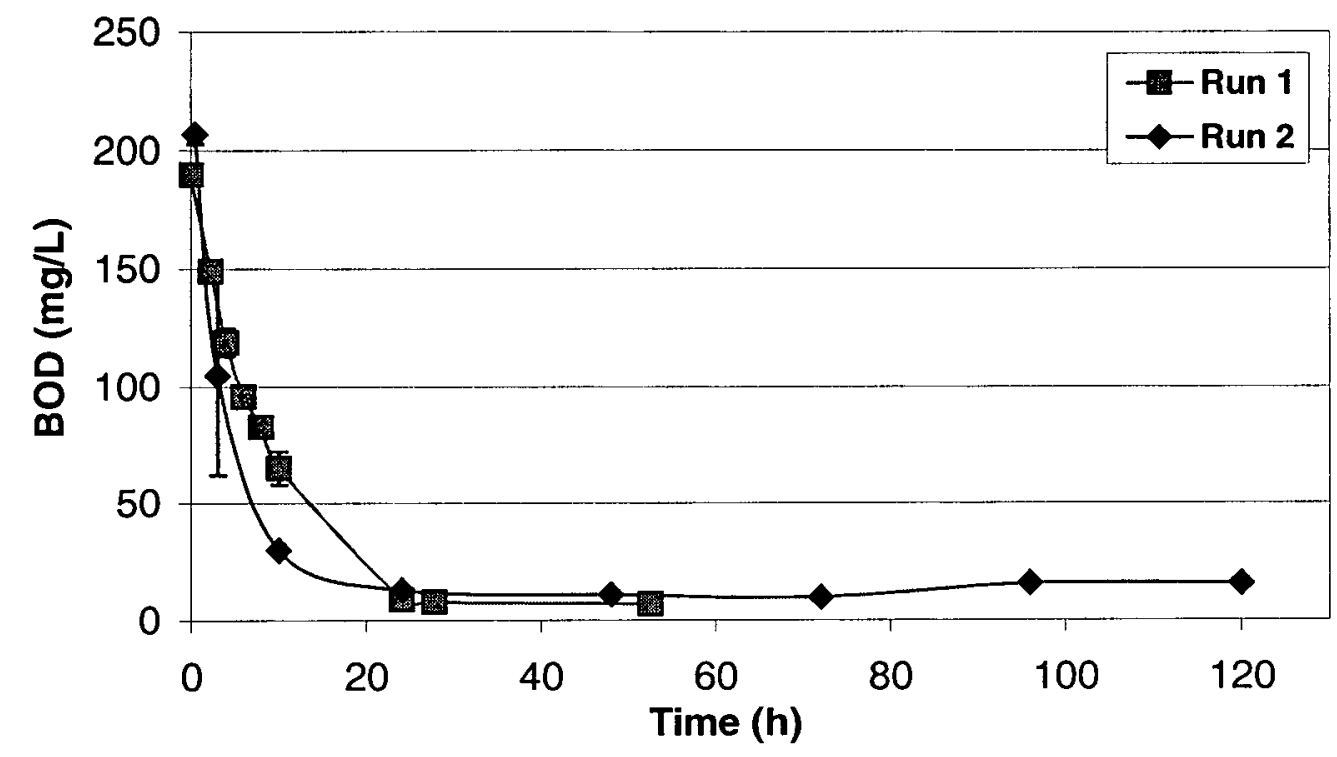

Figure 5.1: BOD Degradation Profile

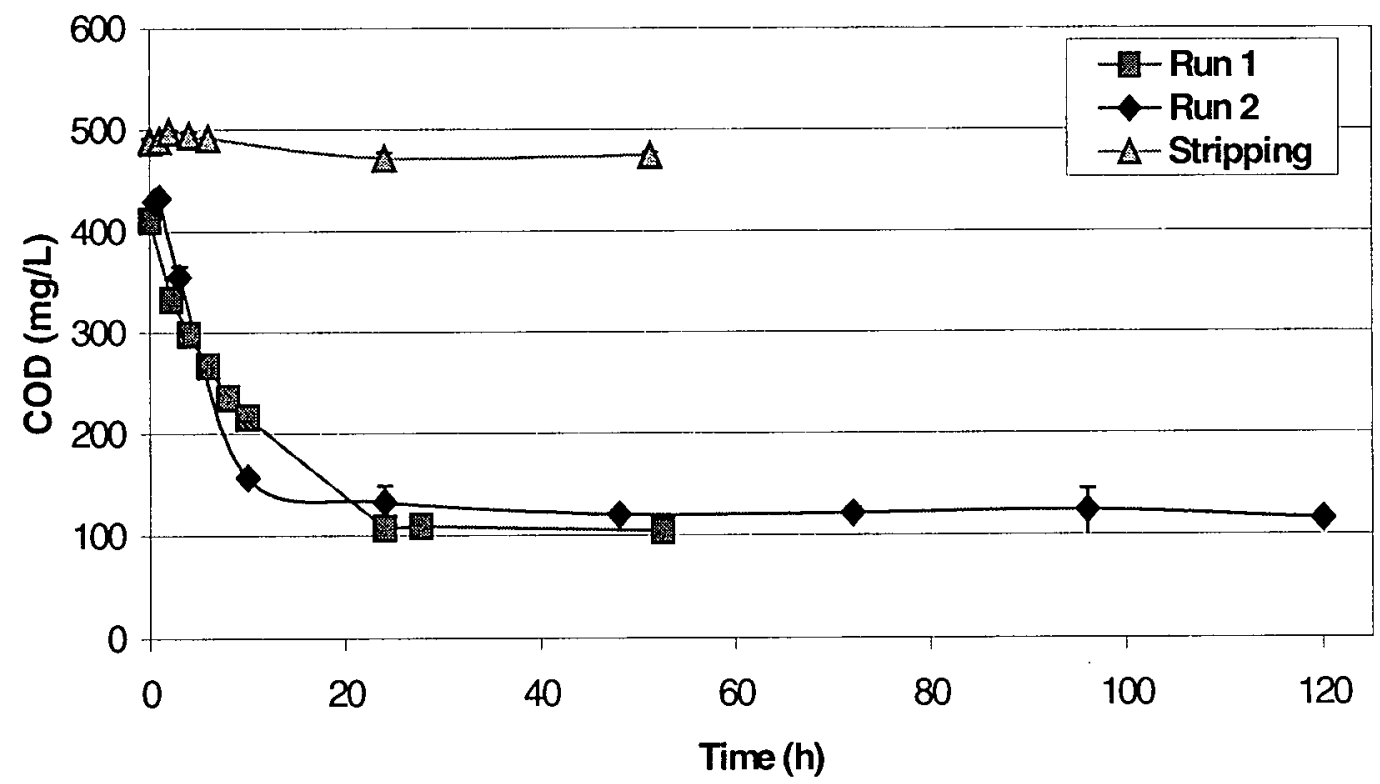

Figure 5.2: COD Degradation Profile 


\section{$\underline{5.2 .2} \underline{\text { Residual }} \underline{\mathrm{COD}}$ and $\underline{\mathrm{BOD}}$}

The residual COD (104-1 $16 \mathrm{mg} / \mathrm{L}$ ) was likely due to the presence of nonbiodegradable compounds originally in the wastewater with a minor fraction due to the accumulation of soluble microbial products. Other studies on the biodegradation of refinery wastewater reported similar residual CODs. Eckenfelder (1988) compiled residual CODs from eight different biodegradation studies of petroleum and petrochemical wastewaters. The residual CODs varied from $22 \mathrm{mg} / \mathrm{L}$ to $106 \mathrm{mg} / \mathrm{L}$ (mean $=77,95 \%$ C.I. $=22$ ). Gulyas et al. (1995) determined the organic compounds at different stages of a refinery WWTP using GC-MS, and found that the few substances detected (i.e. three iso-alkanes, traces of carboxylic acids, and acetic acid 2-(2-butoxyethoxy)-ethyl ester), could not explain the $120 \mathrm{mg} \mathrm{COD} / \mathrm{L}$ of the effluent from the sedimentation tank. They concluded that this residual COD was due to humic acids, which were formed by the activated sludge process. It has also been found that certain bipolymers formed during aerobic biological wastewater treatment contain recalcitrant sugars, uronic acids, and amino acids (Hejzlar, 1986). Similarly, Chudoba (1985) showed that non-degradable organic by-products would accumulate in a biological treatment process.

The possibility that some of the residual COD was due to the sample preservation technique was also investigated. Since each sample was acidified after collection and then filtered prior to testing, it was hypothesized that the acidification process may have resulted in the dissolution of capsular cellular material. This would have resulted in a higher COD than if the samples had been filtered prior to acidification. Based on the data (Figure 5.3), the preservation method did not significantly affect a sample's COD, and the hypothesis was rejected. 


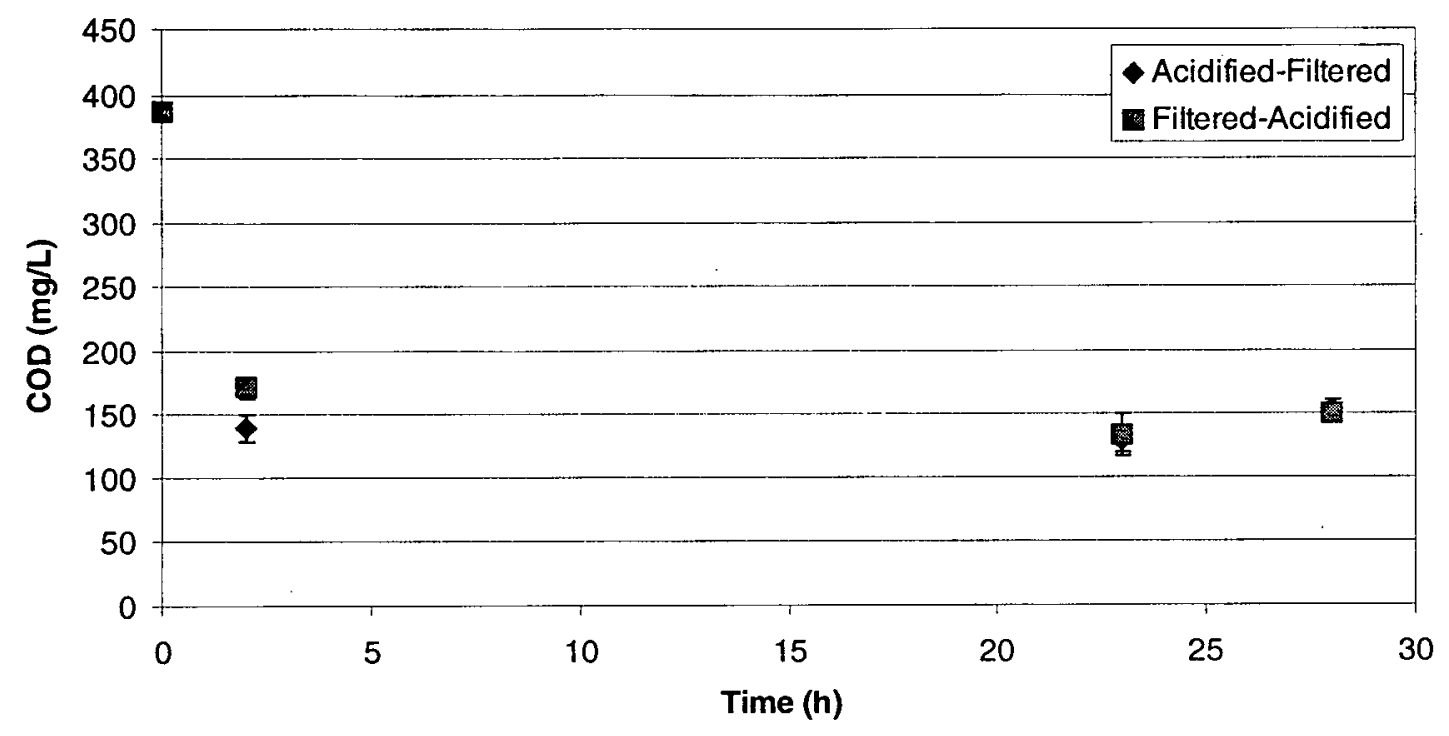

Figure 5.3: Effect of preservation method on COD measurement.

The remaining BOD (7-16 $\mathrm{mg} / \mathrm{L})$ was not necessarily due to substrates initially present in the wastewater. It was hypothesized that due to the long batch time, the accumulation of soluble microbial products (SMP) may have been the source of the remaining BOD.

\section{$\underline{5.2 .3}$ Stripping and sorption}

Volatiles removal by air stripping is a concern in the biological treatment of petroleum wastewaters (Dold, 1989). As shown in Figure 5.2,

stripping accounted for $3 \%$ of the COD removal over 52.5 hours. This $3 \%$ does not account for the COD stripped prior to the start of the test. The initial COD of the wastewater in Run 1 was $593 \pm 6 \mathrm{mg} / \mathrm{L}$, and prior to the start of the stripping test the COD was $518 \pm 3 \mathrm{mg} / \mathrm{L}$. Thus between Run 1 and the stripping test $75 \mathrm{mg}$ COD/L was lost, it is not known whether this was due to stripping or biodegradation. Prior to the start of the stripping test the wastewater's COD was $518 \pm 3 \mathrm{mg} / \mathrm{L}$, and after starting aeration (i.e. time 0 ) the COD was $488 \pm 3 \mathrm{mg} / \mathrm{L}$, thus $30 \mathrm{mg}$ COD/L was either stripped while the wastewater was warmed overnight to $35^{\circ} \mathrm{C}$ or 
immediately after aeration was started. The data presented in Figure 5.2 shows that below a COD of $500 \mathrm{mg} / \mathrm{L}$, stripping was not a significant mechanism for the removal of organic compounds.

The possibility that some of these compounds were removed by sorption onto biomass was not investigated. Rebhun and Galil (1987) quantified the various substrate removal mechanisms in the biological treatment of an oil refinery effluent. The study revealed that $90 \%$ of the hydrocarbons were removed by biodegradation and stripping, and about $10 \%$ of the hydrocarbons were entrapped in the biofloc. Eckenfelder (1988) states that limited sorption on biological solids occurs for a variety of organics, and this phenomenon is not a primary mechanism of organic removal in the majority of cases. Since removal by stripping was limited, and sorption likely minimal, the compounds contributing to BOD and COD were concluded to be primarily removed via biodegradation.

\subsubsection{Biodegradability of wa stewater}

The carbonaceous compounds present in the wastewater can be arbitrarily categorised as follows: readily biodegradable, slowly biodegradable, and recalcitrant. These categories were determined from the COD data for Run 1. As discussed in Section 5.2.1, the rate of biodegradation varied with time, but was relatively constant between 0-6 hours and 6-24 hours (Table 5.2). Thus the COD removed from 0 to 6 hours was called the readily biodegradable fraction, the COD removed from 6 to 24 hours was called the slowly biodegradable fraction, and the remaining COD was called the recalcitrant fraction.

Table 5.2: Wastewater Fractions

\begin{tabular}{|c|c|c|c|c|}
\hline & mg BOD degraded/hr & $\mathrm{R}^{2}$ & $\mathrm{mg}$ COD degraded/hr & $\mathrm{R}^{2}$ \\
\hline $0-6 \mathrm{hr}$ & 16 & 0.9894 & 24 & 0.9615 \\
\hline $6-24 \mathrm{hr}$ & 5 & 0.9809 & 8 & 0.9874 \\
\hline
\end{tabular}


The characteristics of the wastewater treated, based on the above analysis, are shown in Figure 5.4. The readily biodegradable compounds accounted for $35 \%$ of the wastewater's COD, the slowly biodegradable compounds for $39 \%$ of the COD. The remaining $26 \%$ consisted of recalcitrant compounds.

Eeadily Biodegradable

$\square$ Slowly Biodegradable

Recalcitrant

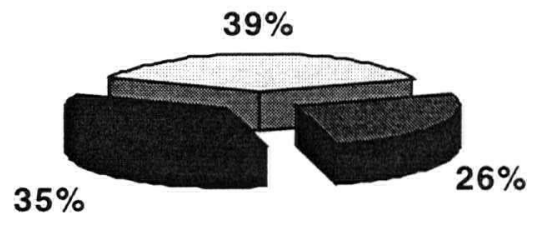

Figure 5.4: Wastewater Degradability Characteristics 


\section{$\underline{5.2 .5} \underline{\mathrm{BOD} / \mathrm{COD}} \underline{\text { ratio }}$}

The BOD/COD ratio was calculated to determine the proportion of the substrates in the wastewater that was biodegradable at a given time. As expected, the ratio decreased throughout the run (Figure 5.5).

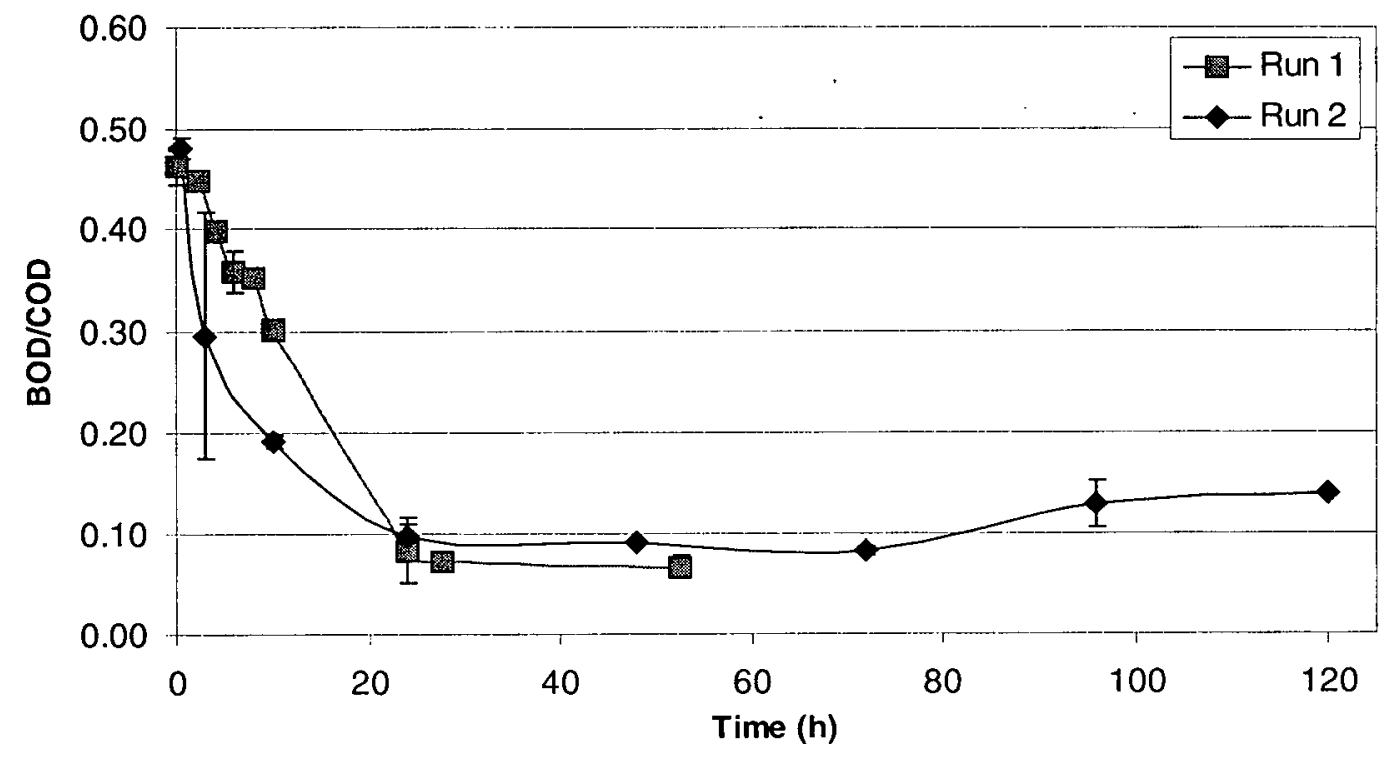

Figure 5.5: BOD to COD Ratio 


\section{$\underline{5.2 .6}$ First order BOD removal rate}

The BOD degradation was modeled as a first order reaction over 24 hours (Figure 5.6). The first order substrate removal rate coefficient (k) was determined based on the method for multicomponent wastewaters outlined by Grau et al. (1975), presented in Section 2.4.2.3. The first order substrate removal rate coefficients for Runs 1 and 2 are 0.5 and 0.4 day $^{-1}$, and the $\mathrm{R}^{2}$ values for the first order fits are 0.9899 and 0.8684 , respectively. Metcalf and Eddy (1991) state that for wastewaters, the range of $\mathrm{k}$ may be 0.05 to 0.3 day $^{-1}$ at $20^{\circ} \mathrm{C}$. Correcting for $\mathrm{T}=35^{\circ} \mathrm{C}$ with the van't Hoff Arrhenius relationship (Equation 1.3, p. 20) results in a range of 0.1-0.7 day ${ }^{-1}$. Metcalf and Eddy also state that the value of reaction-rate constant varies significantly, however, with the type of waste. In comparison to the $\mathrm{k}$ values presented in literature, the refinery wastewater was moderately biodegradable. This was expected, as industrial wastewaters are generally less biodegradable than municipal wastewaters.

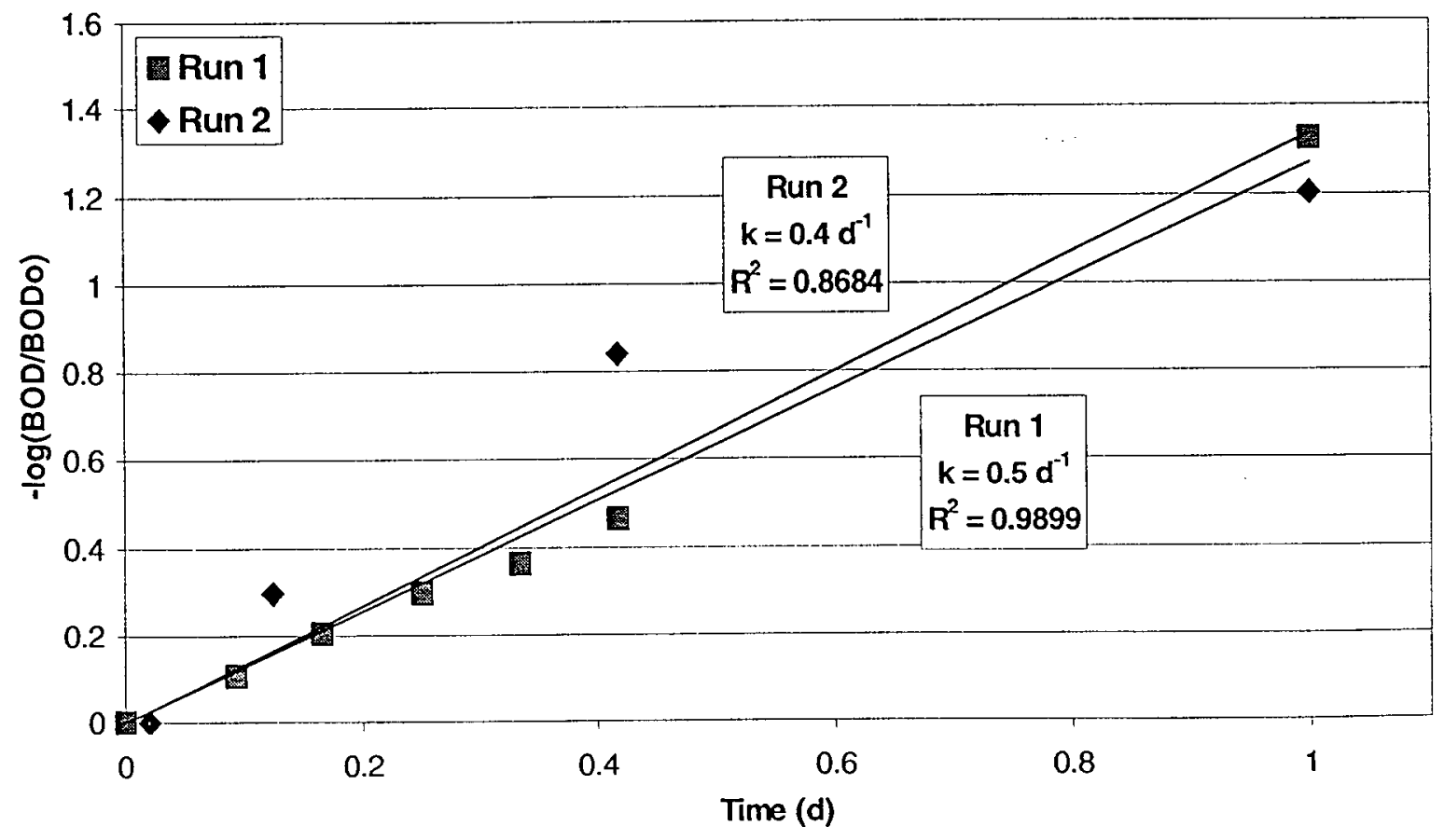

Figure 5.6: First order approximation of BOD degradation 


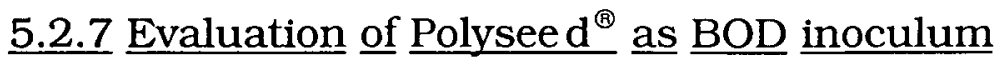

In order to determine the efficacy of Polyseed ${ }^{\circledR}$ as an "all-purpose" BOD seed inoculum, a duplicate set of BOD tests was performed with it on samples from Run 1 (Figure 5.7). It seems that Polyseed ${ }^{\circledR}$ was inhibited at the higher substrate concentrations, but performed well at BOD values less than $100 \mathrm{mg} / \mathrm{L}$. Based on these results, all BOD tests were conducted using seed from the Chevron WWTP.

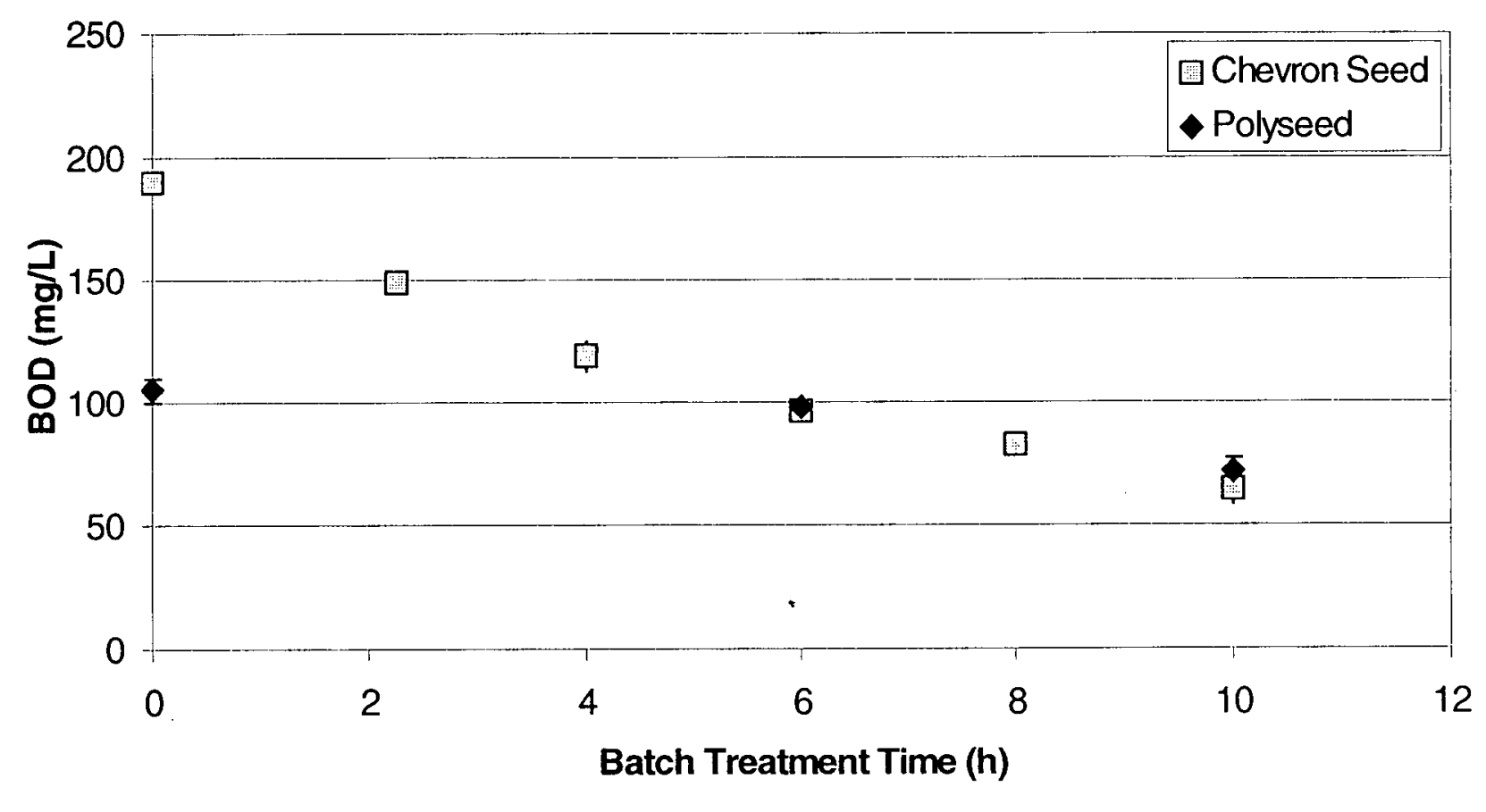

Figure 5.7: BOD Comparison of Polyseed ${ }^{\circledR}$ to Chevron Seed 


\subsection{Specific Oxygen Upt ake Rates}

The specific oxygen uptake rate (SOUR) data (Figure 5.8) are useful in determining the microbial activity in the reactor at a given time. Graph A indicates that the SOUR dropped rapidly in the first seven minutes and then it was relatively constant for six hours. The initial decrease in SOUR may be due to the rapid metabolism of the readily biodegradable compounds. The constant SOUR phase (0.5-6 h) supports the contention that the microbes were consuming the same set of substrates during this time interval. In section 5.2.4, the same conclusion was reached based on BOD and COD data.

The overall SOUR profiles for Runs 1 and 2 as depicted in graphs B and $\mathrm{C}$ are similar to those obtained for BOD and COD. There was a rapid initial drop in SOUR for 24 hours, and then it gradually levelled off at its final value. The readily biodegradable fraction controlled the rate of oxygen uptake for the first six hours, and the slowly biodegradable fraction influenced the SOUR from 6 to 24 hours. The relatively constant SOUR after 24 hours was likely due to the endogenous respiration of the biomass, and possibly a minor fraction of this SOUR was caused by the degradation of the more recalcitrant compounds. 

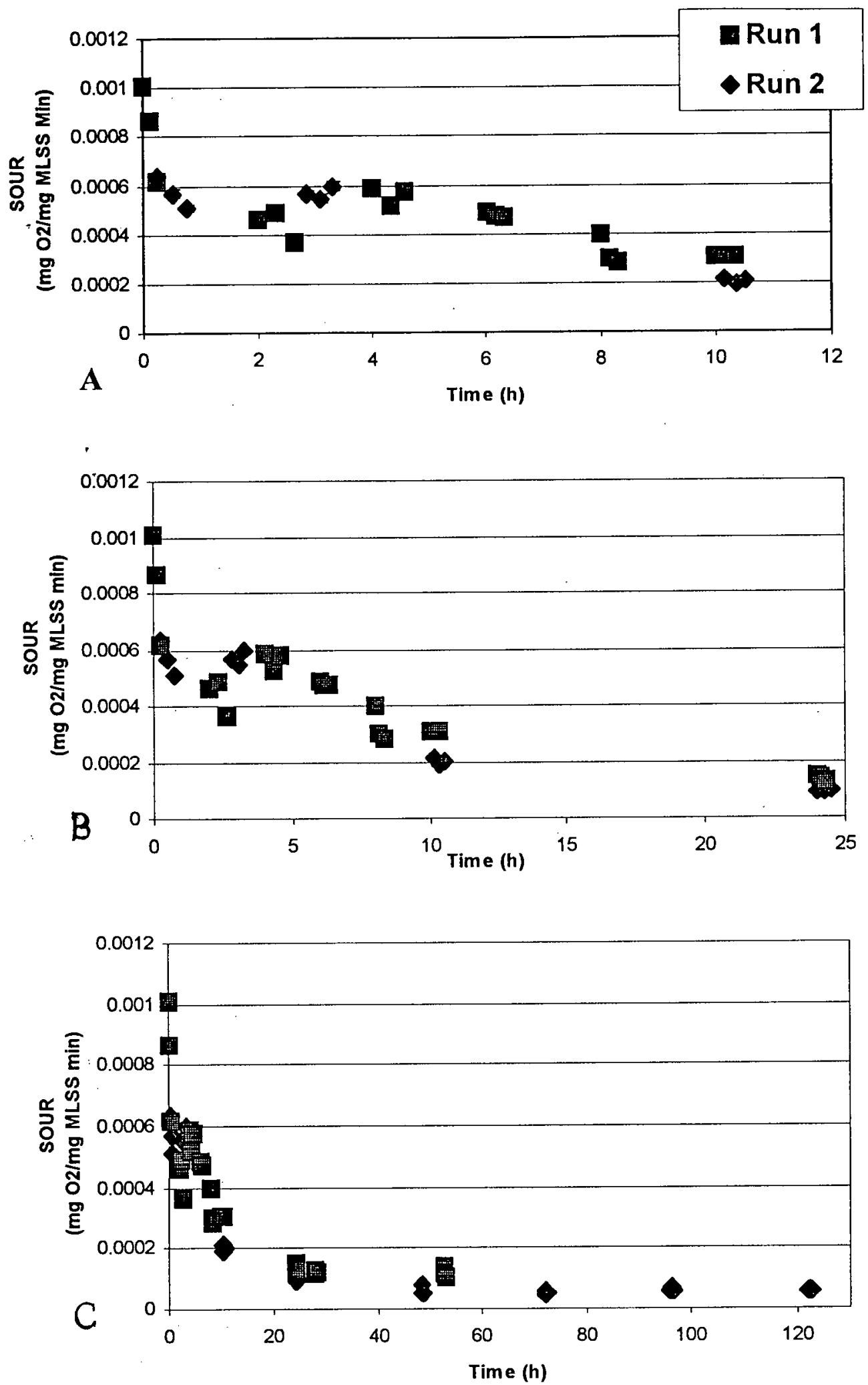

Figure 5.8: SOUR Profiles 


\subsection{Acute Toxicity}

\subsubsection{Toxicity removal}

The toxicity removal in Runs 1 and 2, as measured by the 5 and 15 minute Microtox ${ }^{\mathrm{TM}}$ assays in $\mathrm{EC}_{50}$ units (\%v/v), is depicted in Figure 5.9 and Figure 5.10.

\subsubsection{Run 1}

The mixed liquor in Run 1 had an initial 5-minute $\mathrm{EC}_{50}$ of $4.6 \pm 0.5 \%$. Toxicity was reduced to a 5 -minute $\mathrm{EC}_{50}$ of $7.9 \pm 0.7 \%$ over 10 hours, and further removal did not occur until after 24 hours. A second toxicity removal step resulted in a final 5-minute $\mathrm{EC}_{50}$ of $13.4 \pm 0.5 \%$ at 52.5 hours.

There were two periods when the toxicity appeared to increase during Run 1. The first resulted in an increase to a 5-minute $\mathrm{EC}_{50}$ of $3.9 \pm 0.6 \%$ at 6 hours, and the second, much smaller increase, occurred at 28 hours. It was hypothesized that the incomplete metabolism of the readily biodegradable compounds over the first 6 hours produced toxic intermediates. Chudoba (1985) showed that recalcitrant organic byproducts will accumulate in a biological treatment process, and in some cases these by-products exhibit a greater toxicity than the original compounds present in the wastewater. It is noteworthy that the SOUR of the biomass (Graph A, Figure 5.8) was not significantly affected during these toxic shock periods. Based on these observations it seems that the sample was toxic to Vibrio fischeri, the Microtox ${ }^{\mathrm{TM}}$ culture, but not to the reactor biomass. It has been found that respirometry based activated sludge toxicity tests are less sensitive to toxicity than the Microtox ${ }^{\mathrm{TM}}$ assay (Reteuna et al., 1989). Reteuna et al. concluded that this was likely due to the large concentration of sludge adsorbing the toxicants and reducing the effective concentration. It is also possible that the 
decrease in SOUR due to the increased toxicity was too small to be measured. As discussed in section 5.6.1:1, the change in OUR due to toxic compounds was not discernable for samples that contained a significant fraction of readily biodegradable substrates.

Since toxicity removal had not abated at the end of Run 1, Run 2 was run for a longer time in order to determine the capacity of the biomass for toxicity removal.

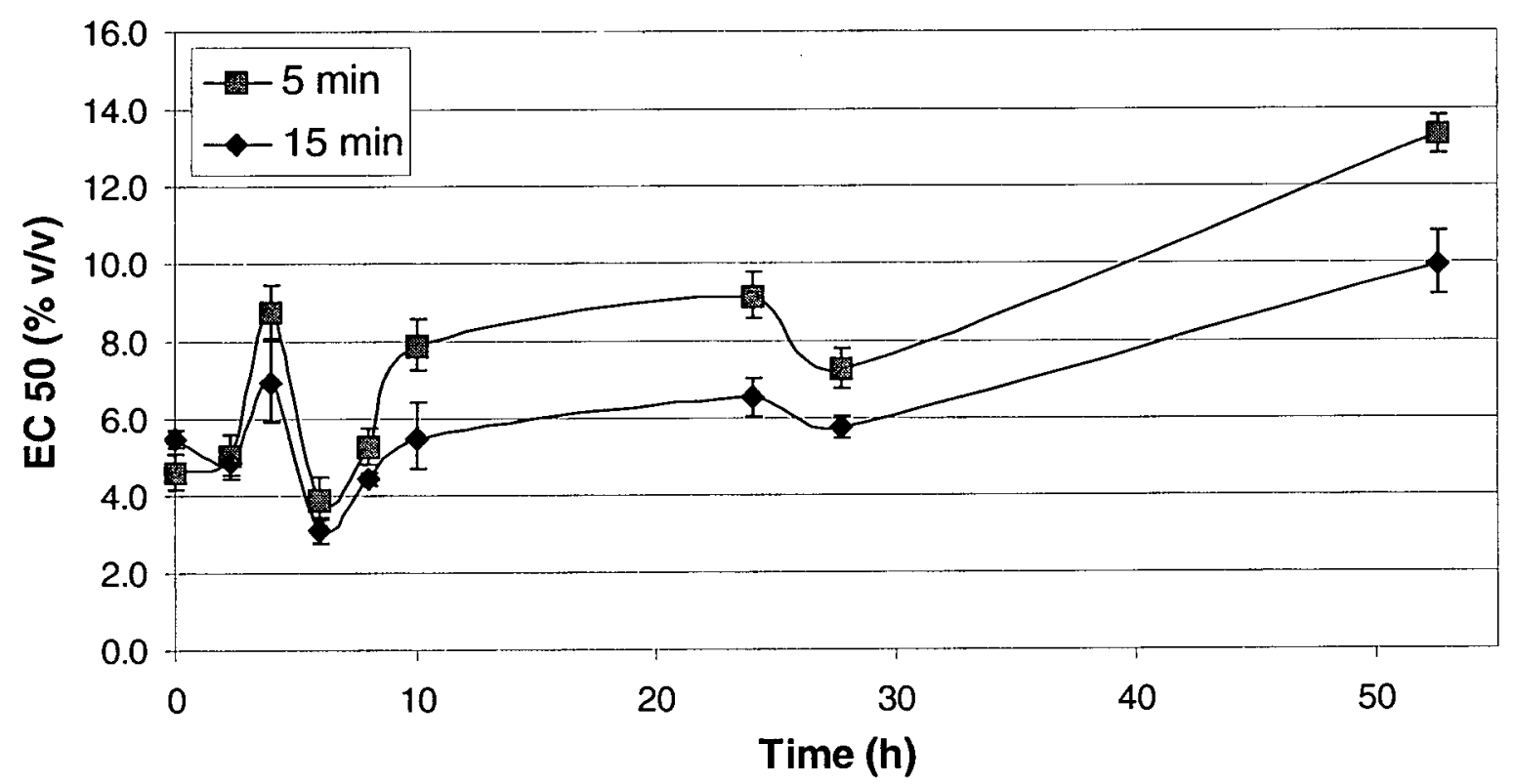

Figure 5.9: Run 1 Acute Toxicity Removal

\subsubsection{Run 2}

The mixed liquor in Run 2 had an initial 5-minute $\mathrm{EC}_{50}$ of $4.9 \pm 0.4 \%$. A 5minute $\mathrm{EC}_{50}$ of $16.0 \pm 3.2 \%$ was achieved over the first 10 hours, and the toxicity remained at this level until 48 hours. A second significant toxicity removal step between 48 and 72 hours resulted in a final 5minute $\mathrm{EC}_{50}$ of $27.8 \pm 1.6 \%$. The toxicity remained at $26.1 \pm 3.1 \%$ from 72 hours until the end of the run at 120 hours. 


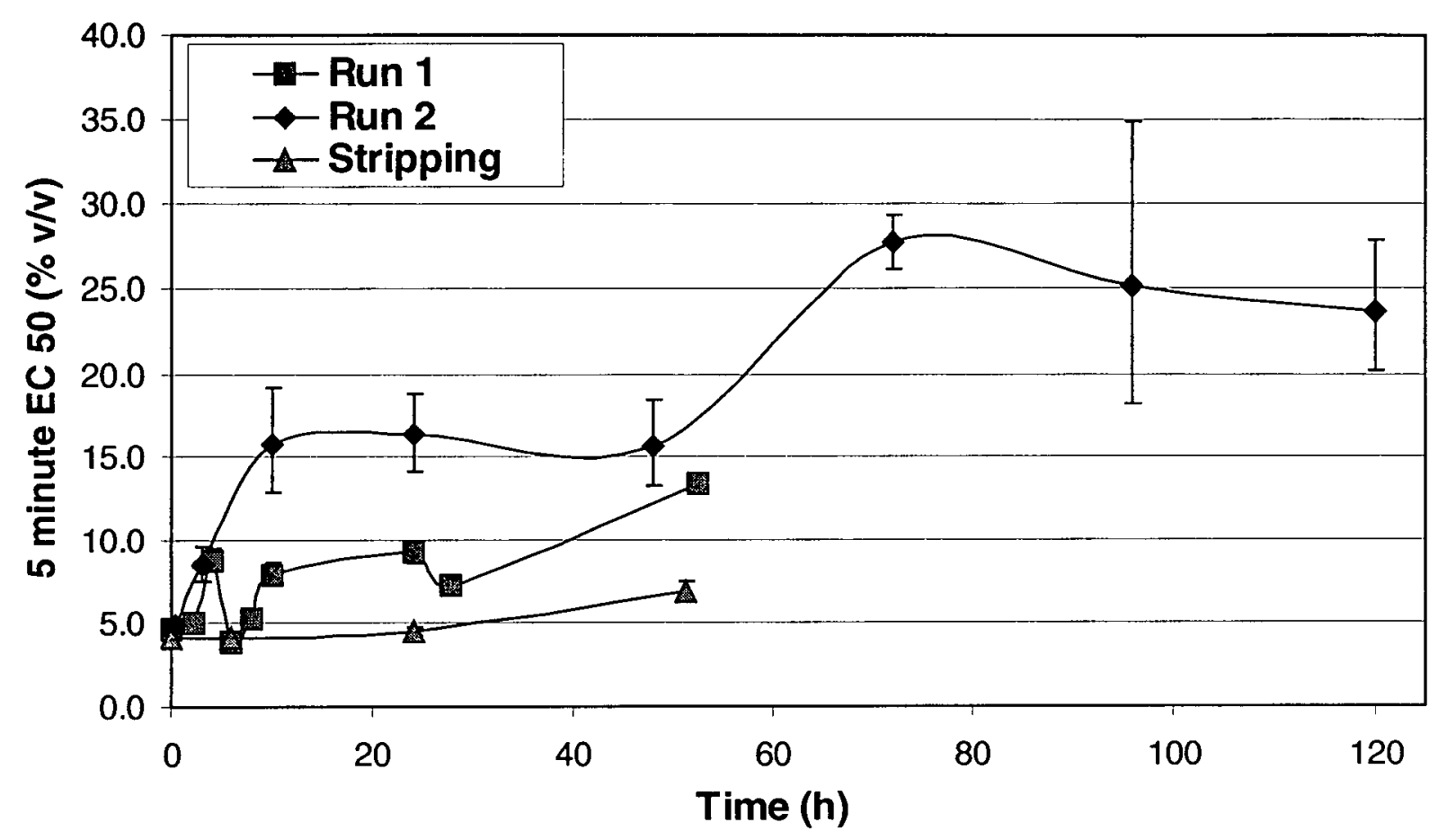

Figure 5.10: Acute Toxicity Removal Comparison

The initial stage of toxicity removal that occurred in Runs 1 and 2 over 24 and 10 hours, respectively, was likely due to the corresponding degradation of BOD and COD (Figure 5.1, Figure 5.2). It is noteworthy that the second stage of toxicity removal significantly lagged behind BOD and COD removal. This implies that the more recalcitrant compounds, which accounted for $26 \%$ of the wastewater's COD (see Section 5.2.4), exerted the secondary toxicity. Since secondary toxicity removal did not result in a COD decrease, the compounds contributing to toxicity were either not detectable by the COD test or they were compounds present in trace quantities (see Section 5.5.3). Certain toxic compounds have been designated as priority pollutants and regulated to the level of trace quantities, in the range of $\mu \mathrm{g} / \mathrm{L}$ (Eckenfelder, 1988). 
Both runs showed similar patterns of toxicity removal. Rather than being continuously removed, as in the case of BOD and COD, toxicity appeared to be removed in discrete stages. The first stage of toxicity removal corresponded to the degradation of $\mathrm{BOD}$ and $\mathrm{COD}$, and the second stage occurred after BOD and COD had been removed. Based on these observations, it was hypothesized that the microbes metabolized the readily biodegradable substrates first, and only then used the more recalcitrant compounds. Another plausible hypothesis is that the population of microbes that degraded the readily biodegradable compounds were not able to degrade the more recalcitrant compounds; and another population of microbes, with much slower growth rates, eventually reached a level necessary for removal of the toxicitycontributing compounds. Eckenfelder (1988) found that in the treatment of petrochemical wastewaters, some toxic organics degrade very slowly in the activated sludge process. Therefore, long sludge retention times (SRT) are required to achieve acceptable toxicity reduction, in spite of the fact that BOD removal is achieved at considerably lower SRTs.

In Run 2, the toxicity was removed more quickly than in Run 1 . This difference may be due to dissimilarity in the sludge ages of the biomass used in Runs 1 and 2 (see sections 5.6.1 and 5.6.2).

As shown in Figure 5.10, toxicity stripping was not a significant mechanism in its removal. Stripping accounted for a 5-minute $\mathrm{EC}_{50}$ change from $4.1 \pm 0.4 \%$ to $6.8 \pm 0.6 \%$ over 52.5 hours.

\subsubsection{Chevron toxicity monitoring program}

A toxicity-monitoring program was carried out at the Chevron refinery's WWTP between January 26, 2000 and March 15, 2000 (Hoy, 2000), and the results are presented in Figure 5.11 and Figure 5.12. A flowsheet of 
the Chevron WWTP is shown in Figure 2.1. In Run 2, the first stage of toxicity removal resulted in a 5-minute $\mathrm{EC}_{50}$ value of $16.1 \pm 1.6 \%$ from 10 to 48 hours and the second stage of toxicity removal resulted in a 5minute $\mathrm{EC}_{50}$ value of $26.1 \pm 3.1 \%$ from 72 to 120 hours. The toxicity level during the first constant toxicity phase (10-48 hours) is similar to the toxicity of the DSTI ${ }^{\mathrm{TM}}$ bioreactor effluent sample, and the toxicity level during the second constant toxicity phase (72-120 hours) is similar to the biofilter effluent sample. Based on these results, it seems that the DSTI $^{\mathrm{TM}}$ bioreactor at the Chevron WWTP removes toxicity up to the first constant toxicity phase, and then the biofilters remove the more recalcitrant compounds that contribute to toxicity. It seems as though the WWTP's toxicity removal capability is limited by the capacity of the biomass for toxicity removal, as determined in Run 2. Yet this result may be merely coincidental, and further work is required to produce a definite conclusion. Since the biomass used in the experimental batch runs was obtained from the DSTI ${ }^{\mathrm{TM}}$ bioreactor, it likely contained fast growing microbes selected for rapid removal of BOD and COD.

Experiments using effluent from a long batch test (such as Run 2) and biomass from the biofilters, which are slow growing and selected for toxicity removal, will determine whether further toxicity removal is possible biologically. 


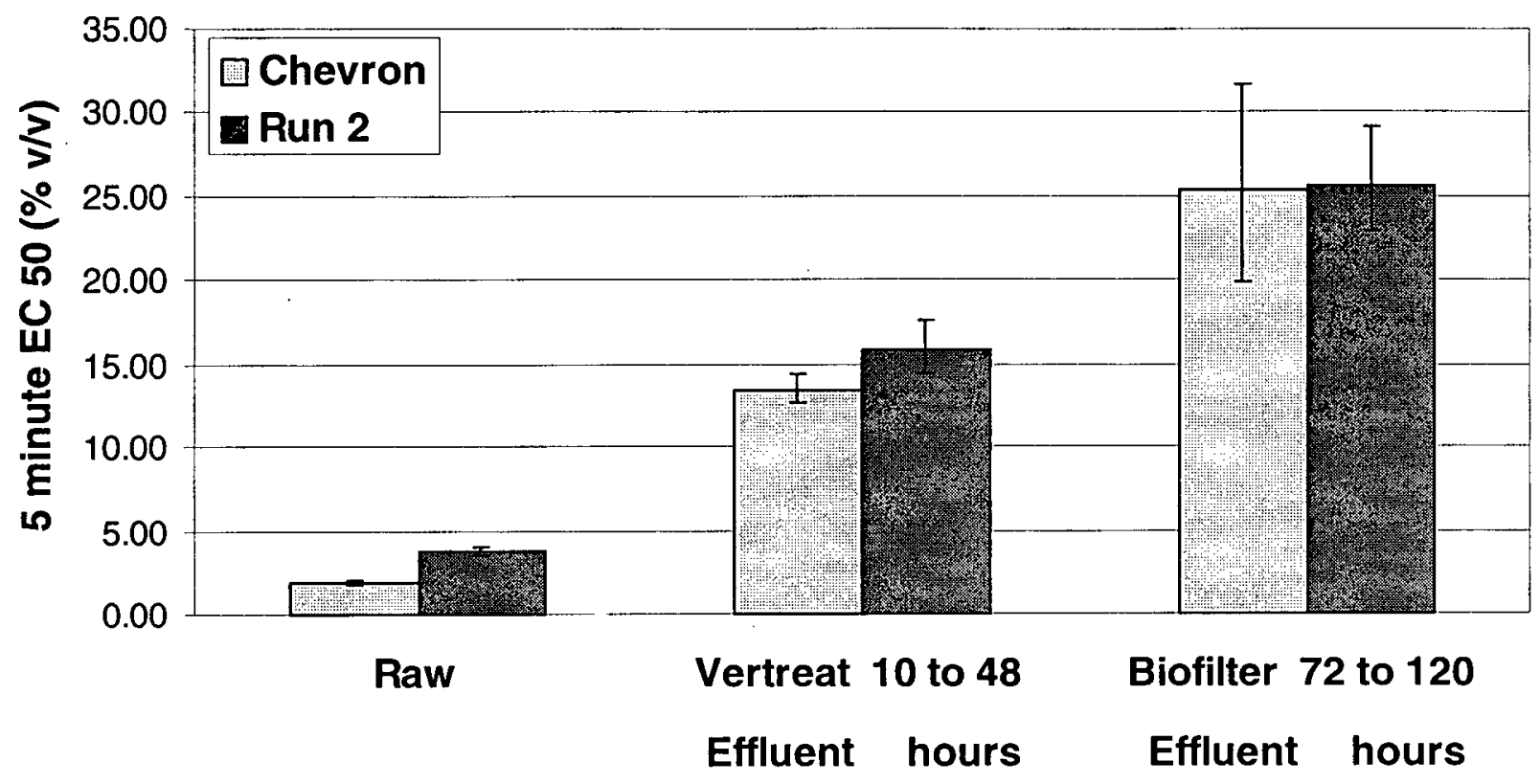

Figure 5.11: Chevron Toxicity Monitoring Program (5 min EC 50 )

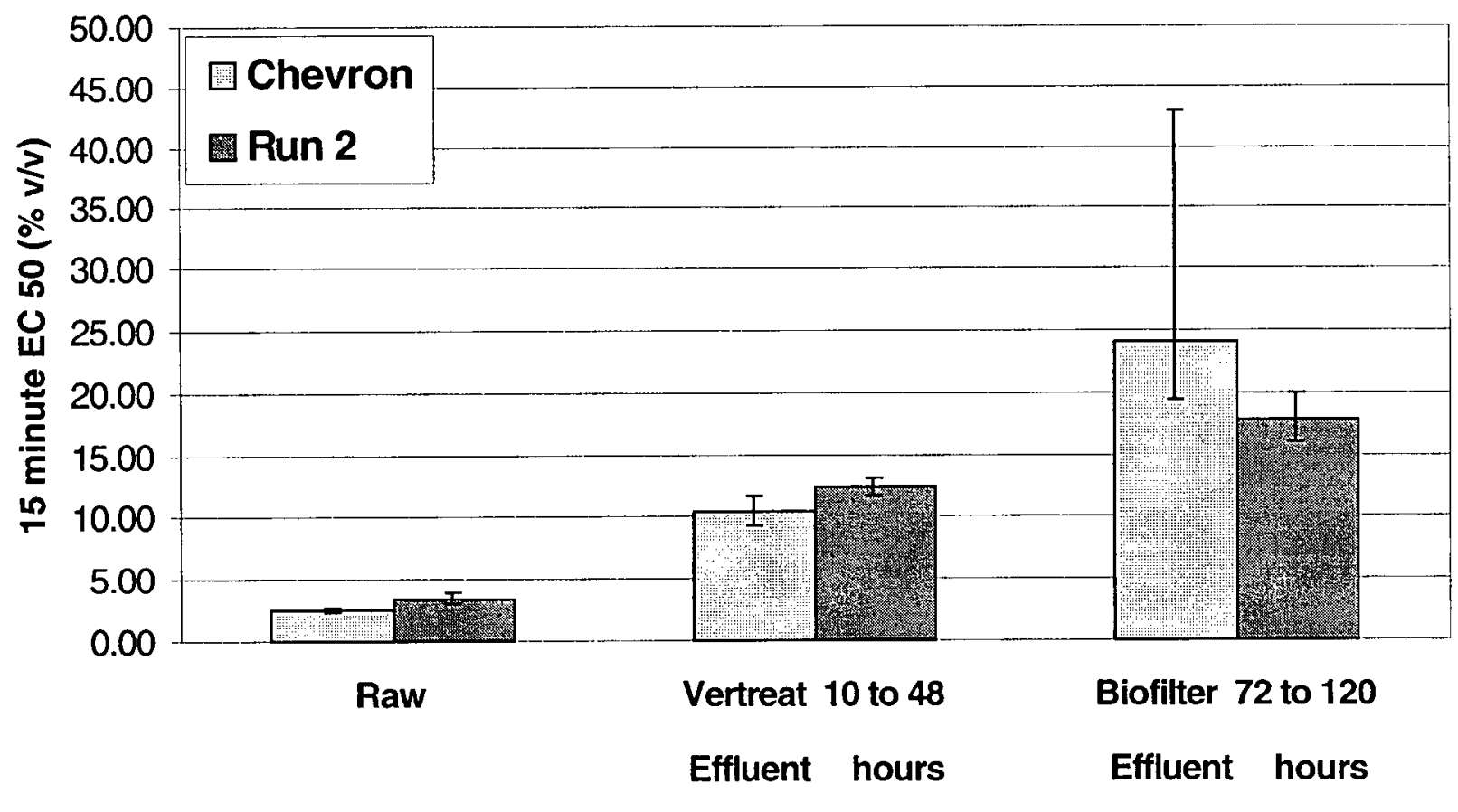

Figure 5.12: Chevron Toxicity Monitoring Program (15 min $\mathrm{EC}_{50}$ ) 


\subsection{Possible BOD, COD, and Toxicity Sources}

\subsubsection{BTEX and MTBE}

In Run 1, the possibility that benzene, toluene, ethyl benzene, xylene (BTEX), and methyl-tertiary butyl ether (MTBE) contributed to the BOD, COD and toxicity of the wastewater was investigated. BTEX compounds are part of a group collectively known as volatile hydrocarbons (VH), as discussed in Section Error! Reference source not found.. Since the VH and MTBE were removed within 8 hours (by various mechanisms), and since BOD, COD and toxicity levels were still significant until 24 hours, it is clear that the

VH compounds and MTBE did not significantly contribute to them.

The total VH concentration of the wastewater was $8.8 \mathrm{mg} / \mathrm{L}$ prior to warming it in the reactor overnight (Raw-Oct 27, Table 5.1). At the start of the run, the VH concentration had dropped to $3.1 \mathrm{mg} / \mathrm{L}$ (Raw-Start). After the reactor was seeded and the aeration started $(0 \mathrm{hr})$, the VH level was $0.8 \mathrm{mg} / \mathrm{L}$. Based on these observations, and the highly volatile nature of the VH they were likely stripped from the wastewater.

Table 5.3: VH and MTBE Concentrations (mg/L) in Run 1

\begin{tabular}{|c|c|c|c|c|c|c|c|}
\hline & $\begin{array}{c}\text { Raw } \\
\text { Oct 27 }\end{array}$ & $\begin{array}{c}\text { Raw } \\
\text { Start }\end{array}$ & $0 \mathrm{hr}$ & $2.25 \mathrm{hr}$ & $8 \mathrm{hr}$ & $24 \mathrm{hr}$ & $52.5 \mathrm{hr}$ \\
\hline VH (C6-C10) & 8.8 & 3.1 & 0.8 & $<0.1$ & $<0.1$ & $<0.1$ & $<0.1$ \\
\hline benzene & 2.43 & 1.03 & 0.267 & 0.0009 & $<0.0005$ & $<0.0005$ & $<0.0005$ \\
\hline toluene & 2.57 & 0.93 & 0.237 & 0.0018 & $<0.0005$ & $<0.0005$ & $<0.0005$ \\
\hline ethyl-benzene & 0.218 & 0.0722 & 0.0176 & $<0.0005$ & $<0.0005$ & $<0.0005$ & $<0.0005$ \\
\hline m-\& p-xylene & 1.09 & 0.308 & 0.0985 & 0.0009 & 0.0005 & 0.0005 & $<0.0005$ \\
\hline o-xylene & 0.564 & 0.21 & 0.0611 & $<0.0005$ & $<0.0005$ & $<0.0005$ & $<0.0005$ \\
\hline MTBE & 0.327 & 0.325 & 0.21 & 0.02 & 0.005 & 0.004 & $<0.001$ \\
\hline
\end{tabular}


The total MTBE concentration of the wastewater was $0.327 \mathrm{mg} / \mathrm{L}$ prior to warming it in the reactor overnight (Raw-Oct 27, Table 5.1). At the start of the run, the MTBE concentration had dropped to $0.325 \mathrm{mg} / \mathrm{L}$ (RawStart). After the reactor was seeded and the aeration started $(0 \mathrm{hr})$, the MTBE level was $0.21 \mathrm{mg} / \mathrm{L}$. MTBE is highly water soluble and resistant to volatilization by air stripping as well as adsorptive removal by activated carbon (API, 1991). Park and Cowan (1997) found that MTBE was biodegradable under aerobic conditions using activated sludge from a petroleum refinery's WWTP. Based on these findings, it is likely that MTBE was biodegraded in Run 1. The tenfold reduction in MTBE concentration over 2.25 hours did not have a significant effect on toxicity removal, as toxicity removal in Run 1 only occurred after 2.25 hrs.

\subsubsection{Phenols and EPH}

In Run 2, the possibility that phenols and extractable petroleum hydrocarbons (EPH) contributed to the BOD, COD and toxicity of the wastewater was investigated. As shown in Table 5.4, the wastewater initially contained $20 \mathrm{mg} / \mathrm{L}$ of phenols, but at 30 minutes the level had dropped to $0.34 \mathrm{mg} / \mathrm{L}$. Hence, it is unlikely that phenol removal significantly contributed to BOD, COD and toxicity degradation.

The EPH level started off at $17.3 \mathrm{mg} / \mathrm{L}$ and dropped to $8.7 \mathrm{mg} / \mathrm{L}$ by 30 minutes. Although the EPH concentration profile follows a gradual degradation pattern, similar to that of BOD and COD degradation, it is unlikely that the EPH are a major source of BOD and COD. Assuming a formula of $\mathrm{C}_{n} \mathrm{H}_{2 \mathrm{n}+2}$ for the EPH, $3.5 \mathrm{mg} \mathrm{O}$ will be consumed per $\mathrm{mg}$ of EPH oxidized. Thus, based on theoretical oxygen demand (ThOD) calculations, $17.3 \mathrm{mg} / \mathrm{L}$ of EPH will exert an oxygen demand of 60.6 $\mathrm{mg} / \mathrm{L}$. Assuming a formula of $\mathrm{C}_{6} \mathrm{H}_{6} \mathrm{O}$ for phenols, $2.4 \mathrm{mg} \mathrm{O}_{2}$ will be consumed per mg of phenols oxidized. Thus, $20 \mathrm{mg} / \mathrm{L}$ of phenols will exert a ThOD of $47.6 \mathrm{mg} / \mathrm{L}$. These values only account for $46 \%$ of the 
initial BOD (i.e. $234 \mathrm{mg} \mathrm{BOD} / \mathrm{L}$ ) and $21 \%$ of the initial COD (i.e. $510 \mathrm{mg}$ COD/L) in Run 2. Gulyas et al. (1995) conducted a study of the organic compounds at different stages of a refinery wastewater treatment plant, and found that the compounds detected (i.e. three iso-alkanes, traces of carboxylic acids, and acetic acid 2-(2-butoxyethoxy)-ethyl ester) could not explain the relatively high COD.

Since the removal of EPH did not correlate with the toxicity removal, it was concluded that EPH degradation did not significantly affect toxicity removal.

Table 5.4: Phenols and EPH Concentrations in Run 2

\begin{tabular}{|c|c|c|c|c|c|}
\hline & Raw & $0.5 \mathrm{hr}$ & $3 \mathrm{hr}$ & $10 \mathrm{hr}$ & $24 \mathrm{hr}$ \\
\hline Phenols & 20 & 0.34 & 0.16 & 0.13 & 0.07 \\
\hline EPH (C10-C32) & 17.3 & 8.7 & 4 & 3.8 & 3 \\
\hline
\end{tabular}

5.5.3 Other toxicity sources

Since BTEX, MTBE, EPH, and phenols do not significantly contribute to toxicity, the major source of toxicity is still unknown. Many other compounds have been detected in refinery wastewaters, and their contribution to toxicity is not fully understood (PACE, 1985; Greenshields et al., 1987; Dold, 1989; MOE, 1989; Gulyas, 1995). As discussed in Section 2.3.1, there has been little success in trying to identify the compounds contributing to toxicity in refinery wastewaters. 


\subsection{Microbial Kinetics}

Microbial kinetics were determined for samples collected throughout Runs 1 and 2. The kinetic parameters were calculated using both the $\triangle$ OUR assay and based on BOD, COD and MLSS data from Runs 1 and 2 . The results from both these methods are presented and discussed in the following sections.

\section{$\underline{5.6 .1} \underline{\Delta O U R}$ assay}

Respirometric kinetic tests were used to determine the maximum substrate uptake rates of biomass from the Chevron WWTP for samples collected throughout Runs 1 and 2. Since Runs 1 and 2 had similar BOD, COD, and SOUR profiles (Figure 5.1, Figure 5.2, and Figure 5.8) it was expected that they would have similar specific substrate uptake kinetics. Any significant difference in the kinetics for samples from Runs 1 and 2 was likely due the dissimilarity between sludge ages of the biomass used to perform the kinetic tests and that used in the batch runs.

It has been shown that sludge age significantly affects the kinetic parameters of the biomass (Chudoba et al., 1989; Helle, 1999). The biomass used to seed Runs 1 and 2 was collected from the Chevron WWTP Deep Extraction sampling port on October 27, 1999 and December 17, 1999, respectively; and the biomass used to perform kinetic tests on these samples was collected on November 12, 1999 and January 13, 2000 respectively. Since sludge age is not controlled at the Chevron WWTP, it is possible that the sludge age of the biomass used varied significantly between October 1999 and January 2000.

The maximum specific substrate uptake rate for Run 1 could only be determined for the samples collected up to 10 hours. Beyond this, the 
BOD of the samples was too low to conduct a respirometric test without "washing out" the biomass in the respirometer by injecting large sample volumes. Similarly for Run 2 , the kinetic constants could only be determined for the samples collected up to 3 hours. The 10-hour sample for Run 2 had insufficient BOD to perform kinetic tests.

As discussed in Section 5.2.4 and 5.3, the microbes were likely metabolizing the same set of substrates from 0 to 6 hours. Yet, the maximum specific substrate uptake rate decreased over this time period (Figure 5.13). This is an indication that the biomass in the reactor behaved differently than that obtained from the WWTP for kinetics tests. The higher maximum specific substrate uptake rates for Run 2 are another indication that the microbial population differed between the reactor run and the kinetic tests. Although, the sludge ages varied, the results from the kinetic tests can still be used to qualitatively determine the nature of the biodegradation process in Runs 1 and 2.

The maximum specific substrate uptake rate for Runs 1 and 2 decreased with time. Since the microbes preferentially metabolized the readily biodegradable compounds prior to consuming the more recalcitrant ones, this result was expected. 


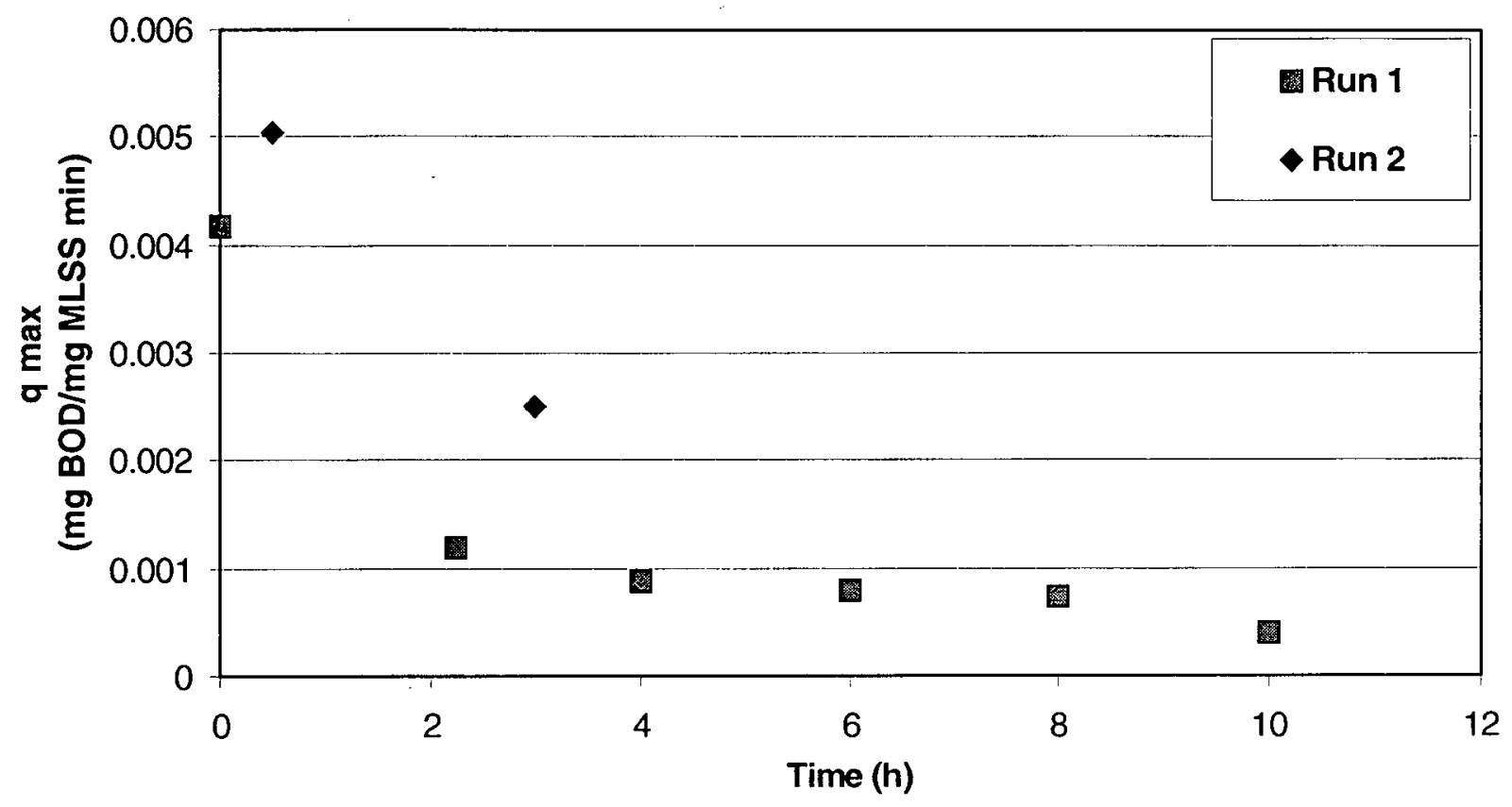

Figure 5.13: Maximum Specific Substrate Uptake Rates

The half-saturation constant, $K_{s}$, for Runs 1 and 2 also decreased with time (Figure 5.14). As discussed in Section 2.6.3, Shuler and Kargi (1992) found that in a single substrate system, uncompetitive inhibition by accumulation of toxic compounds results in the reduction of the maximum specific substrate uptake rate and the $\mathrm{K}_{\mathrm{s}}$ value. Based on the data (Figure 5.13, Figure 5.14, Figure 5.15, and Figure 5.16) it seems that the microbial kinetics of refinery wastewater degradation fits the model proposed by Shuler and Kargi. It was hypothesized that the increasing relative concentration of the more recalcitrant compounds resulted in an effect similar to the accumulation of inhibitory metabolites proposed by the model. This inhibitory effect is further discussed in Section 5.6.1.1. 


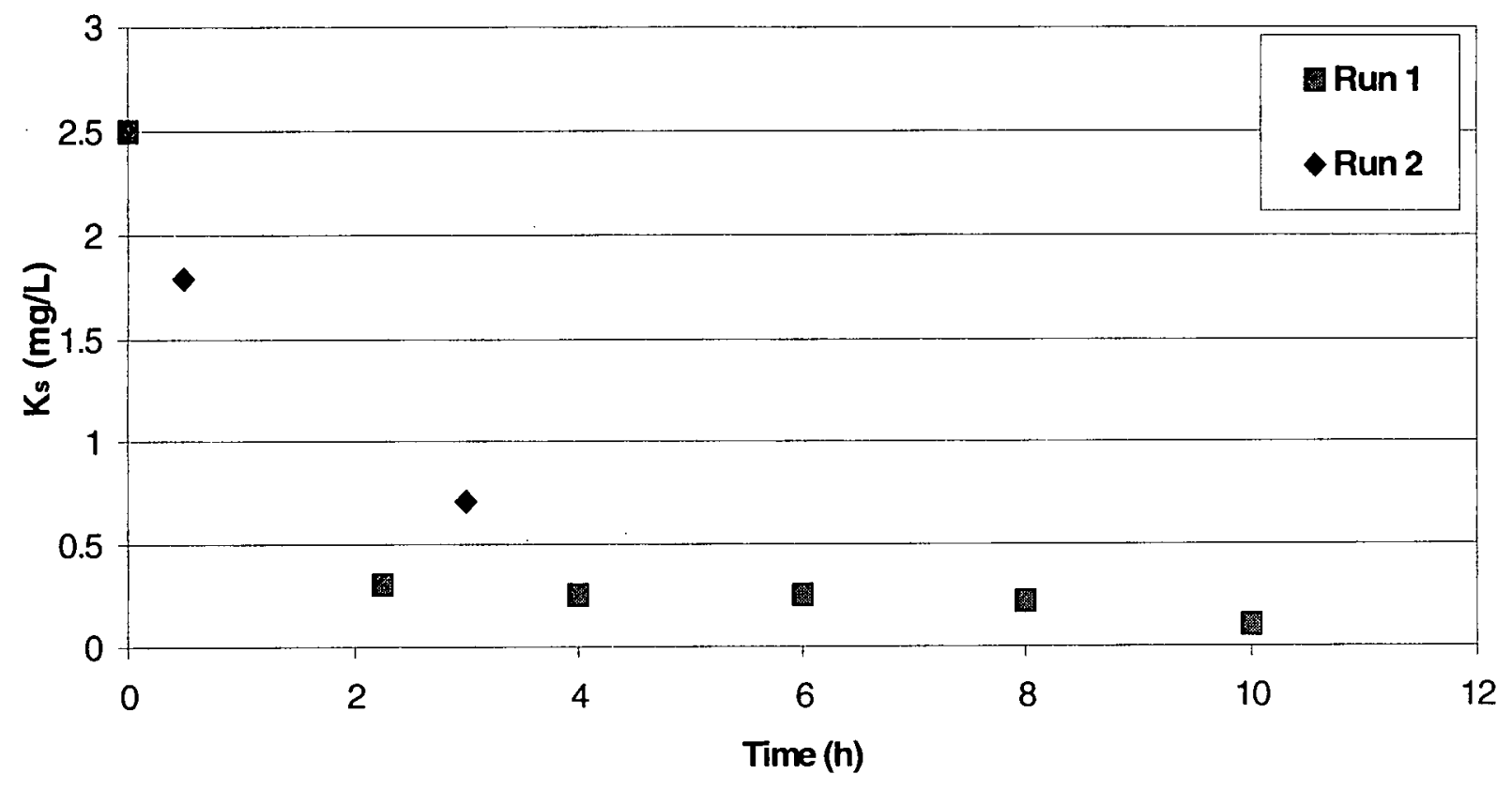

Figure 5.14: Half Saturation Constants for Runs 1 and 2.

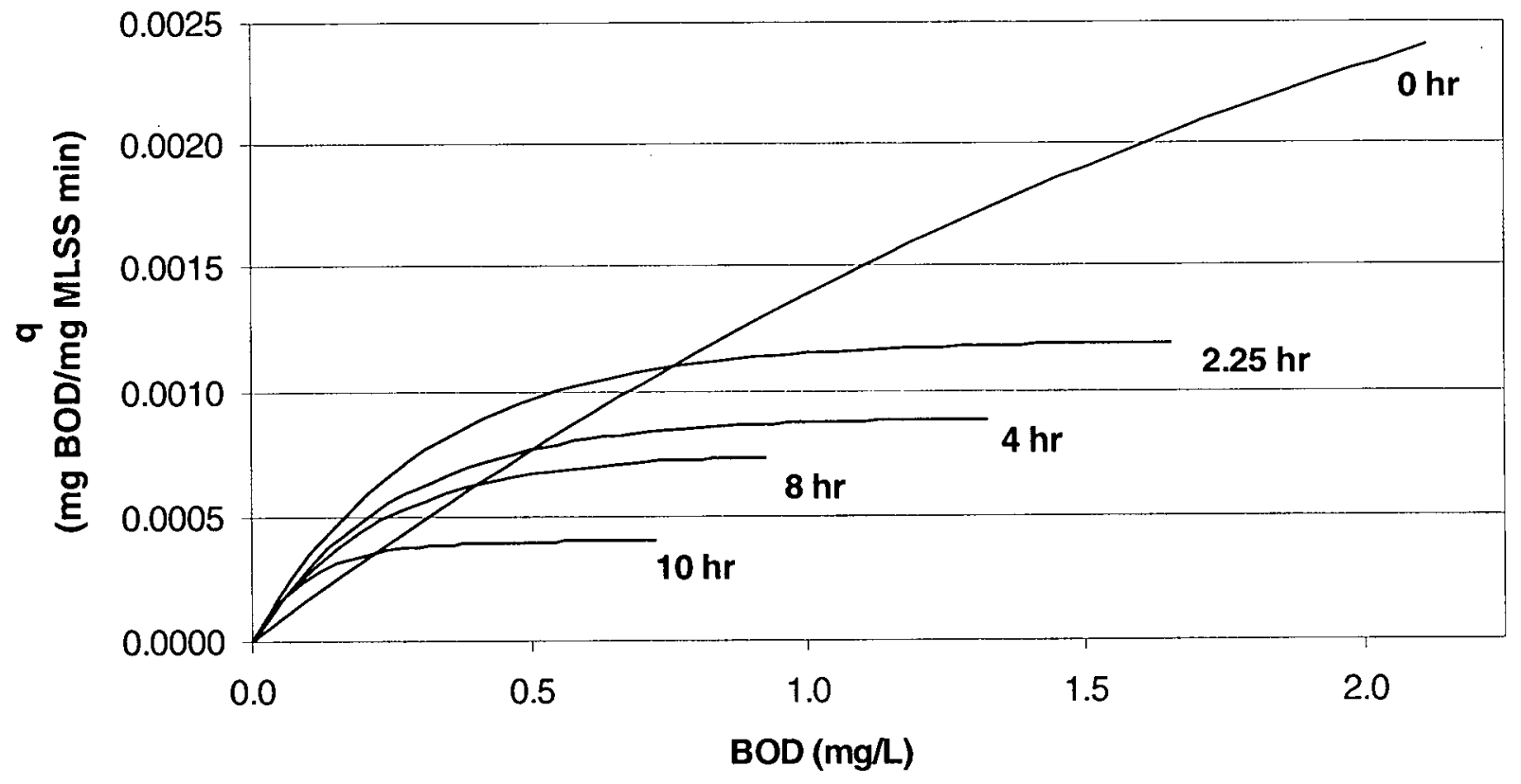

Figure 5.15: Run 1 Substrate Uptake Rate Profiles 


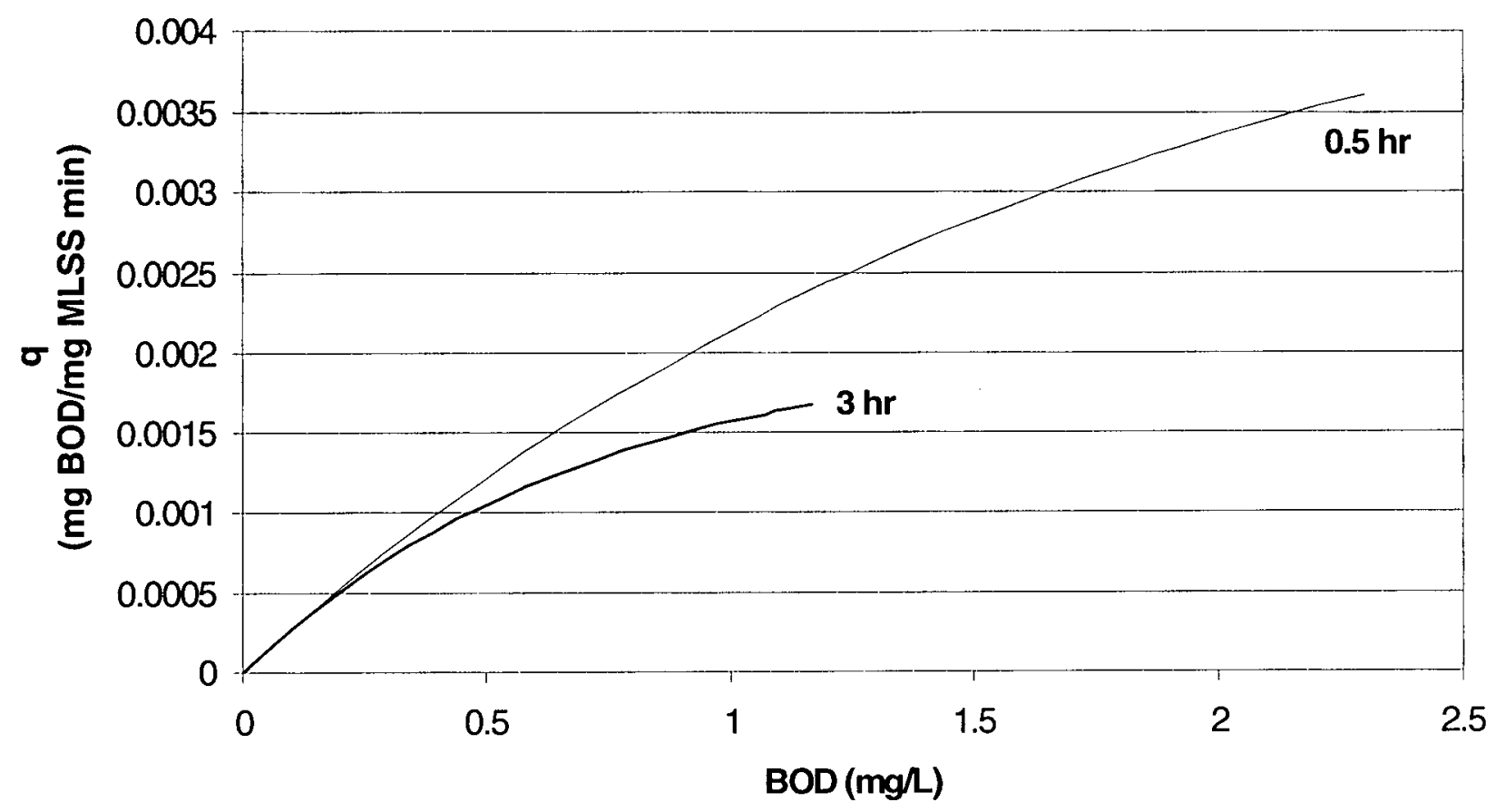

Figure 5.16: Run 2 Substrate Uptake Rate Profiles

\subsubsection{1 $\triangle$ OUR profiles}

The $\triangle$ OUR profiles for $1.5 \mathrm{ml}$ injections of Run 1 samples are shown in Figure 5.17. It is clear that the $\triangle$ OUR decreases with later samples (i.e. the $\triangle$ OUR for the 2 hour injection is smaller than that of the 0 hour injection). Each sample was collected at a later time, thus there was less readily biodegradable substrate available for metabolism. Since the BOD was reduced to its final value in 24 hours, the 24 hour sample did not exert a significant OUR.

Also noteworthy was the presence of an initial decrease in the OUR upon sample injection (at 2 minutes). This decrease was not readily apparent in the 0 and 2-hour samples, but it became significant in the later samples. This decrease in OUR was likely due to the presence of toxic compounds. As discussed in section 5.4, the toxicity was likely due to 
the recalcitrant compounds in the wastewater. The dip in OUR due to toxicity was not discernable in the earlier injections since the OUR exerted by the readily biodegradable compounds was much larger. Once the readily biodegradable compounds were metabolized, and the relative concentration of the recalcitrant compounds increased, the decrease in OUR became more pronounced. Despite the initial toxic shock in the later injections, the biomass was able to return to its endogenous OUR. 

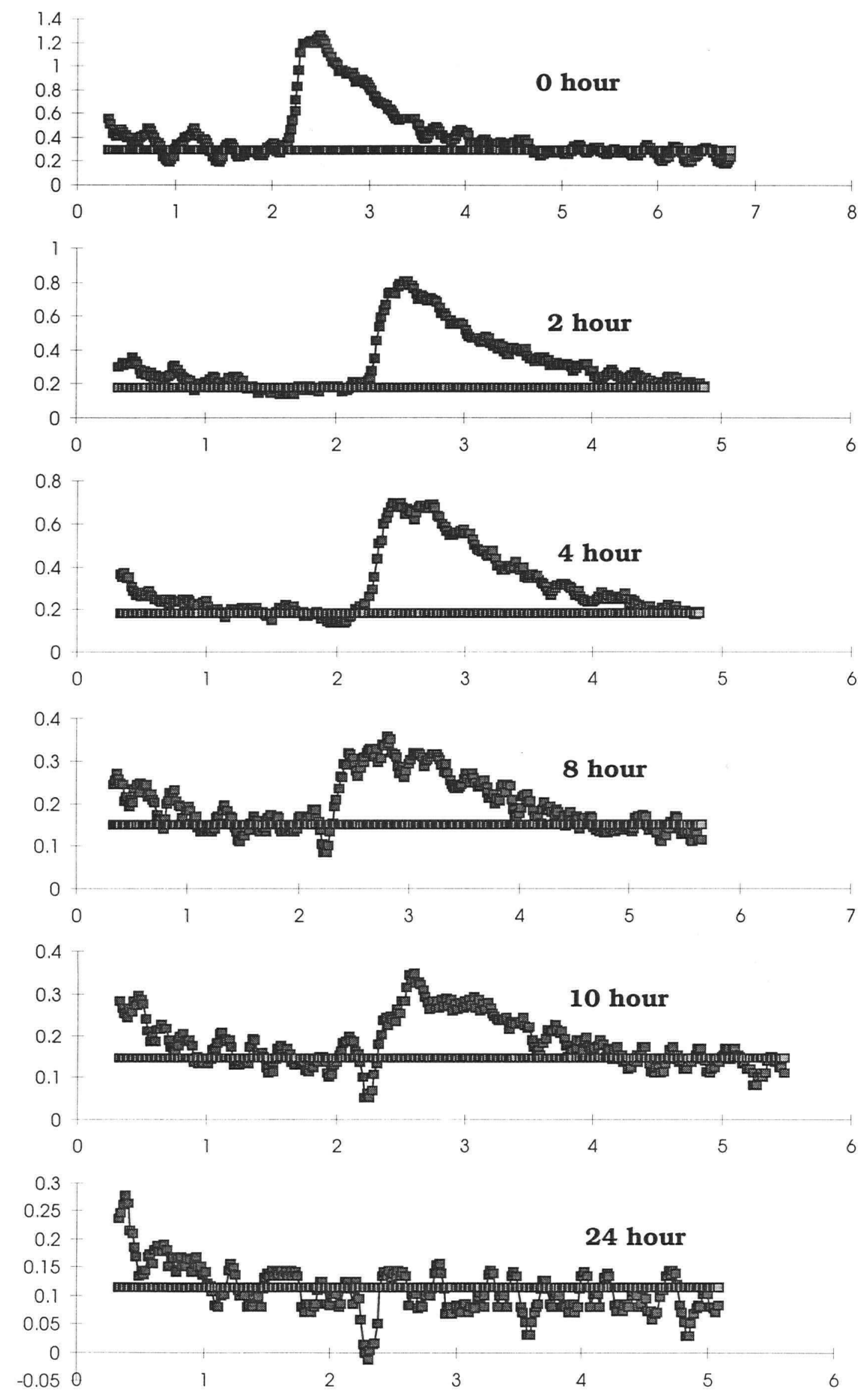

Figure 5.17: Run 1 OUR Injection Profiles (OUR vs. time in minutes) 
$\underline{5.6 .2}$ Kinetics determined from batch test data

Substrate (i.e. BOD), and biomass measurements were used to determine the specific substrate uptake rate throughout the batch runs. Helle (1999) showed that kinetic parameters obtained from the $\Delta$ OUR assay were comparable to those determined from batch test data.

In Run 1, the correlation between the results obtained from the batch test and the $\triangle$ OUR assay is better (Figure 5.18) than in Run 2 (Figure 5.19). As discussed in section 5.6.1, the biomass used in the respirometric studies may have significantly differed from that used in the batch tests. This variation in sludge age may account for the discrepancy between the results from both tests. These results further support the contention that the biomass in the $\Delta$ OUR assays was significantly different than that used in the batch tests.

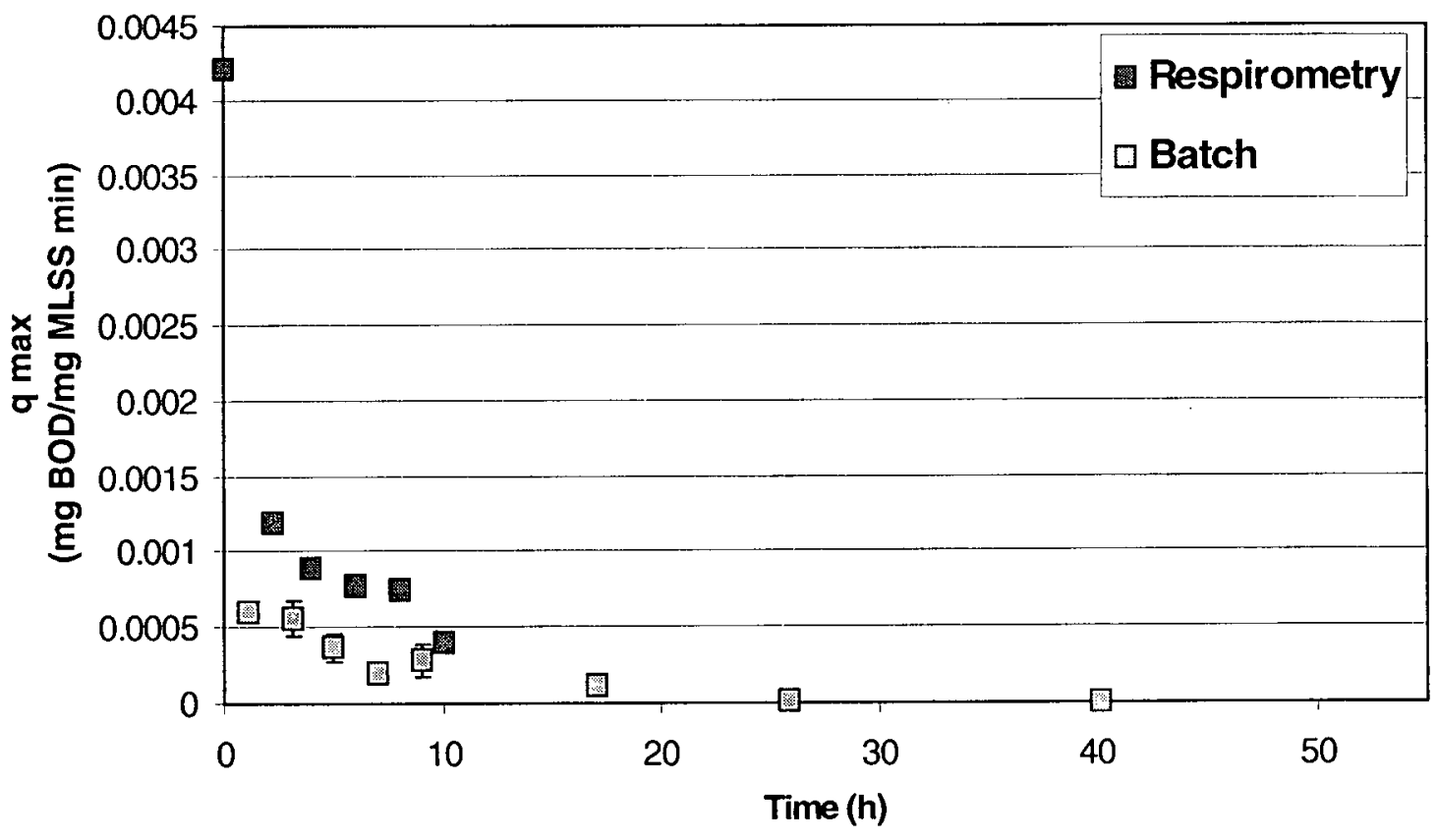

Figure 5.18: Run 1 Batch Results Compared to $\triangle$ OUR Assay 


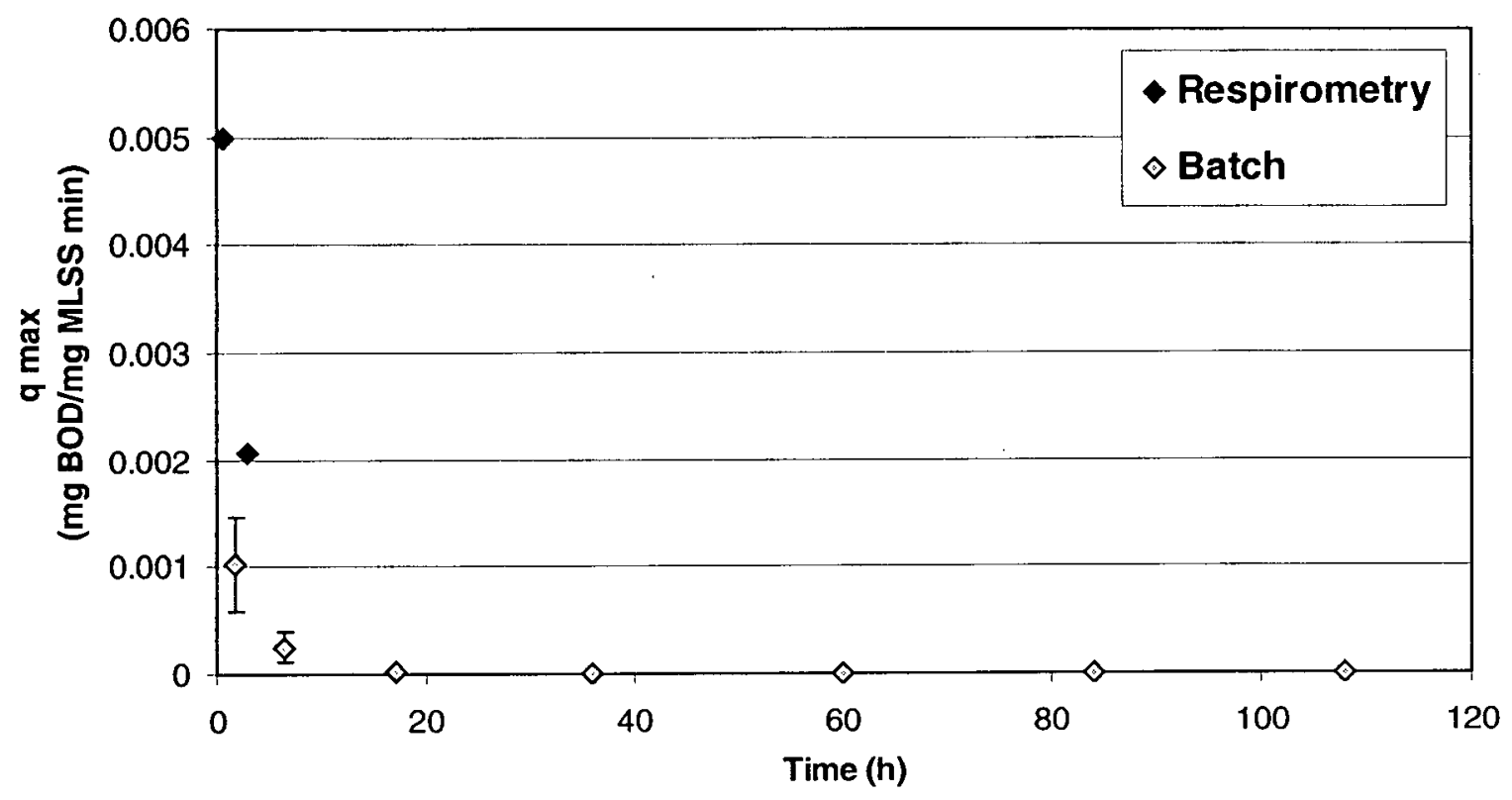

Figure 5.19: Run 2 Batch Results Compared to $\Delta$ OUR Assay 


\section{Conclusions}

In both runs, the BOD and COD reduction occurred over the first 24 hours of treatment. The BOD removal was $92-96 \%$, and the COD removal was $73-75 \%$. These values are similar to the removal levels reported at the Chevron refinery WWTP. Removal of organics by stripping was found to be insignificant, thus the compounds contributing to BOD and COD were concluded to be primarily removed by biodegradation. The removal of BOD over 24 hours fit the first order model proposed by Grau et al. (1975), and the rate coefficients ( $k$ ) were 0.5 and $0.4 \mathrm{~d}^{-1}$, for Run 1 and Run 2, respectively.

The overall SOUR profiles for Runs 1 and 2 are similar to those obtained for BOD and COD. Both runs had a constant SOUR phase from 0.5-6 h, and this supports the contention that the microbes were consuming the same set of substrates during this time interval. The same conclusion was also reached based on BOD and COD data.

Both runs showed similar patterns of toxicity removal. Rather than being continuously removed, as in the case of BOD and COD, toxicity appeared to be removed in discrete stages. The first stage of toxicity removal corresponded to the degradation of BOD and COD, and the second stage occurred after BOD and COD had been removed. The raw wastewater in Runs 1 and 2 had a 5-minute $\mathrm{EC}_{50}$ of $4.6 \pm 0.5 \%$ and $4.9 \pm 0.4 \%$, respectively. In Run 1 , the toxicity was reduced to a 5-minute $\mathrm{EC}_{50}$ of $7.9 \pm 0.7 \%$ in 10 hours, and further removal did not occur until after 28 hours. In Run 2, a 5-minute $\mathrm{EC}_{50}$ of $16 \pm 3.2 \%$ was achieved over the first 10 hours, and the toxicity remained at this level until 48 hours. A second significant toxicity removal step between 48 and 72 hours resulted in a final $\mathrm{EC}_{50}$ of $27.8 \pm 1.6 \%$. 
Comparison of the acute toxicity removal pattern in Run 2 with that at the Chevron WWTP indicates that the DSTI ${ }^{\mathrm{TM}}$ bioreactor at the Chevron WWTP removes toxicity up to the first constant toxicity phase, and then the biofilters remove the more recalcitrant compounds that contribute to toxicity. It seems as though the WWTP's toxicity removal capability is limited by the capacity of the biomass for toxicity removal, as determined in Run 2. Yet this result may be merely coincidental, and further work is required to produce a definite conclusion.

In Run 1, the possibility that volatile hydrocarbons (VH), and methyltertiary butyl ether (MTBE) contributed to the BOD, COD and acute toxicity of the wastewater was investigated. Since the VH and MTBE were removed within 8 hours (by various mechanisms), and since BOD, COD and toxicity levels were still significant until 24 hours, it is clear that the VH and MTBE did not significantly contribute to BOD, COD, and acute toxicity.

In Run 2, the possibility that phenols and extractable petroleum hydrocarbons (EPH) contributed to the BOD, COD and acute toxicity of the wastewater was investigated. Phenols and EPH only accounted for approximately $46 \%$ of the initial BOD (i.e. $234 \mathrm{mg} \mathrm{BOD} / \mathrm{L}$ ) and $21 \%$ of the initial COD (i.e. $510 \mathrm{mg}$ COD/L) in Run 2. The removal of these compounds did not significantly affect toxicity removal.

Microbial kinetics were determined by a respirometric assay and it was found that both the maximum specific substrate uptake rate $\left(q_{\max }\right)$ and the half-saturation constant $\left(\mathrm{K}_{\mathrm{s}}\right)$ decreased throughout the runs. The reduction of both $\mathrm{q}_{\max }$ and $\mathrm{K}_{\mathrm{s}}$ with time fit the model of uncompetitive inhibition by accumulation of toxic compounds (Shuler and Kargi, 1992). 
Since Runs 1 and 2 had similar BOD, COD, and SOUR profiles it was expected that they would have similar microbial kinetics. Since the kinetics of both runs significantly differed, it was concluded that the sludge ages of the biomass used to perform the kinetic tests and that used in the batch runs were dissimilar. 


\section{RECOMMENDATIONS}

Since the biomass used in the experimental batch runs was obtained from the DSTI ${ }^{\mathrm{TM}}$ bioreactor, it likely contained fast growing microbes selected for rapid removal of BOD and COD. Further experiments using effluent from a long batch test (such as Run 2) and biomass from the biofilters, which are slow growing and selected for toxicity removal, will determine whether further toxicity removal is possible biologically.

Since sludge age is currently not measured or controlled at the Chevron WWTP it would be useful to quantify this parameter. Further experiments using various sludge ages may be used to determine a sludge retention time that optimizes BOD, COD and toxicity removal. Further toxicity removal capacity by the addition of powdered activated carbon to the mixed liquor can also be investigated. It would be ideal to implement the results from these further lab-scale tests by performing full-scale tests to optimize the performance of the Chevron WWTP. 


\section{NOMENCLATURE}

API - American Petroleum Institute

BC MELP - British Columbia Ministry of Environment, Lands, and Parks

BPT - Best Practicable Technology

BOD - Biochemical Oxygen Demand $\left(M / L^{3}\right)$

BTEX - Benzene, Toluene, Ethyl-Benzene, Xylene

95\% CI - 95\% Confidence Interval

${ }^{\circ} \mathrm{C}$ - degrees Celsius

COD - Chemical Oxygen Demand $\left(M / L^{3}\right)$

$\mathrm{DAF}$ - Dissolved Air Flotation

DO - Dissolved Oxygen (M/L $\left.{ }^{3}\right)$

EPA - Environmental Protection Agency

EPH - Extractable Petroleum Hydrocarbons

$\mathrm{F} / \mathrm{M}$ - food to microorganism ratio

gpm - Gallons per minute

GC/FID - Gas Chromatography with Flame Ionization Detection

GC/MS - Gas Chromatography with Mass Selective Detection

GVRD - Greater Vancouver Regional District

h - hour

$\mathrm{H}_{2} \mathrm{SO}_{4}$ - Sulphuric Acid

HDPE - High Density Polyethylene

$\mathrm{k}$ - first order substrate removal rate coefficient $\left(\mathrm{T}^{-1}\right)$

$\mathrm{K}_{\mathrm{S}}$ - half saturation constant $\left(\mathrm{M} / \mathrm{L}^{3}\right)$

L - Litre

MLSS - Mother Liquor Suspended Solids (M/L $\left.{ }^{3}\right)$

$\mathrm{NaOH}$ - Sodium Hydroxide

$\mathrm{nm}$ - Nanometers

OC - oxygen consumed

OUR - Oxygen Uptake Rate ( $\mathrm{mg} \mathrm{O}_{2} / \mathrm{L} \mathrm{min}$ )

q - specific substrate uptake rate (mg BOD consumed/mg MLSS min)

$\mathrm{q}_{\max }$ - maximum specific substrate uptake rate

$\mathrm{S}$ - Substrate concentration (mg BOD/L or mg COD/L)

SOUR - Specific Oxygen Uptake Rate ( $\mathrm{mg} \mathrm{O}_{2} / \mathrm{mg}$ MLSS min)

So - Initial Substrate concentration ( $\mathrm{mg} \mathrm{BOD/L}$ or $\mathrm{mg} \mathrm{COD/L})$

SLPM - Standard Litres Per Minute

SMP - Soluble Microbial Products

SRT - Sludge Retention Time

TSS - Total Suspended Solids

US - United States

VH - Volatile Hydrocarbons

VOC - Volatile Organic Carbon

VPH - Volatile Petroleum Hydrocarbons

WWTP - Wastewater Treatment Plant

$\mathrm{X}$ - Biomass concentration (mg MLSS/L) 


\section{ReFERENCES}

American Petroleum Institute, API (1978), "Analysis of refinery wastewaters for EPA priority pollutants”. API Publication no. 4296. Washington, DC.

American Petroleum Institute, API (1991), "Cost-effective, alternative treatment technologies for reducing the concentrations of methyl tertiary butyl ether and methanol in groundwater". IT Corporation, Knoxville, Tennessee.

American Public Health Association, APHA (1992). Standard Methods for the Examination of Water and Wastewater, $18^{\text {th }}$ ed., Washington, DC.

Aruldoss, J. and Viraraghavan, T. (1998), "Toxicity Testing of Refinery Wastewater Using Microtox", Bull. Environ. Contam. Toxicol, 60:456-463.

ASL (1999), Collection and Sampling Guide, Analytical Services Laboratory, Vancouver, BC.

Bader, F.G. (1978), "Analysis of Double-Substrate Limited Growth", Biotechnol. Bioeng. 20 : 183-202.

Baker, A. and Dold, P. (1992), "Activated Sludge Treatment of Petroleum Refinery Wastewater: Part I - Experimental Behaviour”, Wat. Sci. Tech., 26 (1-2): 333-343.

Bleckmann, C., Rabe, B., Edgmon, S., and Fillingame, D. (1995), "Aquatic Toxicity Variability for Fresh and Saltwater Species in Refinery Wastewater Effluent”, Environ. Toxicol. and Chem, 14 (7):1219-1223.

Brenner, R.C. and Convery, J.J., (1980), "Status of Deep Shaft Wastewater Treatment Technology in North America", Proceedings Seventh United States/Japan Conference on Sewage Treatment Technology May 19-21, 1980, Tokyo, Japan. Environmental Protection Agency Report EPA-600/9-80-047, December 1980, p 777-824.

Burks, S.L. (1982), "Review of Pollutants in Petroleum Refinery Wastewaters and Effect Upon Aquatic Organisms", Environ. International, 7: 271-283.

Capps, R. W., Mantelli, G.N., and Bradford, M.L. (1995) "Design Concepts for Biological Treatment of Industrial Wastewater," Environ. Progress, 2, 1-8. 
Cech, J.S., Chudoba, J., and Grau, P. (1984), "Determination of Kinetic Constants of Activated Sludge Microorganisms", Wat. Sci. Tech., 17:259272.

Chapman, P., Paine, M., Moran, T., and Kierstead, T. (1994), "Refinery Water (Intake and Effluent) Quality: Update of 1970s with 1990s Toxicity Testing", Environ. Toxicol. and Chem, 13 (6):897-909.

Chudoba, J. (1985), "Inhibitory Effect of Refractory Organic Compounds Produced by Activated Sludge Micro-organisms on Microbial Activity and Flocculation", Wat. Res., 19 (2): 197.

Chudoba, J., Albokova, J., and Cech, J.S. (1989), "Determination of Kinetic Constants of Activated Sludge Microorganisms Responsible for Degradation of Xenobiotics", Wat. Res., 23 (11): 1431-1438.

Chudoba, P., Capdeville, B., and Chudoba, J. (1992), "Explanation of Biological Meaning of the So/Xo Ratio in Batch Cultivation", Wat. Sci. Tech. 26 (3-4): 743-751.

Chevron Canada Ltd (1991), "Burnaby Refinery at a Glance", Company Brochure, June 1991.

Davis, M. L. and Cornwell, D.A. (1998) Introduction to Environmental Engineering, WCB/McGraw-Hill.

Dobson, H., Woo, N. et al. (1999), "CHML 572 Design Project: Final Report”, UBC Department of Chemical and Biological Engineering CHML 572 Project Report.

Dold. P.L. (1989), "Current Practice for Treatment of Petroleum Refinery Wastewater and Toxics Removal", Wat. Poll. Res. J. Canada, 24 (3): 363390.

Dorris, T.C., Burks, S.L., and Waller, G.R. (1974) "Effects of Residual Toxins in Oil Refinery Effluents and Aquatic Organisms", NTIS OK-BO23, Technical completion report on U.S. Dept. of Interior, Office of Water Research, Washington, DC.

Eckenfelder, W.W., Goronszy, M.C., and Quirk, T.P. (1985), "The Activated Sludge Process: State of the Art", CRC Critical Reviews in Environmental Control, 15 (2) : 111-178.

Eckenfelder, W.W. (1988), "Treatment of Petrochemical Wastewaters-The State of the Art", Wat. Sci. Tech., 20 (10):1-12. 
Eckenfelder, W.W. and Musterman, J.L. (1993), "High Energy Activated Sludge: An Alternative for Industrial Wastewater Treatment", Water Environment Federation $66^{\text {th }}$ Annual Conference \& Exposition, October 3-7, 1993, Anaheim, CA.

Environment Canada (1974), "Petroleum Refinery Effluent Regulations and Guidelines" Water Pollution Control Directorate, Report EPS 1-WP74-1, January 1974.

Environment Canada (1995), “1992 Environmental Status Report on Canadian Petroleum Refinery Effluents”, EPS Report 1/PN/4.

Freeman, R. and Pollack D. (1997), "Unit Process and Hydraulic Commissioning of the Deep Shaft Wastewater Treatment and Bio-solids Digestion Facility for the Chevron Petroleum Refinery at Burnaby, British Columbia", Deep Shaft Technology Inc.

Grady, C. P. L. and Lim, C. (1980), "Biological Wastewater Treatment: Theory and Application", Marcel Dekker, New York.

Grau. P., Dohanyos, M., and Chudoba, J. (1975), "Kinetics of Multicomponent Substrate Removal by Activated Sludge", Wat. Res., 9: 637-642.

Greenshields, J., Maynard, A., Rees, G., and Suboch, W. (1987), "Environmental Contaminants in Petroleum Refinery Wastewaters: An Assessment of Current Information and a Monitoring Approach", Study prepared for the Joint Industry/Government Technical Committee, Petroleum Refining Sector of the Municipal Industrial Strategy for Abatement Program.

Gulyas, H. and Reich, M. (1995), "Organic Compounds at Different Stages of a Refinery Wastewater Treatment Plant", Wat. Sci. Tech., 32 (7): 119-126.

Hejzlar, J. and Chudoba, J. (1986), "Microbial polymers in the aquatic environment-II. Isolation from biologically non-purified and purified municipal waste water and analysis", Wat. Research, 20: 1217-1221.

Helle, S. (1999), "A Respirometric Investigation of Activated Sludge Treatment of BKME During Steady State and Transient Operating Conditions", UBC Department of Chemical Engineering, PhD Thesis, January 1999. 
Hoy, P. (2000), "Toxicity Removal by the Effluent Biofilters at the Chevron Refinery WWTP", UBC Department of Chemical and Biological Engineering, Undergraduate Thesis, April 2000.

Kim, J.W. and Armstrong, N.E. (1981), "A Comprehensive Study of the Biological Treatabilities of Phenol and Methanol - II the Effects of Temperature, pH, Salinity, and Nutrients" Wat. Res., 15: 1233-1247.

Mahendraker, V. and Viraraghavan, T. (1995), "Respirometry in Environmental Engineering”, J. Environ. Sci. Health. A30: 713-734.

Mahmud, Z. and Thanh, N.C. (1979), "Biological Treatment of Refinery Wastewaters" Proceedings 33 ${ }^{\text {rd }}$ Purdue University Industrial Waste Conference, 515-525.

McKinney, R. E. (1963) Biological Treatment of Petroleum Refinery Wastes, American Petroleum Institute, New York.

Metcalf and Eddy (1991), Wastewater engineering - Treatment, disposal and reuse, $3^{\text {rd }}$ ed., Revised by Tchobanoglous, G., Burton, F.L., McGrawHill, New York.

Microbics Corp (1992), How to run a standard Microtox test. Manual Volume 3, Microbics Corporation, Carlsbad, CA.

Ministry of the Environment, MOE (1989), "Preliminary Report for the First Six Months of Monitoring in the Petroleum Refining Sector (December 1, 1988 to May 31, 1989)". Water Resources Branch, Ontario Ministry of Environment.

PACE (1985), "A Survey of Trace Substances in Canadian Oil Refinery Wastewaters and Sludges - A Summary Report", Petroleum Association for Conservation of the Canadian Environment, Ottawa, Ontario.

PACE (1987), "Sampling and Analysis of Refinery Effluents to Assess Variations in Trace Contaminant Concentrations", Petroleum Association for Conservation of the Canadian Environment, Ottawa, Ontario.

Park, K. and Cowan, R.M. (1997), "Effects of Oxygen and Temperature on the Biodegradation of MTBE", Abstract Paper, American Chem. Soc., 213:241-ENVR Part 1, April 13, 1997.

Peavy, H. S.; Rowe, D.R.; and Tchobanoglous, G. (1985) Environmental Engineering, McGraw-Hill, New York. 
Powell, E.O. (1972), "The Growth Rate of Microorganisms as a Function of Substrate Concentration", J. Appl. Chem. Biotechnol. 22: 71-78.

Pujol, R. et al. (1994), "Biofilters: Flexible, Reliable Biological Reactors", Wat. Sci. Tech., 29 (10-11): 33-38.

Rebhun, M. and Galil, N. (1987), "Biotreatment Inhibition by Hazardous Compounds in an Integrated Oil Refinery". Proceedings $42^{\text {nd }}$ Purdue University Industrial Waste Conference, 163-174.

Reteuna C., Vasseur, P., Cabrindenc, R. (1989), "Performance of three bacterial assays in toxicity assessment", Hydrobiologia. 188/189: 13.

Sherry. J., Scott, B. and Dukta, B. (1997), "Use of Various Acute, Sublethal and Early Life-Stage Tests to Evaluate the Toxicity of Refinery Effluents", Environ. Toxicol. and Chem. 16 (11): 2249-2257.

Shuler, M.L. and Kargi, F. (1992), Bioprocess Engineering: Basic Concepts, Prentice Hall International Series in the Physical and Chemical Engineering Sciences, Prentice Hall Inc., New Jersey, USA.

Tanner, A. (2000), "Against a Tide of Doubts", The Province, June 4, 2000 , p. Al6.

UNEP (1987), “Environmental Management Practices in Oil Refineries and Terminals - An Overview", United Nations Environment Programme, United Nations Publication. 


\section{APPENDICES}

\subsection{Run 1 Experimental Data}

Table 10.1: Run 1 BOD and COD Data

\begin{tabular}{|c|c|c|c|c|c|c|}
\hline $\begin{array}{c}\text { Time } \\
(\mathbf{h})\end{array}$ & $\begin{array}{c}\text { BOD } \\
\text { (mg/L) }\end{array}$ & $\begin{array}{c}\mathbf{9 5} \% \\
\text { C.I. }\end{array}$ & $\begin{array}{c}\text { COD } \\
\text { (mg/L) }\end{array}$ & $\begin{array}{c}\text { 95\% } \\
\text { C.I. }\end{array}$ & $\begin{array}{c}\text { BOD/COD } \\
\text { Ratio }\end{array}$ & $\begin{array}{c}\text { 95\% } \\
\text { C.I. }\end{array}$ \\
\hline Raw & 316 & 10 & 593 & 6 & 0.53 & 0.02 \\
\hline 0 & 190 & 3 & 411 & 3 & 0.46 & 0.01 \\
\hline 2.25 & 149 & 1 & 333 & 3 & 0.45 & 0.00 \\
\hline 4 & 119 & 6 & 298 & 4 & 0.40 & 0.02 \\
\hline 6 & 96 & 1 & 267 & 6 & 0.36 & 0.01 \\
\hline 8 & 83 & 0 & 235 & 3 & 0.35 & 0.00 \\
\hline 10 & 65 & 7 & 216 & 3 & 0.30 & 0.03 \\
\hline 24 & 9 & 0 & 108 & 0 & 0.08 & 0.00 \\
\hline 27.75 & 8 & 1 & 109 & 10 & 0.07 & 0.01 \\
\hline 52.5 & 7 & 1 & 104 & 4 & 0.07 & 0.01 \\
\hline Removal & $96 \%$ & -- & $75 \%$ & -- & -- & -- \\
\hline
\end{tabular}

Table 10.2: Run 1 Solids Data

\begin{tabular}{|c|c|c|}
\hline Time (h) & MLSS (mg/L) & $\mathbf{9 5} \%$ C.I. \\
\hline Reactor Seed & 4756 & 240 \\
\hline 2.25 & 501 & 14 \\
\hline 8 & 528 & 16 \\
\hline 24.5 & 572 & 0 \\
\hline
\end{tabular}


Table 10.3: Run 1 SOUR Data

\begin{tabular}{|c|c|c|}
\hline Time (h) & $\begin{array}{c}\text { SOUR } \\
\text { (mg } \mathrm{O}_{2} / \mathrm{min} \text { mg MLSS) }\end{array}$ & $\mathbf{R}^{2}$ \\
\hline 0.00 & 0.001009 & 0.9996 \\
\hline 0.13 & 0.000867 & 0.9997 \\
\hline 0.24 & 0.000615 & $\overline{0.9996}$ \\
\hline 2.00 & 0.000460 & 0.9994 \\
\hline 2.31 & 0.000488 & 0.9994 \\
\hline 2.64 & 0.000366 & 0.9990 \\
\hline 4.00 & 0.000587 & 0.9923 \\
\hline 4.33 & 0.000520 & 0.9994 \\
\hline 4.57 & 0.000577 & 0.9996 \\
\hline 6.00 & 0.000487 & 0.9980 \\
\hline 6.16 & 0.000473 & 0.9994 \\
\hline 6.33 & 0.000471 & 0.9994 \\
\hline 8.00 & 0.000397 & 0.9989 \\
\hline 8.18 & 0.000300 & 0.9982 \\
\hline 8.32 & 0.000284 & 0.9977 \\
\hline 10.00 & 0.000305 & 0.9981 \\
\hline 10.19 & 0.000308 & 0.9987 \\
\hline 10.33 & 0.000308 & 0.9988 \\
\hline 24.00 & 0.000151 & 0.9951 \\
\hline 24.15 & 0.000140 & 0.9941 \\
\hline 24.30 & 0.000129 & 0.9945 \\
\hline 27.75 & 0.000126 & 0.9918 \\
\hline 27.90 & 0.000116 & 0.9886 \\
\hline 28.04 & 0.000120 & 0.9886 \\
\hline 52.50 & 0.000141 & 0.9930 \\
\hline 52.67 & 0.000116 & 0.9926 \\
\hline 52.81 & 0.000106 & 0.9843 \\
\hline
\end{tabular}


Table 10.4: Run 1 Acute Toxicity

\begin{tabular}{|c|c|c|c|c|c|c|}
\hline Time & $\begin{array}{c}\text { EC50 } \\
(\% \mathbf{v} / \mathbf{v}) \\
\mathbf{5 m i n}\end{array}$ & + & - & $\begin{array}{c}\text { EC50 } \\
(\% \mathbf{v} / \mathbf{v}) \\
\mathbf{1 5 m i n}\end{array}$ & + & - \\
\hline 0 & 4.6 & 0.5 & 0.4 & 5.5 & 0.2 & 0.2 \\
\hline 2.25 & 5.0 & 0.6 & 0.5 & 4.9 & 0.5 & 0.4 \\
\hline 4 & 8.7 & 0.7 & 0.7 & 6.9 & 1.2 & 1.0 \\
\hline 6 & 3.9 & 0.6 & 0.5 & 3.1 & 0.3 & 0.3 \\
\hline 8 & 5.3 & 0.5 & 0.4 & 4.4 & 0.2 & 0.2 \\
\hline 10 & 7.9 & 0.7 & 0.6 & 5.5 & 0.9 & 0.8 \\
\hline 24 & 9.2 & 0.6 & 0.6 & 6.5 & 0.5 & 0.5 \\
\hline 27.75 & 7.3 & 0.5 & 0.5 & 5.7 & 0.3 & 0.3 \\
\hline 52.5 & 13.3 & 0.5 & 0.5 & 10.0 & 0.9 & 0.8 \\
\hline
\end{tabular}




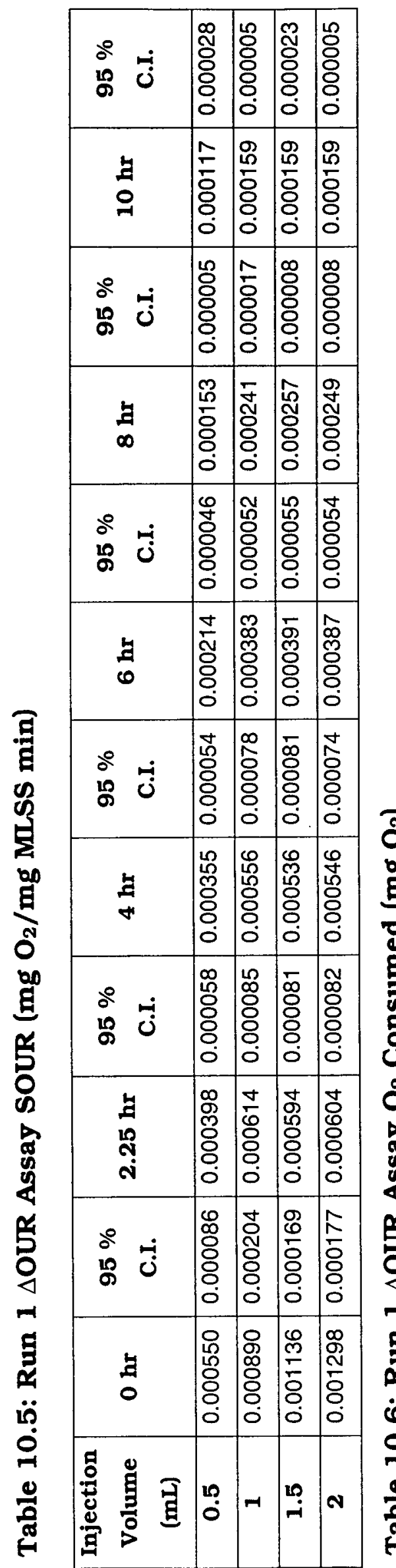

\begin{tabular}{|c|c|c|c|c|}
\hline$\stackrel{\circ}{\stackrel{1}{0}}$ & $\frac{\infty}{\circ}$ & 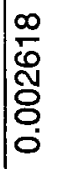 & 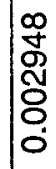 & $\mid \begin{array}{l}N \\
0 \\
8 \\
8 \\
0 \\
0\end{array}$ \\
\hline $\begin{array}{l}1 \\
\vdots \\
0\end{array}$ & 范 & 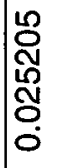 & 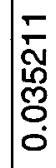 & 号 \\
\hline 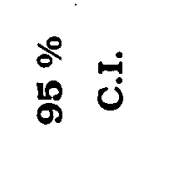 & 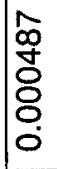 & $\begin{array}{l}\frac{1}{2} \\
\frac{8}{8} \\
0 \\
0\end{array}$ & 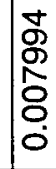 & 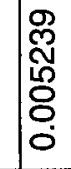 \\
\hline $\begin{array}{l}\mathbf{1} \\
\infty\end{array}$ & 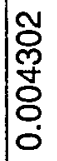 & 命 & 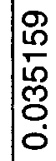 & 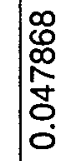 \\
\hline 웅 & 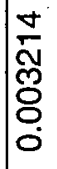 & $\begin{array}{l}5 \\
0 \\
0 \\
8 \\
0 \\
0\end{array}$ & 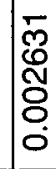 & 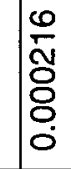 \\
\hline $\begin{array}{l}\mathbf{H} \\
0\end{array}$ & $\begin{array}{l}\tilde{\gamma} \\
\delta \\
0 \\
0 \\
0 \\
0 \\
0\end{array}$ & 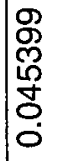 & 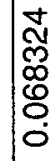 & $\mid \begin{array}{l}\mathbb{N} \\
\text { O̊ } \\
\delta \\
0 \\
0\end{array}$ \\
\hline $\begin{array}{ll}\stackrel{0}{0} & -\dot{j} \\
\text { in } & 0\end{array}$ & 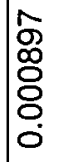 & 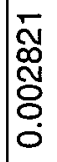 & $\begin{array}{l}0 \\
\infty \\
0 \\
\mathscr{8} \\
8 \\
0 \\
0\end{array}$ & 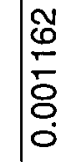 \\
\hline $\begin{array}{l}\mathbf{5} \\
+\end{array}$ & 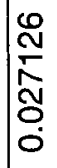 & $\begin{array}{l}- \\
\infty \\
m \\
0 \\
0 \\
0 \\
0\end{array}$ & $\begin{array}{l}1 \\
\text { L } \\
0 \\
8 \\
8 \\
8 \\
0 \\
0\end{array}$ & $\begin{array}{l}\tilde{O} \\
0 \\
N \\
\tilde{N} \\
\end{array}$ \\
\hline $\begin{array}{l}\text { i } \\
\text { 10 }\end{array}$ & $\begin{array}{l}3 \\
0 \\
10 \\
n \\
0 \\
0 \\
0\end{array}$ & 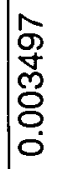 & 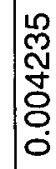 & $\mid \begin{array}{l}m \\
\dot{\gamma} \\
\infty \\
8 \\
0 \\
0\end{array}$ \\
\hline \begin{tabular}{l}
\multirow{5}{*}{} \\
ஸ⿱ \\
ง
\end{tabular} & 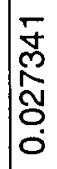 & 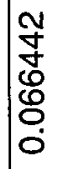 & 总 & $\mid \begin{array}{l}\infty \\
0 \\
\delta \\
8 \\
\vdots \\
0\end{array}$ \\
\hline$\stackrel{\circ}{\stackrel{0}{0}}$ & $\frac{\sigma}{\frac{9}{7}}$ & $\frac{0}{\frac{0}{N}}$ & $\begin{array}{l}\mathscr{M} \\
\text { N్} \\
\text { n్ } \\
0 \\
0 \\
0\end{array}$ & \begin{tabular}{l}
0 \\
\multirow{1}{0}{} \\
0 \\
8 \\
0 \\
0
\end{tabular} \\
\hline $\begin{array}{l}\text { H } \\
0 \\
0\end{array}$ & $\mid \begin{array}{l}10 \\
0 \\
0 \\
0 \\
0 \\
0\end{array}$ & 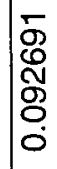 & 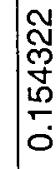 & 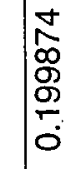 \\
\hline 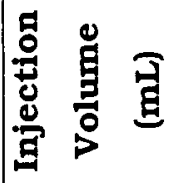 & 10 & -1 & קִ & N \\
\hline
\end{tabular}

$\infty$

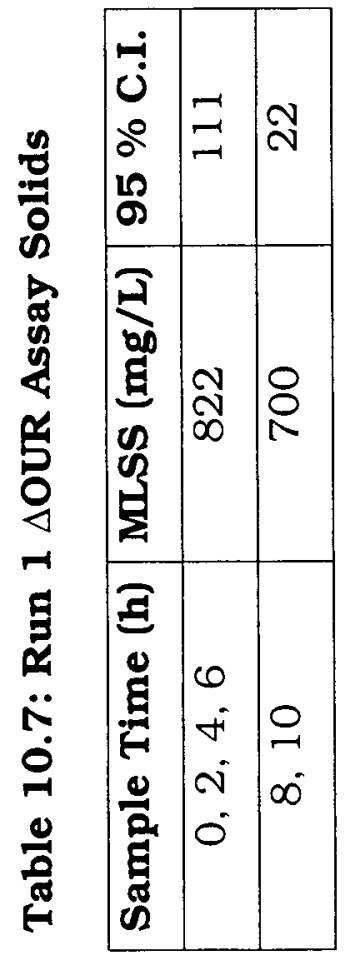


Table 10.8: Run 1 Kinetic Constants

\begin{tabular}{|c|c|c|c|c|c|c|}
\hline Time & $\mathbf{O ~ h}$ & $2.25 \mathrm{~h}$ & $4 \mathrm{~h}$ & $6 \mathrm{~h}$ & $8 \mathrm{~h}$ & $10 \mathrm{~h}$ \\
\hline \multicolumn{7}{|c|}{ Tessier } \\
\hline$q_{\max }\left(\min ^{-1}\right)$ & 0.00421 & 0.00119 & 0.00089 & 0.00077 & 0.00074 & 0.00040 \\
\hline $\mathbf{K}_{\mathbf{s}}(\mathbf{m g} / \mathbf{L})$ & 2.5 & 0.3 & 0.25 & 0.25 & 0.21 & 0.1 \\
\hline \multicolumn{7}{|c|}{ Monod } \\
\hline$q_{\max }\left(\min ^{-1}\right)$ & 0.00418 & 0.00119 & 0.00088 & 0.00079 & 0.00073 & 0.00040 \\
\hline $\mathrm{K}_{\mathrm{s}}(\mathrm{mg} / \mathrm{L})$ & 1.76 & 0.07 & 0.06 & 0.09 & 0.05 & 0.02 \\
\hline
\end{tabular}


10.2 Run 2 Experimental Data

Table 10.9: Run 2 BOD and COD Data

\begin{tabular}{|c|c|c|c|c|c|c|}
\hline $\begin{array}{c}\text { Time } \\
(\mathbf{h})\end{array}$ & $\begin{array}{c}\text { BOD } \\
\text { (mg/L) }\end{array}$ & $\begin{array}{c}\mathbf{9 5} \% \\
\text { C.I. }\end{array}$ & $\begin{array}{c}\text { COD } \\
\text { (mg/L) }\end{array}$ & $\begin{array}{c}\mathbf{9 5 \%} \\
\text { C.I. }\end{array}$ & $\begin{array}{c}\text { BOD/COD } \\
\text { Ratio }\end{array}$ & $\begin{array}{c}\mathbf{9 5 \%} \\
\text { C.I. }\end{array}$ \\
\hline Raw & 234 & 62 & 510 & 0 & 0.46 & 0.12 \\
\hline 0.5 & 207 & 4 & 433 & 4 & 0.48 & 0.01 \\
\hline 3 & 105 & 43 & 355 & 10 & 0.30 & 0.12 \\
\hline 10 & 30 & -- & 158 & 5 & 0.19 & 0.01 \\
\hline 24 & 13 & -- & 133 & 16 & 0.10 & 0.01 \\
\hline 48 & 11 & -- & 120 & 0 & 0.09 & 0.00 \\
\hline 72 & 10 & -- & 122 & 6 & 0.08 & 0.00 \\
\hline 96 & 16 & -- & 124 & 22 & 0.13 & 0.02 \\
\hline 120 & 16 & -- & 116 & 2 & 0.14 & 0.00 \\
\hline Removal & $92 \%$ & -- & $73 \%$ & -- & -- & -- \\
\hline
\end{tabular}

Table 10.10: Run 2 Solids Data

\begin{tabular}{|c|c|c|}
\hline Time (h) & MLSS (mg/L) & 95\% C.I. \\
\hline Reactor Seed & 6053 & 26 \\
\hline 0 & 636 & 19 \\
\hline 10 & 720 & 8 \\
\hline 24 & 704 & 12 \\
\hline 48 & 707 & 15 \\
\hline 72 & 727 & 13 \\
\hline 96 & 711 & 23 \\
\hline 120 & 702 & 12 \\
\hline
\end{tabular}


Table 10.11: Run 2 SOUR Data

\begin{tabular}{|c|c|c|}
\hline Time (h) & $\begin{array}{c}\text { SOUR } \\
\text { (mg O/min mg MLSS) }\end{array}$ & $\mathbf{R}^{2}$ \\
\hline 0.25 & 0.000637 & 0.9997 \\
\hline 0.5 & 0.000569 & 0.9997 \\
\hline 0.75 & 0.000513 & 0.9997 \\
\hline 2.833333 & 0.000566 & 0.9991 \\
\hline 3.083333 & 0.000549 & 0.9997 \\
\hline 3.283333 & 0.000600 & 0.9998 \\
\hline 10.15 & 0.000213 & 0.9976 \\
\hline 10.36667 & 0.000192 & 0.9978 \\
\hline 10.51667 & 0.000203 & 0.9982 \\
\hline 24 & 0.000090 & 0.9905 \\
\hline 24.23333 & 0.000091 & 0.9910 \\
\hline 24.48333 & 0.000099 & 0.9931 \\
\hline 48.13333 & 0.000084 & 0.9446 \\
\hline 48.41667 & 0.000051 & 0.9382 \\
\hline 48.65 & 0.000052 & 0.9717 \\
\hline 72 & 0.000056 & 0.9668 \\
\hline 72.25 & 0.000048 & 0.9623 \\
\hline 72.46667 & 0.000051 & 0.9456 \\
\hline 96 & 0.000059 & $\overline{0.9846}$ \\
\hline 96.28333 & 0.000067 & 0.8897 \\
\hline 96.5 & 0.000057 & 0.9818 \\
\hline 122.1333 & 0.000057 & 0.9788 \\
\hline 122.4167 & 0.000057 & 0.9800 \\
\hline 122.6333 & 0.000057 & 0.9798 \\
\hline
\end{tabular}


Table 10.12: Run 2 Acute Toxicity

\begin{tabular}{|c|c|c|c|c|c|c|}
\hline Time & $\begin{array}{c}\mathbf{E C}_{50} \\
(\% \mathbf{v} / \mathbf{v}) \\
\mathbf{5 m i n}\end{array}$ & + & - & $\begin{array}{c}\mathbf{E C}_{50} \\
(\% \mathbf{v} / \mathbf{v}) \\
\mathbf{1 5 m i n}\end{array}$ & + & - \\
\hline Raw & 3.8 & 0.3 & 0.3 & 3.5 & 0.5 & 0.4 \\
\hline 0.5 & 4.9 & 0.4 & 0.4 & 3.9 & 0.6 & 0.5 \\
\hline 3 & 8.4 & 1.1 & 1.0 & 8.5 & 0.9 & 0.8 \\
\hline 10 & 15.7 & 3.5 & 2.9 & 12.6 & 1.7 & 1.5 \\
\hline 24 & 16.3 & 2.6 & 2.2 & 12.7 & 0.4 & 0.4 \\
\hline 48 & 15.6 & 2.8 & 2.4 & 11.9 & 1.5 & 1.3 \\
\hline 72 & 27.8 & 1.7 & 1.6 & 21.3 & 2.3 & 2.1 \\
\hline 96 & 25.2 & 9.7 & 7.0 & 16.7 & 4.4 & 3.5 \\
\hline 120 & 23.7 & 4.2 & 3.6 & 15.2 & 4.3 & 3.4 \\
\hline
\end{tabular}


Table 10.13: Run $2 \Delta O U R$ Assay SOUR (mg $\mathrm{O}_{2} / \mathrm{mg}$ MLSS min)

\begin{tabular}{|c|c|c|c|c|}
\hline $\begin{array}{c}\text { Injection } \\
\text { Volume (mL) }\end{array}$ & $\mathbf{0 . 5} \mathbf{~ h r}$ & $\mathbf{9 5} \%$ C.I. & $\mathbf{3 ~ h r}$ & $\mathbf{9 5} \%$ C.I. \\
\hline $\mathbf{0 . 3}$ & 0.000347 & 0.000030 & 0.000185 & 0.000072 \\
\hline $\mathbf{0 . 6}$ & 0.000594 & 0.000036 & 0.000356 & 0.000016 \\
\hline $\mathbf{0 . 9}$ & 0.000765 & 0.000011 & 0.000475 & 0.000025 \\
\hline $\mathbf{1 . 5}$ & 0.000975 & 0.000017 & 0.000617 & $0.00001 \mathbf{1}$ \\
\hline $\mathbf{2}$ & 0.001084 & 0.000165 & 0.000645 & 0.000047 \\
\hline
\end{tabular}

Table 10.14: Run $2 \Delta$ OUR Assay $\mathrm{O}_{2}$ Consumed (mg $\mathrm{O}_{2}$ )

\begin{tabular}{|c|c|c|c|c|}
\hline $\begin{array}{c}\text { Injection } \\
\text { Volume (mL) }\end{array}$ & $\mathbf{0 . 5} \mathbf{~ h r}$ & $\mathbf{9 5} \%$ C.I. & $\mathbf{3} \mathbf{~ h r}$ & $\mathbf{9 5} \%$ C.I. \\
\hline $\mathbf{0 . 3}$ & 0.074677 & 0.015883 & 0.032397 & 0.044075 \\
\hline $\mathbf{0 . 6}$ & 0.252456 & 0.008825 & 0.173647 & 0.038857 \\
\hline $\mathbf{0 . 9}$ & 0.388232 & 0.022669 & 0.233808 & 0.021784 \\
\hline $\mathbf{1 . 5}$ & 0.572492 & 0.032429 & 0.361161 & 0.020382 \\
\hline $\mathbf{2}$ & 0.749972 & 0.050758 & 0.472980 & 0.093501 \\
\hline
\end{tabular}

Table 10.15: Run $2 \Delta$ OUR Assay Solids

\begin{tabular}{|c|c|c|}
\hline Sample Time (h) & MLSS (mg/L) & 95 \% C.I. \\
\hline $0.5,3$ & 669 & 8 \\
\hline
\end{tabular}


Table 10.16: Run 2 Kinetic Constants

\begin{tabular}{|c|c|c|}
\hline Time & $\mathbf{0 . 5} \mathbf{~ h}$ & $\mathbf{3 ~ h}$ \\
\hline \multicolumn{3}{|c|}{ Tessier } \\
\hline $\mathbf{q}_{\max }\left(\mathbf{m i n}^{-1}\right)$ & 0.00499 & 0.00206 \\
\hline $\mathbf{K}_{\mathbf{s}}$ (mg/L) & 1.79 & 0.70 \\
\hline \multicolumn{3}{|c|}{ Monod } \\
\hline $\mathbf{q}_{\max }\left(\mathbf{m i n}^{-1}\right)$ & 0.00505 & 0.00250 \\
\hline $\mathbf{K}_{\mathbf{s}}$ (mg/L) & 1.29 & 0.70 \\
\hline
\end{tabular}




\subsection{Stripping Experimen tal Data}

Table 10.17: Stripping COD

\begin{tabular}{|c|c|c|}
\hline $\begin{array}{c}\text { Time } \\
\text { (h) }\end{array}$ & $\begin{array}{c}\text { COD } \\
\text { (mg/L) }\end{array}$ & $\begin{array}{c}\mathbf{9 5 \%} \\
\text { C.I. }\end{array}$ \\
\hline Raw & 518 & 3 \\
\hline 0 & 488 & 3 \\
\hline 1 & 490 & 3 \\
\hline 2 & 498 & 2 \\
\hline 4 & 495 & 3 \\
\hline 6 & 492 & 0 \\
\hline 24 & 472 & 6 \\
\hline 51.25 & 475 & -- \\
\hline Removal (0-51.25 h) & $3 \%$ & -- \\
\hline Removal (Raw-51.25 h) & $8 \%$ & 3 \\
\hline
\end{tabular}

Table 10.18: Stripping Acute Toxicity

\begin{tabular}{|c|c|c|c|c|c|c|}
\hline Time & $\begin{array}{c}\mathbf{E C}_{50} \\
(\% \mathbf{v} / \mathbf{v}) \\
\mathbf{5 m i n}\end{array}$ & + & - & $\begin{array}{c}\mathbf{E C}_{50} \\
(\% \mathbf{v} / \mathbf{v}) \\
\mathbf{1 5 m i n}\end{array}$ & + & - \\
\hline 0 & 4.1 & 0.4 & 0.4 & 3.8 & 0.6 & 0.5 \\
\hline 6 & 4.1 & 0.5 & 0.4 & 4.1 & 0.6 & 0.5 \\
\hline 24 & 4.5 & 0.2 & 0.2 & 4.4 & 1.0 & 0.8 \\
\hline 51.25 & 6.8 & 0.6 & 0.6 & 6.2 & 1.6 & 1.3 \\
\hline
\end{tabular}


10.4 Chevron Toxicity M onitoring Program (Hoy, 2000)

Table 10.19: Raw Wastewater Acute Toxicity

\begin{tabular}{|c|c|c|c|c|c|c|}
\hline Date & $\begin{array}{c}\text { EC50 } \\
(\% \mathbf{v v} / \mathbf{v}) \\
\mathbf{5 m i n}\end{array}$ & + & - & $\begin{array}{c}\text { EC50 } \\
(\% \mathbf{v} / \mathbf{v}) \\
\mathbf{1 5 m i n}\end{array}$ & + & - \\
\hline 26-Jan & 2.0 & 0.1 & 0.1 & 7.5 & 0.7 & 0.6 \\
\hline 02-Feb & 2.6 & 0.3 & 0.3 & 2.6 & 0.3 & 0.3 \\
\hline 09-Feb & 2.8 & 0.4 & 0.4 & 2.5 & 0.3 & 0.3 \\
\hline 23-Feb & 1.2 & 0.2 & 0.2 & 1.2 & 0.2 & 0.2 \\
\hline 01-Mar & 2.2 & 0.3 & 0.2 & 1.8 & 0.3 & 0.2 \\
\hline 08-Mar & 1.3 & 0.7 & 0.5 & 1.3 & 0.8 & 0.5 \\
\hline 15-Mar & 1.2 & 0.2 & 0.2 & 0.2 & 0.1 & 0.1 \\
\hline Average & $\mathbf{1 . 9}$ & $\mathbf{0 . 1}$ & $\mathbf{0 . 1}$ & $\mathbf{2 . 5}$ & $\mathbf{0 . 2}$ & $\mathbf{0 . 1}$ \\
\hline
\end{tabular}

Table 10.20: Deep Shaft Effluent Acute Toxicity

\begin{tabular}{|c|c|c|c|c|c|c|}
\hline Date & $\begin{array}{c}\text { EC50 } \\
(\% \mathbf{v} / \mathbf{v}) \\
\mathbf{5 m i n}\end{array}$ & + & - & $\begin{array}{c}\text { EC50 } \\
(\% \mathbf{\%} / \mathbf{v}) \\
\mathbf{1 5 m i n}\end{array}$ & + & - \\
\hline 26-Jan & 16.7 & 1.2 & 1.1 & 12.7 & 1.0 & 1.0 \\
\hline 02-Feb & -- & -- & -- & 12.2 & 3.0 & 2.4 \\
\hline 09-Feb & 14.0 & 2.5 & 2.1 & 12.8 & 1.8 & 1.6 \\
\hline 23-Feb & 10.0 & 1.9 & 1.6 & 7.3 & 0.5 & 0.5 \\
\hline 01-Mar & 23.2 & 4.2 & 3.5 & 15.4 & 9.0 & 5.7 \\
\hline 08-Mar & 8.6 & 1.6 & 1.3 & 6.3 & 1.1 & 0.9 \\
\hline 15-Mar & 8.3 & 1.1 & 1.0 & 5.9 & 0.5 & 0.4 \\
\hline AVG & $\mathbf{1 3 . 5}$ & $\mathbf{0 . 9}$ & $\mathbf{0 . 8}$ & $\mathbf{1 0 . 4}$ & $\mathbf{1 . 4}$ & $\mathbf{0 . 9}$ \\
\hline
\end{tabular}


Table 10.21: Biofilter Effluent Acute Toxicity

\begin{tabular}{|c|c|c|c|c|c|c|}
\hline Date & $\begin{array}{c}\text { EC50 } \\
(\% \mathbf{\%} / \mathbf{v}) \\
\mathbf{5 m i n}\end{array}$ & + & - & $\begin{array}{c}\text { EC50 } \\
(\% \mathbf{\% v} / \mathbf{v}) \\
\mathbf{1 5 m i n}\end{array}$ & + & - \\
\hline 26-Jan & -- & -- & -- & -- & -- & -- \\
\hline 02-Feb & 31.8 & 2.5 & 2.3 & 25.5 & 4.5 & 3.9 \\
\hline O9-Feb & 30.0 & 10.4 & 27.7 & 21.2 & 3.0 & 2.6 \\
\hline 23-Feb & 20.8 & 9.4 & 0.0 & 17.8 & 3.5 & 3.0 \\
\hline 01-Mar & 43.3 & 23.7 & 15.3 & 35.1 & 10.6 & 8.2 \\
\hline 08-Mar & 14.7 & 6.0 & 4.3 & 33.4 & 110.3 & 25.6 \\
\hline 15-Mar & 11.5 & 25.9 & 8.0 & 12.2 & 22.3 & 7.9 \\
\hline AVG & $\mathbf{2 5 . 4}$ & $\mathbf{6 . 4}$ & $\mathbf{5 . 5}$ & $\mathbf{2 4 . 2}$ & $\mathbf{1 8 . 9}$ & $\mathbf{4 . 8}$ \\
\hline
\end{tabular}

